\title{
Surface Acoustic Wave Sensors/Gas Chromatography Low Quality Natural Gas Sulfur Removal and Recovery CNG Claus Sulfur Recovery Process
}

\section{RECEIVED OCT 061998 \\ OSTI}

\section{Topical Report}

December 1997

\author{
By: \\ Bruce W. Klint \\ Peter R. Dale \\ Charles Stephenson
}

Work Performed Under Contract No.: DE-AC21-92MC29470

For

U.S. Department of Energy Office of Fossil Energy

Federial Energy Technology Center

P.O. Box 880

Morgantown, West Virginia 26507-0880

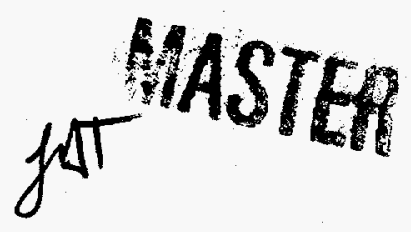

Givitum of the poxpent

CHATED

By

Global Environment \& Technology Foundation

7010 Little River Turnpike

Suite 300

Aunandale, Virginia 22003 


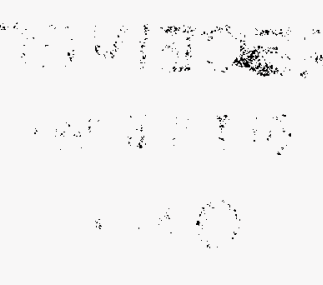

$y^{x}=$

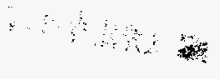

a 


\section{Disclaimer}

This report was prepared as an account of work sponsored by an agency of the United States Government. Neither the United States Government nor any agency thereof, nor any of their employees, makes any warranty, express or implied, or assumes any legal liability or responsibility for the accuracy, completeness, or usefulness of any information, apparatus, product, or process disclosed, or represents that its use would not infringe privately owned rights. Reference herein to any specific commercial product, process, or service by trade name, trademark, manufacturer, or otherwise does not necessarily constitute or imply its endorsement, recommendation, or favoring by the United States Government or any agency thereof. The views and opinions of authors expressed herein do not necessarily state or reflect those of the United States Government or any agency thereof. 


\section{DISCLAIMER}

Portions of this document may be illegible electronic image products. Images are produced from the best available original document. 


\section{Surface Acoustic Wave Sensors/Gas Chromatography Electronic Sensor Technology Table of Contents}

Section 1 The GETE Screening Document

Section 2 DOE Technology Summary Report "Surface Acoustic Wave/Gas Chromatography"

Section 3 Company Supplied Brochure "Test the Air Anywhere!" 
I

I

1

I

I

I

1

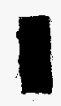

I

1

I

I

I

I

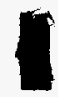

I

] 


\section{A: BASIC}

\section{GETE ID:}

Date:

Technology:

IP Holder:

Interviewer:

\section{Affiliation:}

1. What is the the relative importance, priority or' significance of the technology to the focus ares?

2. Is there a private sector company already involved with the technology? (If the answer is yes then procesul; if the anawer is no, then the focus area must decide whether there is sufficient interest to warrant the search fer a partner, and if so with what urgency.)

3. Is the technology nearing commercial readiness? (This requires a definition of the status of the technology as defined by the DOE (EM-50) Technology Decision Model. The CAC can become involved early or late in the process depending on EM's needs for a particular technology).

4. Is the company bringing the technology to market one that requires no assistance? (This requires a decision whether the commercial partner requires assistance in the commercialization process. If there is a strong conmercial partner for example, fewer commercialization activlties are Iikely to be required. Some of the considerations fior this ovaluation are as follows).

a) What size is the company?

Employees:

Offices:

b) Is it publicly or privately owned?

c) Is an annual report available?

d) What are the annual revenues?

e) What relevant experience does the company possess?

t) What is the company's capability and interest in commercializing the technology?

g) Has the company a previous track record commercializing environmental technologies?
Model 4100 Vapor Detector and Analyzer

Electronic Sensor Technology

Tory Failmezger

G.E.T.F./G.E.T.E.

Yes, the technology is available for use.

The commercialization effort is being aided by a partnership between Amerasia, the managing limited partnership company of Electronic Sensor Technology, Inc., and Federal Energy Technology Center (Morgantown).

Westiake Village, California

Private

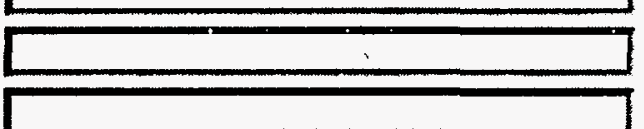


h) Has the company a track record

working in the DOE complex?

If yes, explain

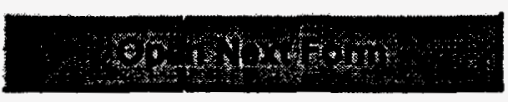


GETE ID:

1. What is the technology? (Defined and described in simple non-ecientific terms.)

2. What primary problem areas does this technology address?

\section{Have realistic potential secondary applications been} identified?(Llst)

4. Is data avellable that supports the dovelopers: claims regarding the offectiveness of the technolagy? Can that data be readily obtained?

5. Is adequate information avaliable abour the technologr in order to allow the investigator to defint the market(s) into which the technoloax can be sold?

\section{Are test/demonstration results available?}

7. In what stage of development is the trechnology?

8. Is the technology ready for examination and review by potential licensees/users?

9. How does new technology compare to current technologies doing the same job? (Quantify)

10. How readily can it be modified to address additional markets?

11. What problems have occurred in the development cycle? How were they addrassed?

12. What are the limitations of the techrology?

13. How else is this technology unique?

14. How difficult is it to "try before you buy"?

15. Where can it be viewed?
The $\mathbf{4 1 0 0}$ uses a Surface Acoustic Wave (SAW) detector to determine the mass density of a vapor or particle sample. Initially, the sample is collected in a cryo-focus chamber and passed through a gas chromatograph. The SAW detector reports the results to a database in a 486 laptop computer. The sample is compared with a library of chemical signatures on file and a Windows based program calculates the mass. All of the components are shock mounted in a rugged field-portable fiberglass carrying case.

The technology address the problem of measuring emissions from various sources in a small amount of time.

Detection of contraband and explosives.

The technology was successfully field tested at the Savannah River Site.

Yes

Yes.

The technology is available for use.

Yes

The advantages of the technology are portabillity, accuracy, and speed. 



\section{C: INTELLECTUAL PROPERTY}

GETE ID: 17

1. Who holds the Intellectual Property?

2. In the developer (principal investigator) of the tochnology easily identifiable?

3. Who are the other team members/partners government. commercial or otherwise?

\section{What is the attitude of the intellectual property} holderist towerds commercialization?

5. Is the intellectual property custody trail welldocumented end are there no serious impediments epparent to the use/licensing of the patents by commercial for-profit parties?

\section{Is the technology elioible for a patent?}

\section{Heve patents been applied for (or issued)?}

8. Does DOE have the rights for can expisditiously obtain the rights) to license (or otherwise transfer) the technology and is a cloar process to do su defined?

\section{Who has already licensed the technokgy?}

10. Can the intellectual property team bil reached by parties seeking to commercialize the

11. What are the inteliectual property team views on how this product can be privatized?
Model 4100 Vapor Detector and Analyzer

Electronic Sensor Technology

Yes, the prinicpal investigator is Edward J. Staples.

Federal Energy Technology Center (Morgantown) has partnered with Electronic Sensor Technology.

The intellectual property holder is aggressively initiating commercialization.

No. 


\begin{abstract}
e) How big is the
market? Total/Each

f) How diversified?
\end{abstract}

g) What primary torces; influence it?

(Federal, State, Local, International)

h) How is the market siegmented?

i) Is it mature, saturated, fragmented?

j) Where do the specific near term opportunities lie for this technology?

k) What market advantage does this technology have? (Estimate valuel

1) Who are the primary competitors? (US, Foreign)

m) Who are "easy competitors (i.e. who has ready access to the murket this technology will address)?"

n) What are the market berriers to entry?

9. How can this technology be marketed?

10. Does this technology have any "leverage" in opening new markets? 


\section{E: COMPETITIVENESS}

GETE ID:

17

Technology:

Model 4100 Vapor Detector and Analyzer

1. The technology can be clearly differentiated from existing in-use technologye, has a cloar competitive

The technology has advantages that include portability, accuracy, and speed.

advantage over other compettion, and the by products/residues and final treatment and disposal costs ue simnificantly lower than exiating or compettive technologies.

a) What are the by product:s?

N/A

b) What are the residues?

N/A

c) What additional treatmenit is required?

N/A

d) What is the final disposal cost?

2. What are the specific competitive advantages of this product?
a) Cost

b) Simplicity

c) Pollution prevention features

d) Risk

-) Maintenance

f) Waste straam quality (aniount)

g) Remediation properties

h) Safoty/Health lany obvious doal breakers)

3. DOE is not supportinn other directhy competitlve approaches to this technology's taroet depplications. A technology selected by the commercialization sctivity should have e clegs market niche and be expopgrted by DOE.

4. The cost effectiveness of the technilogy (cost vs. applicationl is defined and reasonable, while other cost profiles for acquiring, building, operating, maintaining and dismantling the technology are reasonable in view of the potential market

5. These cost drivers are understood by the principal investigators (PIs) and documented in the data. 
I

I

I

,

I

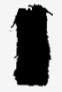

I

I

I

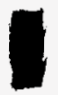

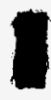

I

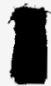

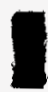

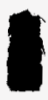

.

,

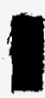

1 


\section{F: COMMITMENT}

\begin{tabular}{|c|c|}
\hline Technology: & Model 4100 Vapor Detector and Analyzer \\
\hline \multirow{2}{*}{\multicolumn{2}{|c|}{ 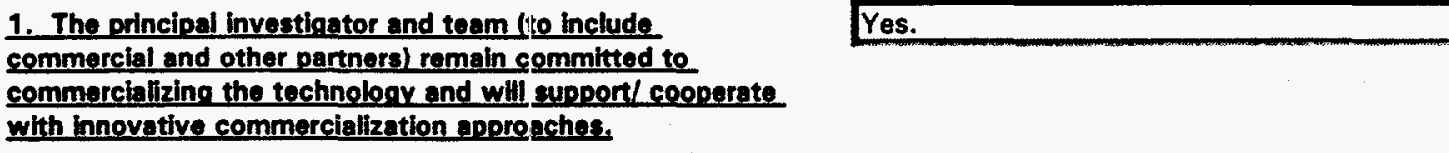 }} \\
\hline & \\
\hline $\begin{array}{l}\text { 2. The technoloay has an active supporter whin the } \\
\text { governmont establishment. }\end{array}$ & $\begin{array}{l}\text { Yes, Mr. Eddie Christy, the METC contracting } \\
\text { officer is supporting this technology. }\end{array}$ \\
\hline 3. The intellectual property holder is suleportive and & Yes \\
\hline
\end{tabular}

4. Who is sponsoring/supporting the technology (By Namel?
a) EM50
b) EM30
c) EM40
d) DP
•) LAB
f) $M$ and $O$
g) DOE Regional Offica
h) Universtty
I) Industrial Partner
J) Small companies
k) Foreign partners
n Other government
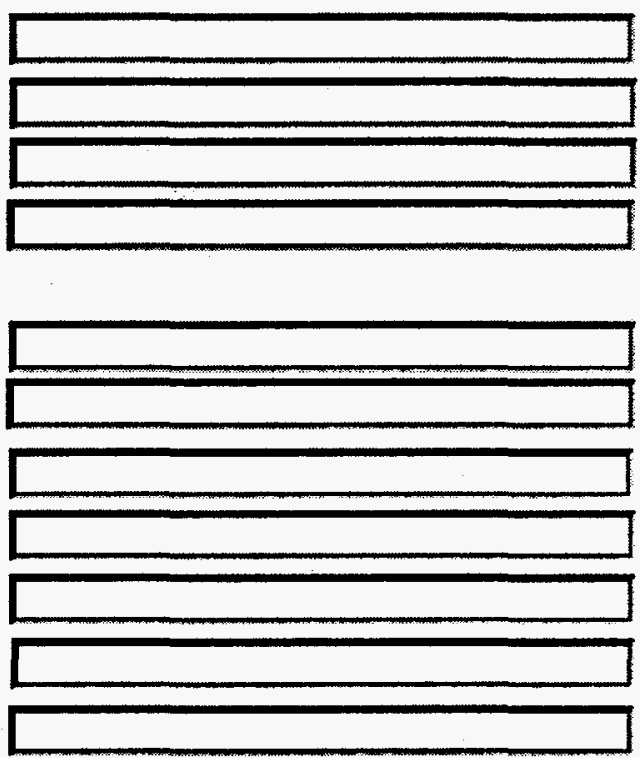

5. What is the committed future funding line for this tachnology? if any, by year?

6. The investment profile of the technulogy is documented. Is the investment significant, relative to the size of the overall market, and the problem(s) to be solved?

7. The resources and financial ability of the "supporters" relative to this technology are known and documented and indicate an ability to follow through on a commercialization initiative? 
8. What are the resources of any proposed "commercializer" of the technology and are they financially capable of following through on their commitments?

9. What is the initial non-government investment in this technology, if any?

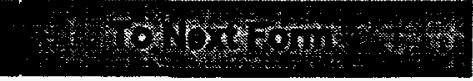




\section{H: COST INFORMATION}

\section{GETE ID: 17 Technology:}

Model 4100 Vapor Detector and Analyzer

1. What information is available on cost effectiveness?

2. What are the cost profiles?

a) To acquire intellectual property rights?

b) To build?

c) To operate? (utilities, equipment, disposable supplies, time, etc.)

d) To train personnel?

e) To maintain?

f) What unique materials aria required for the design?

g) What unique equipment is required for the design?

h) What is product's projected operating lifetime? Projected technology lifetime?

3. What are the cost drivers for use of thils technology?
a) Materials?
b) Equipment?
c) Software?
d) Hardware?

el Labor?

f) Time?

g) Oand $M$ ?

h) Digging/Drilling/Fabrication/nnstallation?

N/A

i) Disposal?

N/A

i) Regulations?

N/A 
4. What are the resources of the "partners" sponsoring this technology (i.e. company, government agency, financiers)?

5. How rapidly is assistance required?

6. What defines a "good" result in the target market (minimum standards)?

7. How is the company "getting by" in the interim period (before full financing)?

8. Are there significant stockholder conciarns about the product/procedures? Should there be? 
GETE ID: 17 Tochnology: Model 4100 Vapor Detector and Analyzer

1. What further demonstrations are planned or necessary?

2. What is needed before the technology is available in the field as an off-the-shelf item or service?

The technology is currently available.

3. Is the technology dependent on any seperate developing

No. technology prior to implementation?

4. Are there any other critical issues that remain to be addressed (science, technology, scale-up. environmental, other)? 
I

1

] 


\section{Surface Acoustic Wave/ Gas Chromatography}

INNOVATIVE TECHNOLOGY SUMMARY REPORT

demonstrated at

U.S. Department of Energy Sites:

Savanriah River Site, SC

Idaho National Engineering and

Environmental Laboratory, ID

Hanford Site, WA

prepared for

\section{U.S. Department of Energy}

Office of Environmental Management

Office of Science and Technology 


\section{TABLE OF CONTENTS}

1 SUMMARY

page 1

2 TECHNOLOGY DESCRIPTION

page 4

3 PERFORMANCE

page 7

4 TECHNOLOGY APPLICABILITY \& ALTERNATIVES

page 11

5 Cost

page 12

6 REGULATORY/POLICY ISSUES

page 14

7 LESSONS LEARNED

page 15

APPENDIX

A References

page 16 


\section{DISCLAIMER}

This report was prepared as an account of work sponsored by an agency of the United States Govemment. Neither the United States Government nor any agenc' thereof, nor any of their employees, makes any warranty, express or implied, or assumes any legal liability or responsibility for the accuracy, completeness, or usefulness of any information, apparatus, product, or process disclosed, or represents that its use would not infringe privately owned rights. Reference herein to any specific commercial product, process, or service by trade name, trademark, manufacturer, or otherwise does not necessarily constitute or imply its endorsement, recommendations or favoring by the United States Govemment or any agency thereof. The views and opinions of authors expressed herein do not necessarily state or reflect those of the United States Government or any agency thereof. 


\section{SECTION 1}

\section{SUMMARY}

\section{Technology Description}

Surface Acoustic Wave/Gas Chromatography (SAW/GC) provides a cost-effective system for collecting real-time field screening data for characterization of vapor streams contaminated with volatile organic compounds (VOCs). The technology was developed by the Amerasia Technology Corporation supported by the U.S. Department of Energy (DOE) Office of Science and Technology (OST). A new company, Electronic Sensor Technology (EST), was incorporated to manufacture, distribute, and market the Model 4100 SAW/GC.

The Model $\mathbf{4 1 0 0}$ can be used in a field screening mode to produce chromatograms in 10 seconds. This capability will allow a project manager to make immediate decisions and to avoid the long delays and high costs associated with analysis by off-site analytical laboratories. The Model $\mathbf{4 1 0 0}$ will not replace a reference laboratory but instead provides a cost-effective means of quickly analyzing a large number of samples during site characterization and minimizes the number of 'clean samples', i.e. those below threshold contamination levels, that nead to be analyzed.

\section{The Model 4100 SAW/GC:}

- is based on gas chromatography (GC) and surface acoustic wave (SAW) technologies;

- consists of the following two components connected with an umbilical cord:

- a handheld module containing a piezoelectric surface acoustic wave sensor, a capillary gas chromatograph, an air pump and a six-way GC valve;

- a support module, which supplies the belium gas and the electrical power and incorporates a laptop computer;

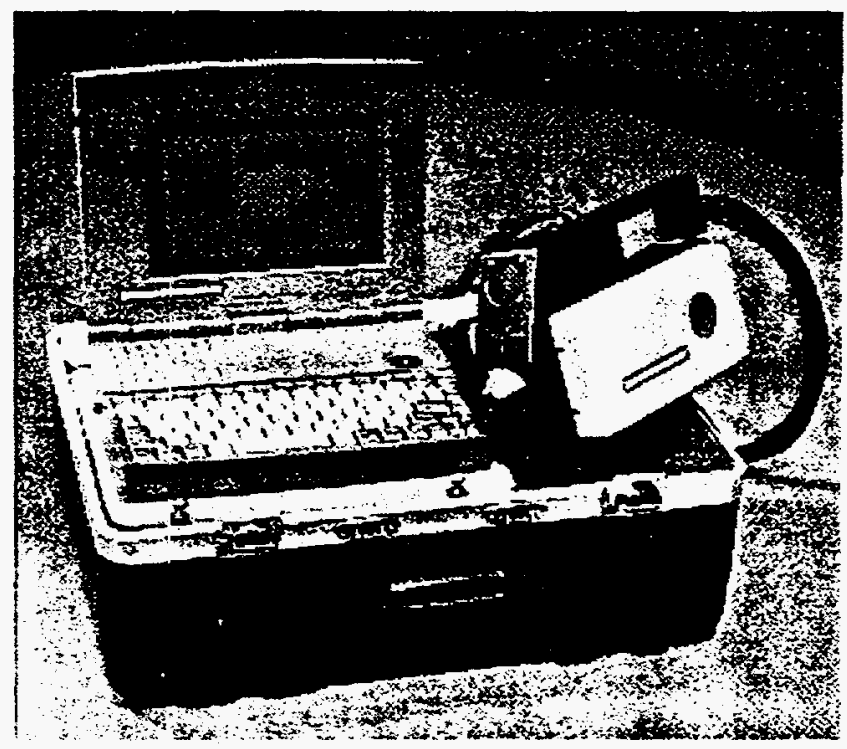

Figure 1. Model 4100 SAW/GC

- can be used for sampling vapor streams from environmental characterization and monitoring applications, remediation waste streams, processing applications that include food and medical analyses, and other monitoring applications such as workplace monitoring;

- specific environmental applications include air monitoring, stack emissions monitoring, underground storage tank monitoring, soil and ground water characterization and screening of hazardous workplaces;

- is fast, portable, rugged, and can detect compounds at the parts per billion level using extremely low-volume samples. 
- should be considered for field monitoring and characterization if there is a need:

- to make in-situ measurements; .

$\checkmark$ to make decisions in real time, i.e. 8 hours or less;

$\checkmark$ to reduce fixed laboratory costs;

$\checkmark$ to identify and characterize contaminant hot spots instead of sampling a complete site.

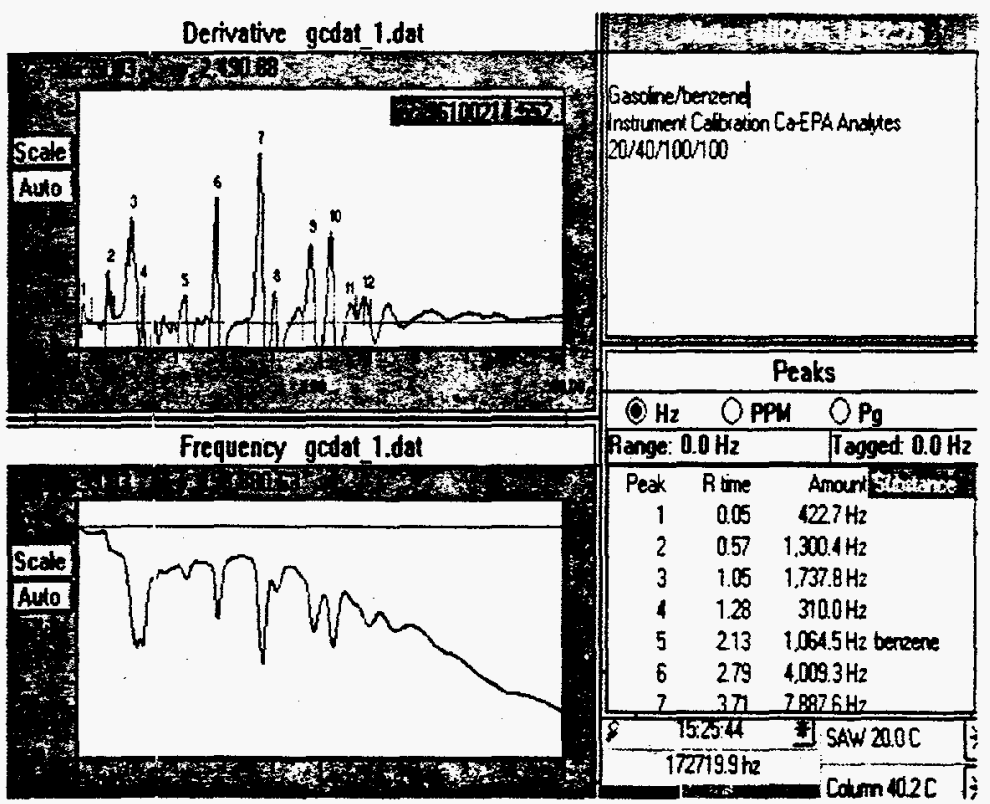

Figure 2. Representative chromatogram showing the use of Model 4100 in field mode tio analyze soils near a leaking underground fuel tank (LUFT).

\section{Technology Status}

The Model 4100 SAW/GC has been demonstrated and evaluated at a number of DOE sites (Savannah River Site [SRS], Lawrence Berkeley National Laboratory [LBNL], Hanford, and Idaho National Engineering and Environmental Laboratory [INEEL]) to verify its performance under a number of different applications.

The Model 4100 SAW/GC is currently under evaluation by the California Environmental Protection Agency (Cal EPA) Technology Certification Program. This process requires the review of all quality control aspects in the field, operational and manufacture. Initial certification focuses upon the following compounds:

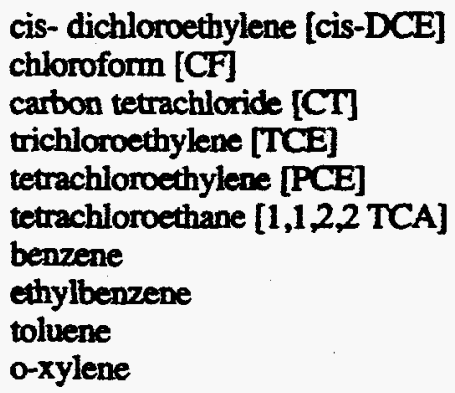

Specific and defensible performance clairns will be available when certification is completed. Cal EPA certification is expected in the Second Quarter of 1997. Cal EPA certification is accepted currently by all state, county, and municipal agencies in California and by five other states: New York, Massachusetts, New Jersey, Ilinois, and Pennsylvania. 
- The SAW detector shows a large dynamic range and is linear over a wide range of concentrations.

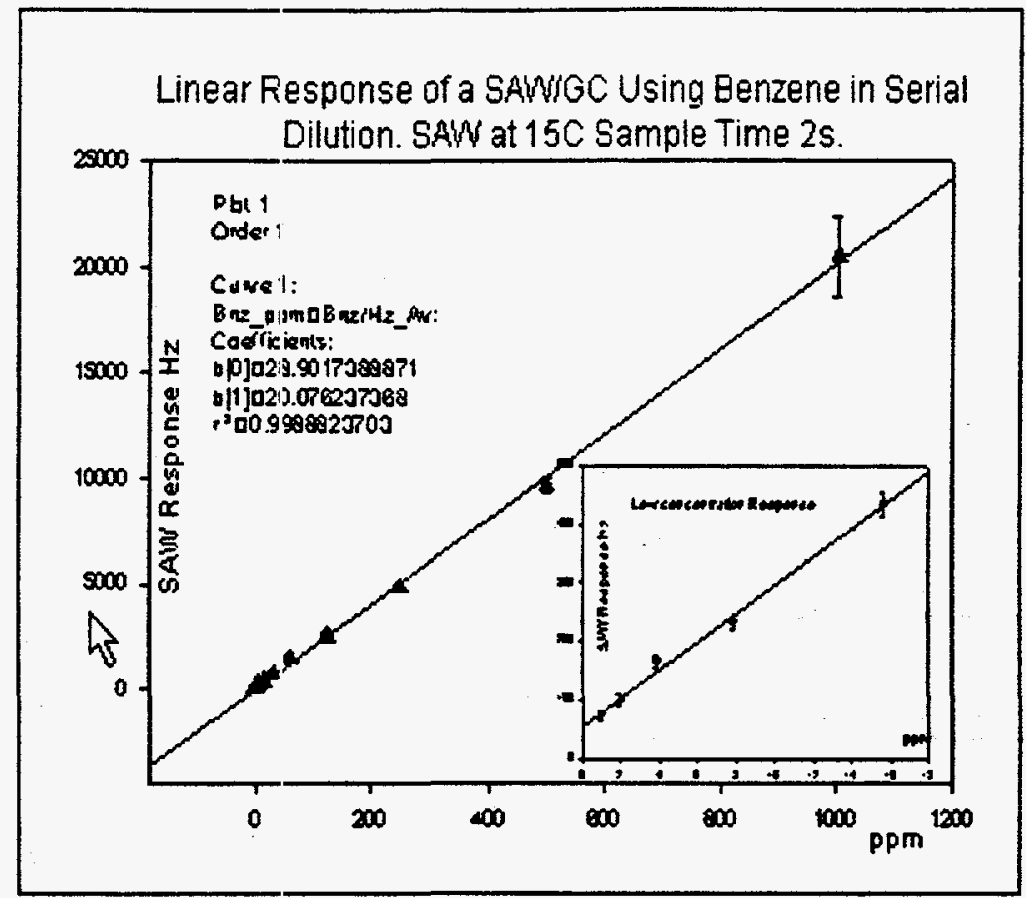

Figure 3. Representative chronatogram of benzene samples generated during CalEPA certification.

- The $r^{2}$ for this calilsration curve was found to be 0.9998 .

- The dynamic range for this calibration at a $2 \mathrm{~s}$ sample time was $450 \mathrm{ppb}$ to $1100 \mathrm{ppm}$.

The Model 4100 SAW/GC is commercially available at this time from Electronic Sensor Technology (EST), which holds a US. patent (number $5,289,715$ ) for the technology. The computer programs controlling the Model 4100 are proprietary and restricted. This includes all algorithms for peak detectiona and signal processing.

\section{CONTACTS}

\section{Technical}

Edward Staples, Electronic Sensor Technology Inc., (805) 495-9388, homepage: www.estcal com, e-mail: staples@estcal com. George Pappas, Electronic Sensor Technology Inc., (805) 495-9388, homepage: wwwestcal.com, e-mail: pappas@estcal.com.

\section{Management}

Eric Lightner, DOE Characterization, Monitoring, and Sensor Technology Crosscutting Program, (301) 903-7935,

C. Edward Christy, DOE Federal Energy and Technology Center, (304) 285-4604.

James B. Wright, Subsurface Contaminants Focus Area Implementation Manager, (803) 725-5608. 


\section{TECHNOLOGY DESCRIPTION}

\section{Overall System Description}

- The Model 4100 SAW/GC instrument couples a piezoelectric surface acoustic wave sensor (SAW) and a capillary gas chromatograph (GC) with a dynarric particle/vapor sampling interface. The instrument is comprised of two parts: a head assembly containing the capillary column, the six port valve, oven trap and SAW detector, and a support chassis containing the helium carrier gas, laptop computer, and the thermoelectric processors. The unit is 14 by 20 by 10 inches and weighs only 35 pounds. The components are housed in a shock-mounted field-portable fiberglass carrying case.

- Samples are introduced to the Model 4100 using a tedlar bag or by direct injection. A needle attached to the nose of the instrument is used to puncture the septum of the tedlar bag and approximately $5 \mathrm{ml}$ of sample is injected for one analysis.

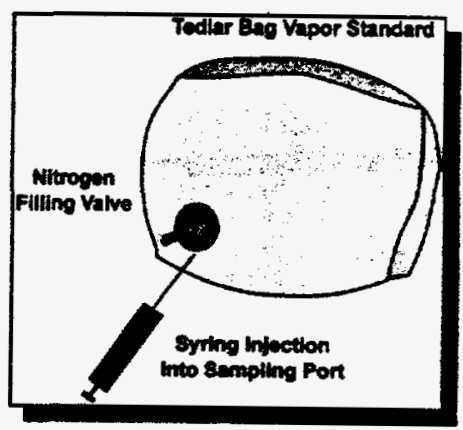

Figure 4. Tedlar Bag

- The instrument is controlled by proprietary software that allows the operator to select or develop a method. to program various component temperatures, and to automatically record the data for future recall.

- The system uses a two-position, six-port GC valve to switch between sampling and injection modes.

- In the sample position, headspace vapor is first passed through an inlet preconcentrator or water trap and then through the inlet, valve and loop trap. The loop trap concentrates the suspect compounds. At the same time. helium carrier gas passes through the altemate poits of the valve to a capillary column, impinging on the surface of a temperanue-controlled SAW resonator.

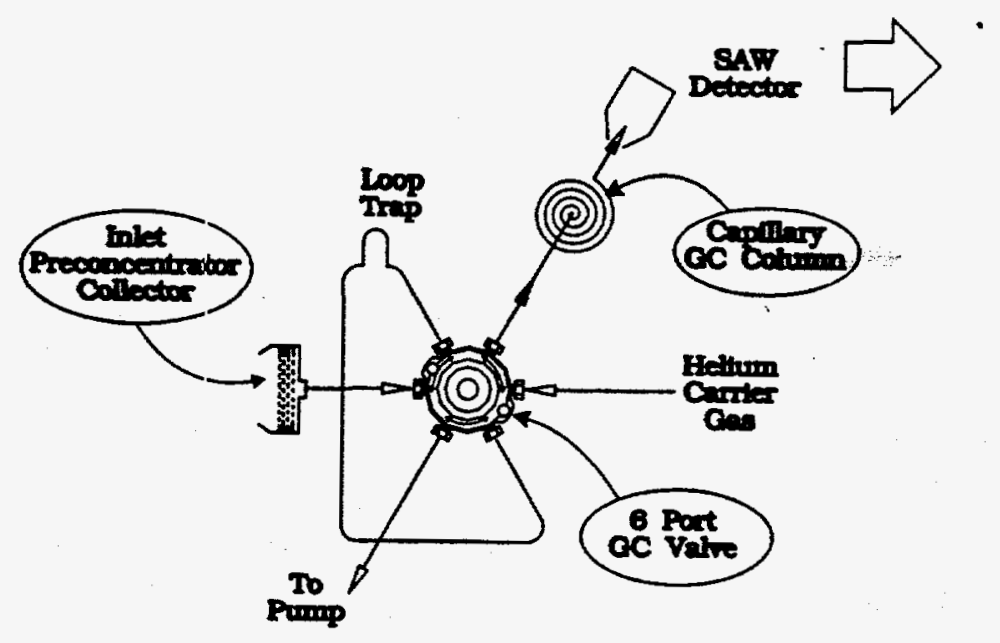

Figure 5. System Diagram 
- When the yalve trap is switched into the injection position, the flow of hclium carrier gas is reversed through the column, and the loop trap is rapidly heated to $200^{\circ} \mathrm{C}$ causing the release of the contaminants to the head of the GC column. The temperature of the GC column is linearly ramped to approximately $125^{\circ} \mathrm{C}$ over 10 seconds causing the VOCs to separate as they travel down the column.

- As the contaminants pass through the GC column, they are separated. As the resolved analytes strike the surface of the resonant SAW sensor, they cause the resoriant frequency of the crystal to change. The frequency shift is recorded and the concentration level of the compound is calculated in parts per billion (ppb) or picugrams (pg).

- The adsorption to the surface of the re:onator causes a change in the charactcristic frequency of the piezoelectric crystal. The adsorption efficiency for a given compound is dependent on the crystal icmperature.

- By operating the crystal at different temperatures using the system software, the crystal can be made specific for given materials based on the vapor pressure is the material.

- The SAW sensor determines the mass density of the compound and reports it to the database maintained in the 486 laptop computer.

- To obtain a conventional chromatogram plot of retention time, the derivative of frequency versus time is calculated. A representative chromatogram with a peak identification table is shown in Figure 6.
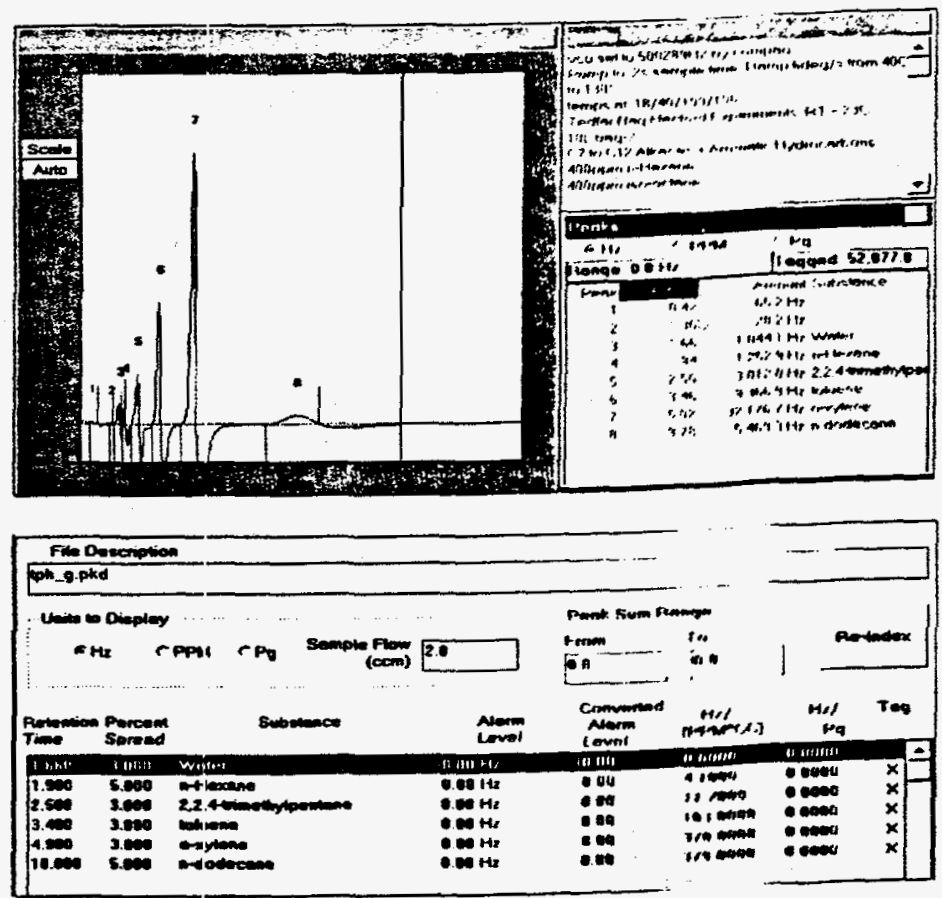

Figure 6. A 20-second chromatogram with a Peak Identification Table

In the Leaking Underground Fuel Tank (LUFT) configuration a useful set of standards is the alkane hydrocarisons homologous series from $\mathrm{C} 6-\mathrm{C} 12$.

- A peak identification table shows alkanes and aromatic hydrexiarbons.

- Several standard compounds are used for ixontaminant identification. The Model 41100 identifies the uniknown compounds through comparison with the many chemical signatures stored in the database. For screening analyses, benzene is needed to establish retention time reference. For quantitative results at the ppm level in real time, additional standards can be nun before field screening to determine a scaling factur for compounds.

- SAW sensors are quartz crystals having patterned electrodes that allow a high freyuency (60-1000 Mhz.) surface acoustic wave to be maintained on their surface. 


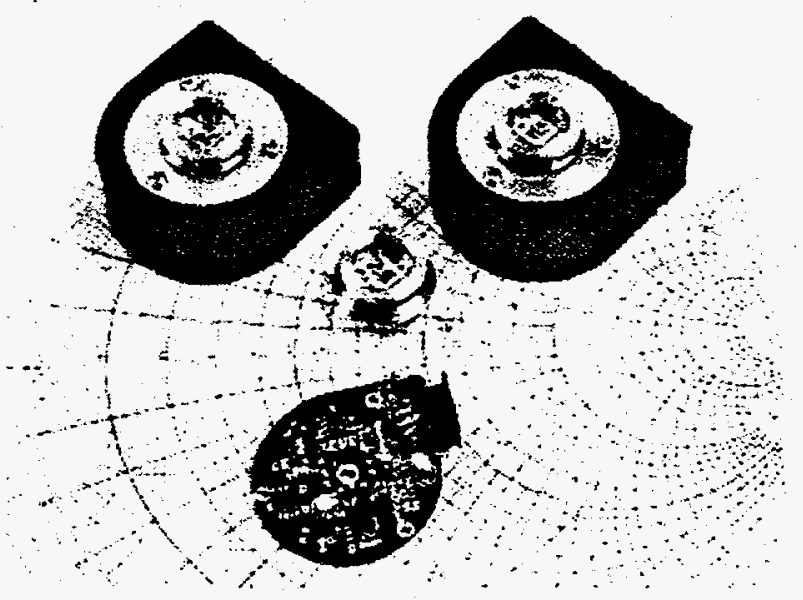

Figure 7. Photo of the SAW Detector

v The crystal frequency is dependent on the spacing of the electrode pattem, the crystal temperature, and the condition of the surface. Because the electrode pattern of a given SAW crystal is fixed, the frequency of the SAW sensor is dependent on the material adsorbed onto the quartz surface.

- The innovative feature of the SAW resonator is that the temperature of the SAW sensor can be programmed using a thermoelectric cooling/heating module bonded under the SAW crystal.

- In this configuration, the detector displays a wide dynamic operational range, up to 6 orders of magnitude. This dynamic range is not found in other detectors.

- The thermoelectric module is controlled by the computer, maintaining the SAW crystal at temperatures between 20 and $200^{\circ} \mathrm{C}$. Lower temperatures can the obtained by cascading thermoelectric coolers. The SAW resonator can be cooled during the analysis time when the materials are eluting from the column, thus insuring that materials will adsorb onto the SAW surface.

- At the end of the inject cycle, the SAW can be heated to temperatures greater than $150^{\circ} \mathrm{C}$ to boil off materials from the previous injection, thus cleaning the SAW surface for the subsequent analysis. This feature makes it unique among existing detectors.

- During development of the technology, a quality control plan was implemented. This plan called for the use of UL approved wiring for safety and thermal imaging of the column and oven to optimize performance while minimizing cold spots. The instrument was reduced in size and weight by fifty percent. Significant changes were made to the electronic and mechanical design to reduce power consumption while increasing sensitivity.

- The system is simple to operate and can be used safely by properly trained technicians. Technicians should complete 16 hours of basic training provided by the venitor. 


\section{SECTION 3}

\section{PERFORMANCE}

\section{Laboratory Testing}

Laboratory testing first established ideal minimum detection levels for selected target compounds (Table 1). Representative compounds typical of those found at hazardous waste sites were tested using two different GC columns.

Table 1. Measurement Range of Model $\mathbf{4 1 0 0}$ for Selected Compounds

\begin{tabular}{|l|c|c|}
\hline \multicolumn{1}{|c|}{ Analyte } & $\begin{array}{c}\text { Minimum } \\
(\mathrm{ppb})\end{array}$ & $\begin{array}{c}\text { Maximum } \\
(\mathrm{ppm})\end{array}$ \\
\hline Carbon Tetrachloride (CT) & 70 & 100,195 \\
\hline cis-Dichloroethylene (DCE) & 110 & 186,420 \\
\hline Chloroform (CF) & 65 & 182,351 \\
\hline Trichloroethylene (TCE) & 10 & 74,926 \\
\hline Tetrachloroethylene (PCE) & 3 & 17,965 \\
\hline $1,1,2,2$ Tetrachloroethane (TCA) & 1.3 & 6,256 \\
\hline Benzene (B) & 45 & 106,711 \\
\hline Toluene (T) & 4.5 & 29,276 \\
\hline Ethylbenzene (E]3) & 2.0 & 98,263 \\
\hline O-Xylene (O-X) & 2.0 & 6,465 \\
\hline
\end{tabular}

A typical display screen presenting both visual and numerical data results is shown in Figure 8.

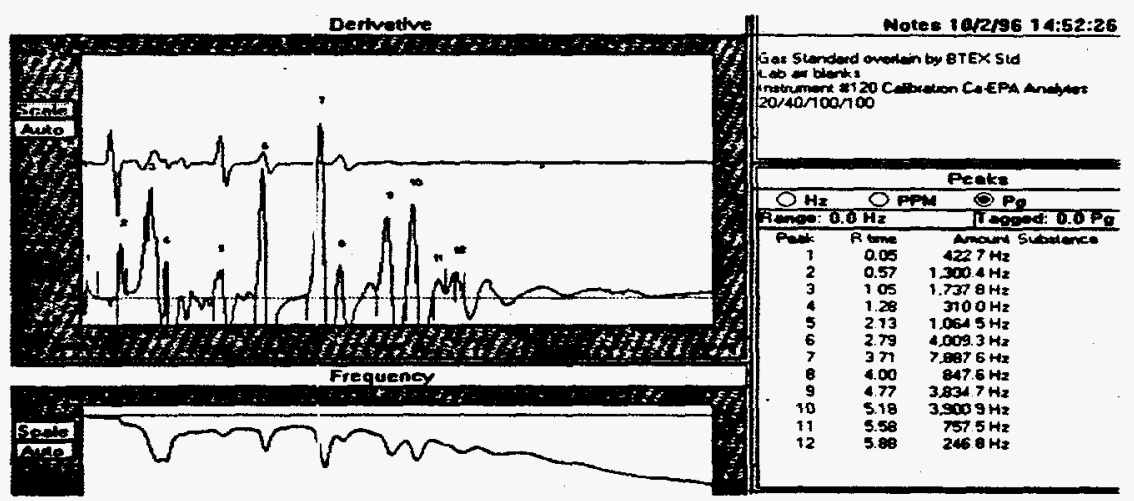

Figure 8. Chromatogram displaying screen presenting visual and numerical data results 
The instrument was able to characterize and separate a calibrated mixture of TO-14 compounds in 20 seconds. Figure 9 displas the result of such an analysis.

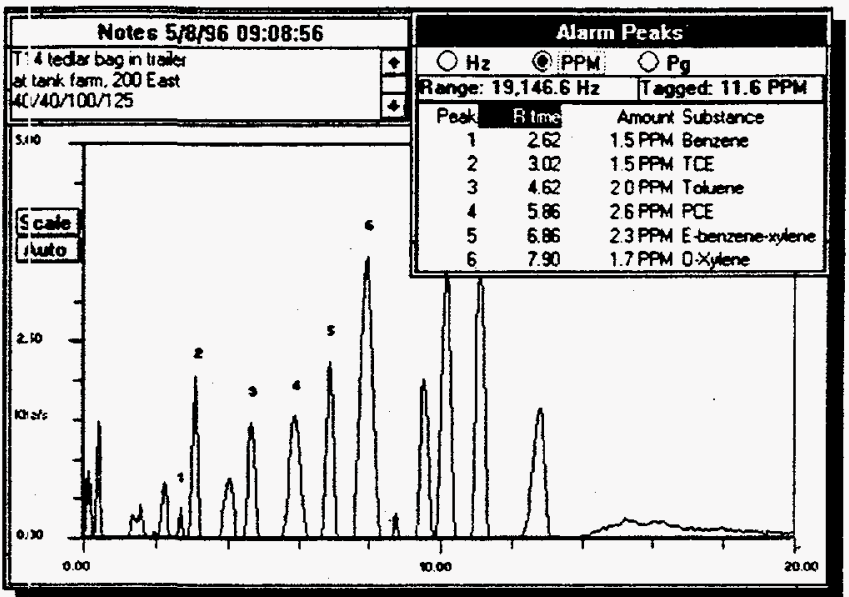

Figure 9. TO-14 analysis with optional peak tagging

\section{Demonstrations and Evaluations}

- Field testing of the SAW/GC was first performed in M-Area at SRS in 1995. Testing was done on water, soil, and gas samples. The performance of the SAW/GC prototype was validated with results obtained with an on-site Hewlett Packard ga chromatograph. The comparison showed that results agreed within $20 \%$. This evaluation documented that the Model 4100 could identify and quantify the presence of VOCs, specifically TCE and PCE. Figure 10 shows results of analysis of gas samples from the headspace of contaminated wells.

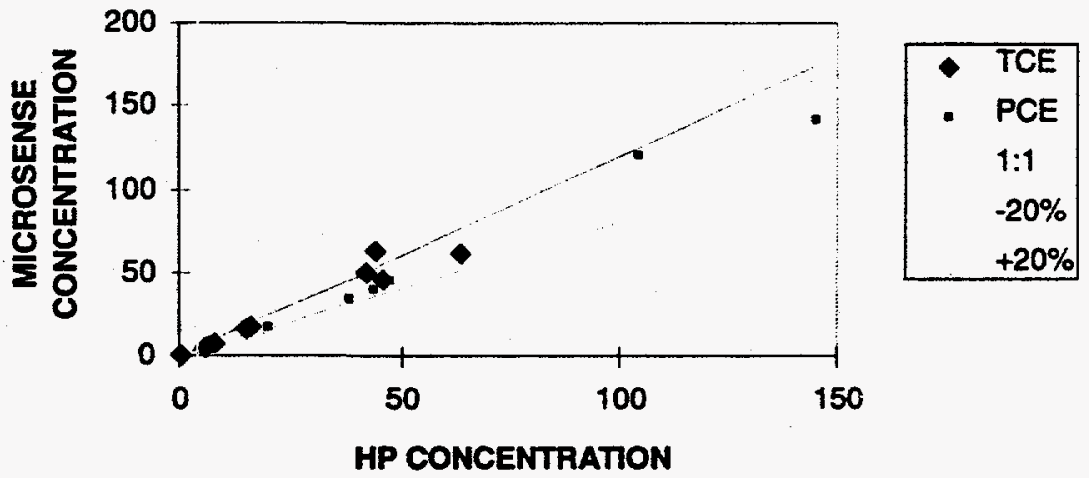

Figure 10. Verification of the SAW/GC with the SRS gas chromatograph. Measurement units are ppm.

- At LBNL in February 1996, the Model 4100 was used for characterization of soil gas and ground water with PCE and TCE at the ppb kevels. Samples were collected from wells fitted with septum lids designed to accumulate soil gas. The Model 4100 demonstrated its ability to speciste contaminants in real-time. Instrument calibration and compound identification was provided by preparing a one-liter: tedlar bag with the analytes at a one ppm concentration level.

- In April 1996, the Model 4100 was demonstrated at DOE's INEEL to perform vapor monitoring in wells surrounding the Radioactive Waste Management Complex (RWMC) and ground water monitoring at the Test Area North (TAN).

- At the first site, the Central facility in the RWMC, the Model 4100 was evaluated as a well headspace monitor. Forty tedlar bags from twenty wells (samples were collected at different depths within a well) were analyzed in approximately one hour for carbon tetrachlcride, chloroform, and TCE. Accuracy over the range of $20-500 \mathrm{ppm}$ was validated by more than ten calibration runs. Samples were also collected directly from the sampling port at the wellhead for field analysis. thus removing the need and cost of tedlar bags. 


\section{PERFORMANCE Continued}

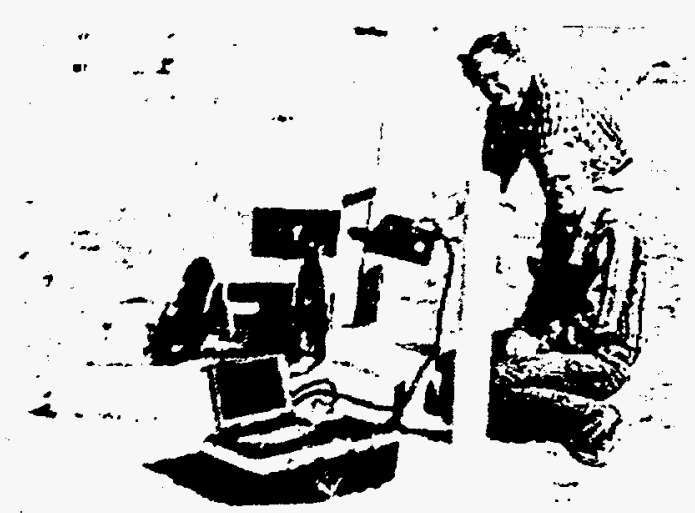

Figure 11 . Sampling a well head at INEEL, Idaho.

- At the second site, the Ground Water Treatment Facility (GWTF) at TAN, the Model 4100 successfully detected DCE, TCE and PCE at the ppb level. Figure 12 displays is chromintogram of the analytes of interest at the GWTF.

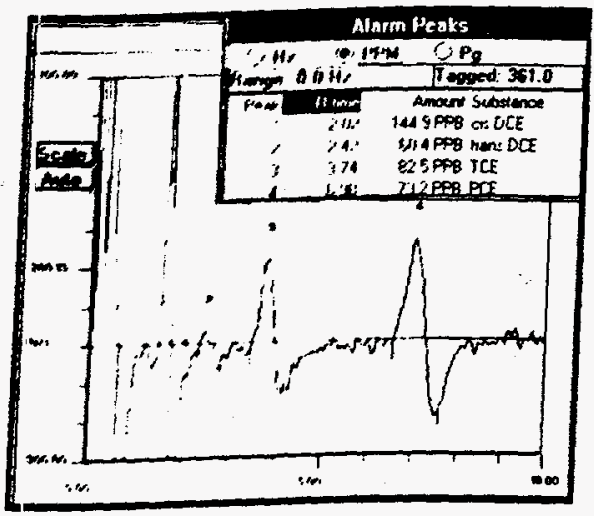

Figure 12. Chrmatngsam of (jWTF analytes of interest

- During May 1996, demonstrations were conducted at the IX) JF: I fanford Site, both the 200 Area West and the 200 Area East. Samples were collected from the headspace of tanks crmtaining mixed wastes. Both tedlar bags and summa canisters were used for sample collection. Two instrumerits with different coslumns were demonstrated first in the laboratory and then in the
field.

- Typically, the samples are collected and sent $v$, s labrratury for analysis of hydrocarbons by GC-MS using an EPA method for TO-14 compounds.

- For this demonstration, the samples wiste analymes using standards supplied by the laboratory. Total hydrocarton content was determined by summation of the individual ummprments. The Model 4100 reduced the time required for an individual sample analysis from 50 minutes using a GCAMS in the tat tor two minutes using the Model 4100 in the field.

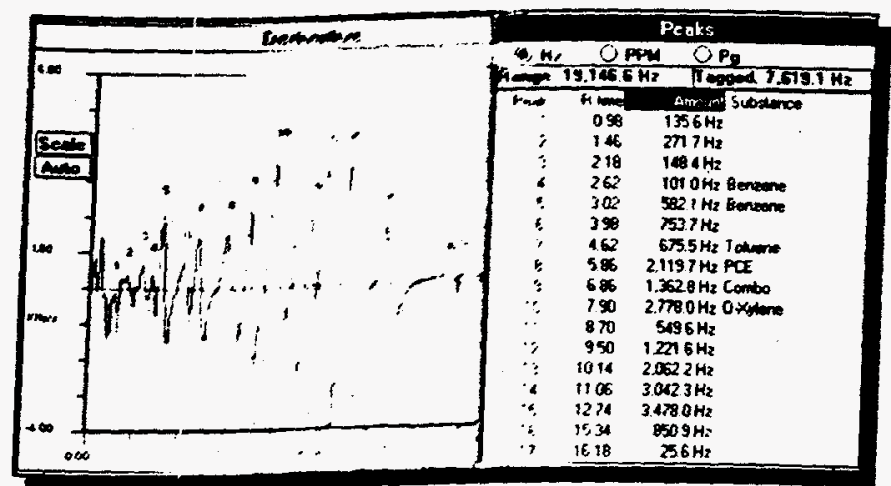

Figure 13. Chronsoms; sers ef tank farm analytes of interest 
- The Model 4100 SAW/GC was rested at the Cal EPA Hazardous Materials Laboratory, Berkeley, CA, for specificity and sensitivity toward dioxins, furans, and PCB's. Because these compounds have vapor pressures of 5-12 orders of magnitude less than VOCs, the SAW was modified to operate at significantly higher temperatures to ensure uniform evaporation. Target detection limits were established at the ppm levels by using calibrated amounts of the subject compounds (EPA-prepared solvent solutions with contaminant concentrations ranging from $0.1 \mathrm{ppm}$ to $50 \mathrm{ppm}$ ).

- The instrument was able to detect these compounds at the $0.1 \mathrm{ppm}$ level. Subsequent experiments using real samples of fly ash containing dioxins and PCB's showed that the instrument was sensitive to five picograms over a sampling time of 10 seconds.

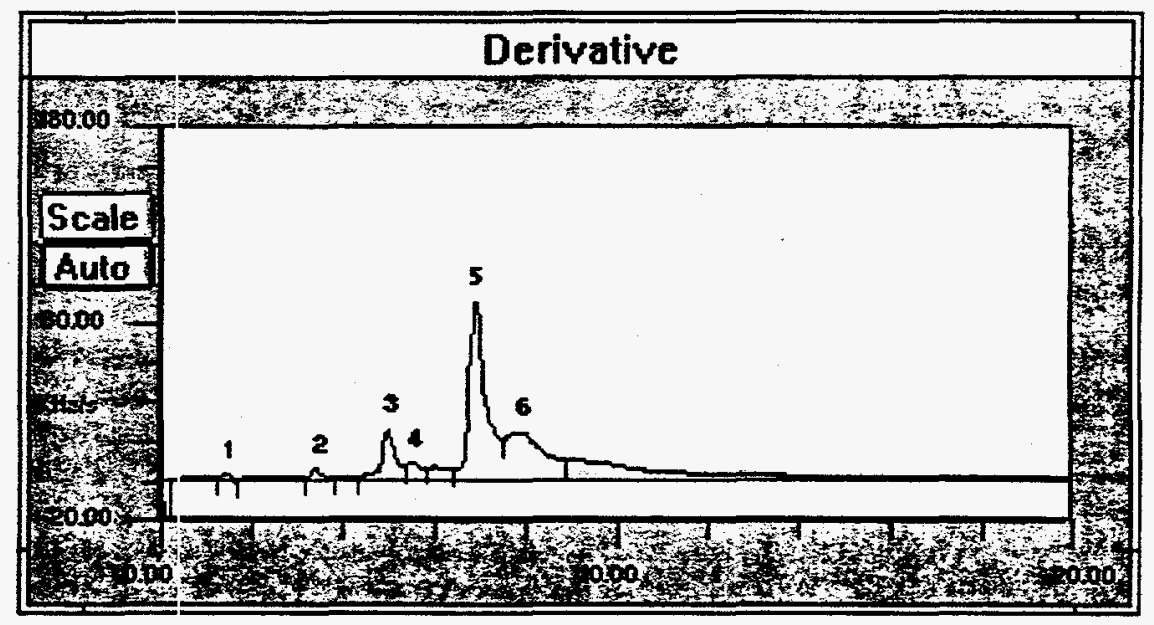

Figure 14. Response to dioxin-dibenzofurans mixture

- The Model 4100 SAW/GC was demonstrated at a Chicago Refinery to identify and quantify carbon scrubber efficiency in the containment of VOCs. The Model 4100 accurately detected benzene and toluene at the inlet and outlet to the scrubber.

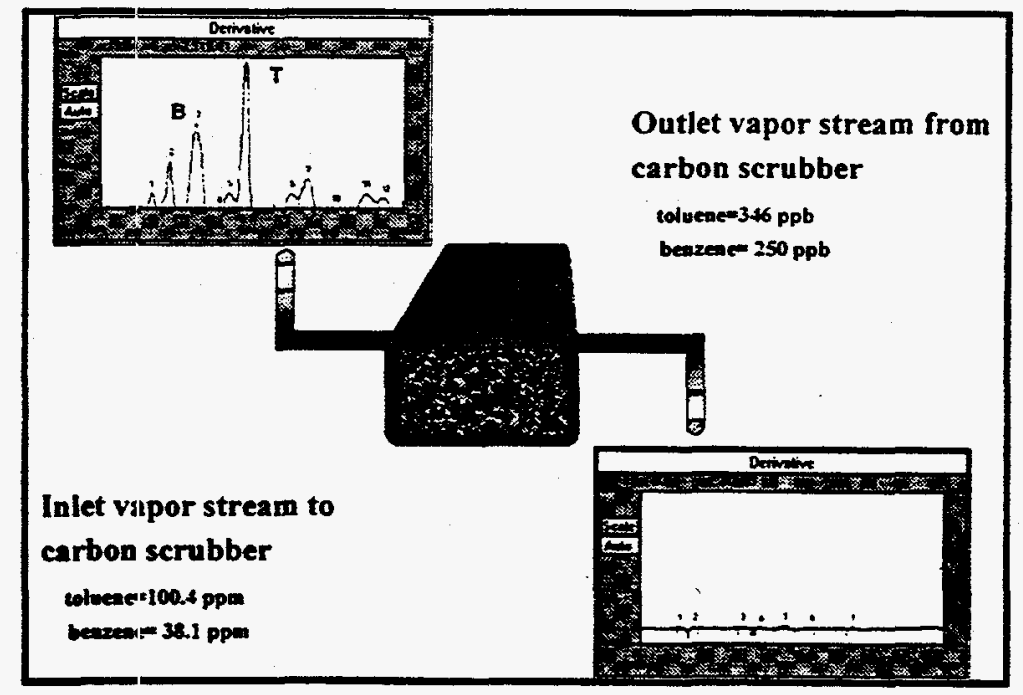

Figure 15. VOCs detected at the inlet and outlet of a carbon scrubber 


\section{TECHNOLOGY APPLICABILITY AND ALTERNATIVE TECHNOLOGIES}

\section{Technology Applicability}

- The specific problem targeted for this technology is quantitative field analysis of non-polar compounds, generally solvents and PCBs, at hazardous waste sites. The technology is especially effective at waste sites where historical information is available on the expected contaminant suite and concentration. SAWS/GC can be used for site characterization and monitoring, and remediation waste stream (e.g. offgas) monitoring.

- The SAWS/GC technology can also be used for other applications such as:

- environmental monitoring of chemical processes, fugitive emissions and OSHA/CAA materials;

- industrial monitoring including continuous emissions monitoring (CEM) of stack emissions, particle chemical processes, and other processes;

- detection of contraband, drugs, explosives, and lethal chemicals for law enforcement and the military;

- workplace monitoring for environmental health and safety.

- It is not expected that field screening with the: Model 4100 will replace laboratory analysis but can be used to significantly reduce the number of samples sent offsite for more expensive laboratory analysis.

- Field screening with the Model $\mathbf{4 1 0 0}$ allows collection of large data sets because of the relatively low cost of analyzing additional samples. Collection of a large number of replicate quantitative measurements at a low cost allows for a more robust statistical evaluation of the analytical results.

\section{Competing Technologies}

- In the Cost Section (\#5), the technology is compared with two baseline scenarios:

- The first comparisön is to a stationary anilytical laboratory using RCRA protocols.

The standard method for analysis of soil and ground water samples is to package and document the sample according to EPA handling and chain-of-custody rexpirements and to ship the samples to a commercial laboratory for analysis. Laboratory analyses are done using procedures defined by the EPA in document SW-846.

- The second comparison is with other portable analytical instruments including GC and GCMS.

- Analyses by a commercial laboratory on a per sample basis are significantly more expensive than field screening.

- Field analysis of samples minimizes probleuns associated with potential loss of VOCs during sample handling, transport and holding.

- Field analysis of samples eliminates problems associated with holding time requirements.

- Many other portable field instruments are cornmercially available but most are not comparable because either they do not adequately speciate contaminants or they do not have adequate sensitivity (e.g., FTIR, fluorescence, Raman, simple surface acoustic wave spectroscopy, solid stale sensors on a chip, photoionization detectors, electron capture detectors, flame ionization detectors, immunoassay test kits).

- The performance of field portable GCMS insinuments is comparable with the Model 4100 but capital costs are approximately three times as expensive. 
In 1992, the Los Alamos National Laboratory (LANL) compared the cost of analysis for VOCs in soil, water and gas samples by commercial laboratory and by six different field instruments (Henricksen and Booth, 1992). The study concluded that field sampling and analysis of VOCs offers substantial savings above a certain threshold number of samples per year (the order of 100 samples per year). They documented a factor of five reduction in cost per sample using field screening methods over com mercial laboratory analysis. They compared six field screening instruments several of which are comparable in performance tc the Model 4100 . The cost decision for selection of the field screening devices was driven by capital cost of the instrument anc supporting equipment, because the: annual operating costs of the six methods was relatively constant. The capital costs, in 199. dollars, ranged from $\$ 42 \mathrm{~K}$ to $\$ 16 \epsilon \mathrm{K}$ while the estimate of annual operating expenses ranged from $\$ 147 \mathrm{~K}$ TO $\$ 159 \mathrm{~K}$.

\section{Discussion}

A direct comparison of the Model 4100 with the results obtained from the LANL study is not possible for the following reasor First, due to lack of operating experience, reliable estimates of the operating cost for the EST Surface Acoustic Wave/GC (SAW/GC) are not available. A rough estimate was obtained from the vendor and is included below. Second the LANL report was written in 1992 and is priced in 1992 dollars. While it is reasonable to escalate operating costs to 1997 dollars, it is not rec sonable to escalate hardware price; because they typically do not increase. Most often, the equipment manufacturer releases a new version of the instrument with improved capabilities and at an increased price.

The following analysis summarizes capital and operating cost estimates for the Model 4100 instrument. It is very important to note that a rather robust operational scenario for the equipment was used. This includes the cost of two technicians and a vehic to support the use of the instrument. In most DOE applications, personnel and vehicles are available and are currently assignec to sampling and analysis tasks. The cost of implementation in this case is much less than estimated here. This scenario was che sen so that the operational costs can be compared with the other instruments in the referenced LANL report. In fact, the report showed that operational costs for the selected field screening instruments are very similar. Because a price was not available from the vendor, the estimated capital price of $\$ 44,000$ is based on similar technology used in the security industry.

\begin{tabular}{lr} 
MODEL 4100 CAPITAL COST ESTIMATE & 1997 dollars \\
& $\$ 44,000$ \\
Instrument & $\$ 2,000$ \\
Training and User Support Kit & $\$ 20,000$ \\
Vehicle** & $\$ 66,000$ \\
\hline Total & $\$$
\end{tabular}

\section{SAW/GC OPERATING COST ESTIMATES 1997 dollars}

\begin{tabular}{lr} 
Two full time technicians** & $\$ 139,200$ \\
Trap & $\$ 350$ \\
Helium carrier gas $99.9995 \%$ & $\$ 740$ \\
VOC Offgas Treatment & $\$ 1,000$ \\
GC Column & $\$ 4,000$ \\
Maintenance Contract & $\$ 2,500$ \\
Other Consumables & $\$ 2,500$ \\
Vehicle Operation** & $\$ 3,560$ \\
Admin Overhead & $\$ 7,420$ \\
Total & $\$ 161,270$ \\
\hline
\end{tabular}

**Sponsoring organizations at SRS, INEEL, and Hanford currently have technicians and vehicles in place within the organization. The cost of the technicians and vehicle is included to allow comparison with the following instruments. 
The following is a summary of the LANL data for detectors summarized in Table 5 (page 35-36) of the LANL report. The escalation o 1997 dollars is a compounded $3.1 \%$ per year and no atcmpt was mide 10 reprice the instruments evaluated in the report.

Table 2: LANL ESTIMATFS OF CAPITALAND OPERATING COSTS FOR SLX METHODS OF VOC ANALYSIS IN THE FIELD

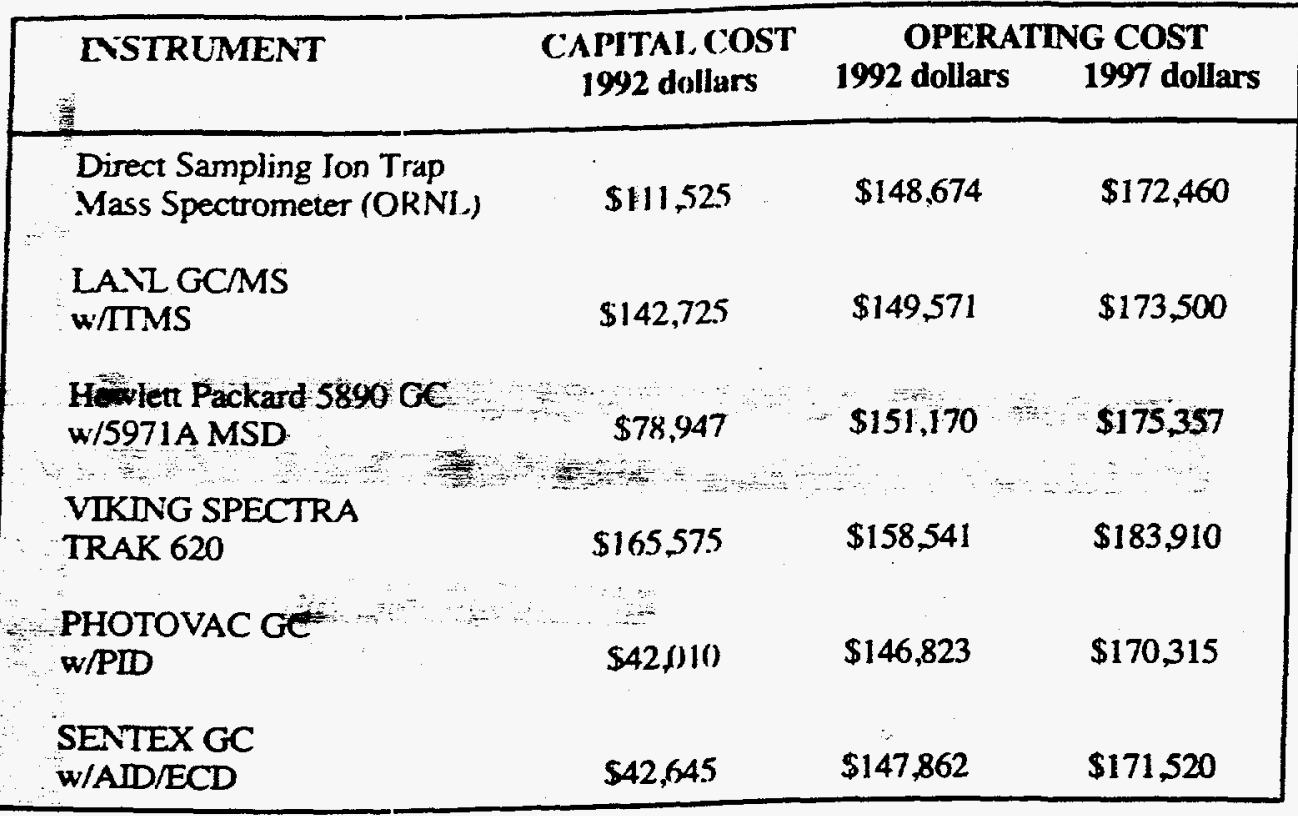

Assumes 3.1\% per year escalation rate 1992-1997.

Extimated operating costs for all instruments ircluding the Model 4100 are very similar. A detailed discussion of the performunce characteristics of the instruments is convained in the LANL repont. In summary, the DSITMS, the GC MS, and the Model 4100 can detect most compounds of interest at the low ppb level in real time. The Sentex instrument requires preconcentration to routinely detect at the ppb level and in real time can only detect at the ppm level. The Photovac can detect from ppm to low ppb for some compounds but in reid time only at the ppm level.

\section{Conclusions}

- The LANL study clearly documents a significant crost savings (a factor of five) when field screening instruments are used for analysis of VOCs in ground water and sedinents, reducing the number of samples sent to comemrcial labs for analysis.

- The LANL study shows that field screening technolingy selection decisions are driven by capital cost of the instrument, because annual opetating costs are relatively similar for differcnt instruments.

- The only commeneially available analytical instruments that provide unambiguous compound identification with ppb levels of sensitivity utilize mass spectrometric techniques.

- The cost comparison of the Model 410 ) to mas: spectrometric techniques is very favorable (capital costs of Model $4100 \approx 30 \%$ of mass spectrometer). 


\section{REGULATORY/POLICY ISSUES}

\section{Regulatory Considerations}

- Although field screening methods, such as the Model 4100 SAW/GC, generally provide rapid, high quality, compound-specific data with minimal instrument maintenance and operating cost, procedures and application for their use are not generally as well documented as the EPA reference methods.

- A significant effort must be made ty technology developers to acquire regulatory acceptance for new field methods.

- Secondary waste stream generation is the same or slightly reduced with the use of the Model 4100 over baseline methods.

- Field analysis of samples minimizes problems associated with potential loss of VOCs during sample handling, transport and holding.

- Field analysis of samples eliminates problems associated with holding time requirements

- Chain of custody requirements do rot apply because samples are not transported.

\section{Safety, Risks, Benefits and Community Reaction}

\section{Worker Safety}

- The system is simple to operate and can be used safely by properly trained technicians. Technicians are required to complete sixteen hours of basic training.

\section{Community Safety}

- Field analysis of samples minimizess risks posed by sample handling, transport and holding.

- Use of field screening methods can significantly reduce the time necessary for site characterization.

\section{Environmental Impact}

- None

\section{Socioeconomic Impacts and Community Perception}

- Use of the technology will have minimal impact on the labor force and the economy of the region. 


\section{LESSONS LEARNED}

\section{Implementation Considerations}

- The site manager must work with the regulator to assure acceptance of the data collected. The pending Cal EPA Certification will assist in this acceptance.

- Field screening is not expected to replace laboratory analysis but can be used to significantly reduce the number of samples sent offsite.

\section{Technology Limitations/Needs for Future Development}

- The Model 4100 will not distinguish constituents that elute from the GC column at the same time. Careful choice of GC columns taking into consideration anticipatted constituents will eliminate this problem.

- The Model 4100 is an excellent choice for robust field screening of non-polar compounds. Baseline GC-MS may provide better speciation in some settings, but capital costs are approximately three times as much.

\section{Technology Selection Considerations}

- Field screening methods, such as the Model 4100 SAW/GC, have the potential to provide rapid, high quality, compoundspecific data with minimal instrument maintenance and operating cost when compared to EPA reference methods. These methods should be used in conjunction with laboratory analysis of a subset of samples for verification of the technology's performance.

- The accuracy of the Model 4100 SAW/GC usually derives from the fact that an expected suite and concentration of contaminants at DOE sites are generally known. Field screening using the Model 4100 can provide very good data where there is historical information to serve as a. guide.

- Field screening methods allow collection of a large data set at a low cost, consistent with the well documented statistical approaches in exploration geochemistry. 


\section{APPENDIX A}

\section{REFERENCES}

Anne D. Henriksen and Steven R. Booth, 1992, Cost Effectiveness of an Innovative Technology for VOC Detection: The Direct Sampling Ion Trap Mass Spectrometer", Los Alamos National Laboratory, LA-UR 92-3527. 
This report was prepared by:

Westinghouse

Savannah River Company

Savannah River Site

Aiken, SC 29808

Contact: Carol Eddy Dilek

(803) 725-2418

in conjunction with:

\section{Colorado Center}

for

Environmental Management

999 t8th Street Suite 2750

Denver, Colorado 80202

Contact: Dawn Kaback

(303) 297-0180 Ext. 111

and

Hazaridous Waste Remedial Actions Program Lockheed Martin Energy Systems

P.O. Box 2003

Oak Ridge, Tennessee 37831

Contact: Scott Colbum

(423) $435-3470$

Assistance was provided by

Amerasia Technology Corporation 
I

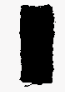

I.

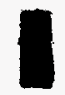

I

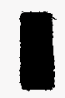

I

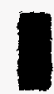

3

I

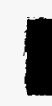

I

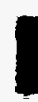

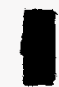

I 


\section{IEST THE AIR ANYWHERE!}
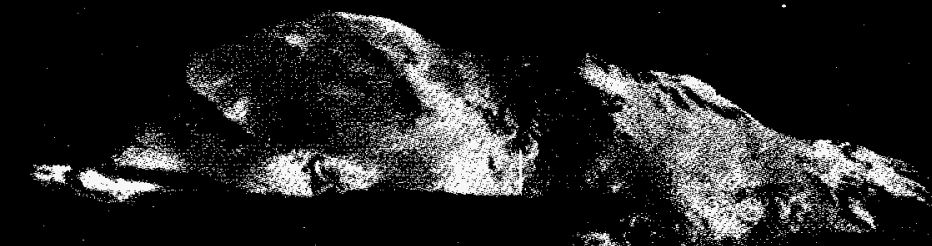

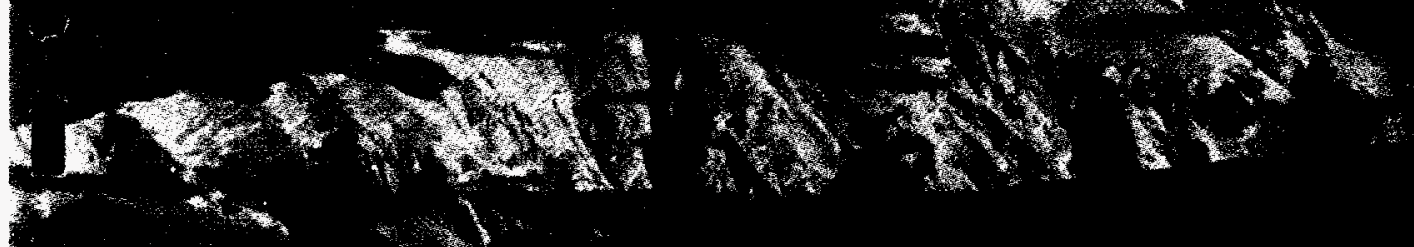



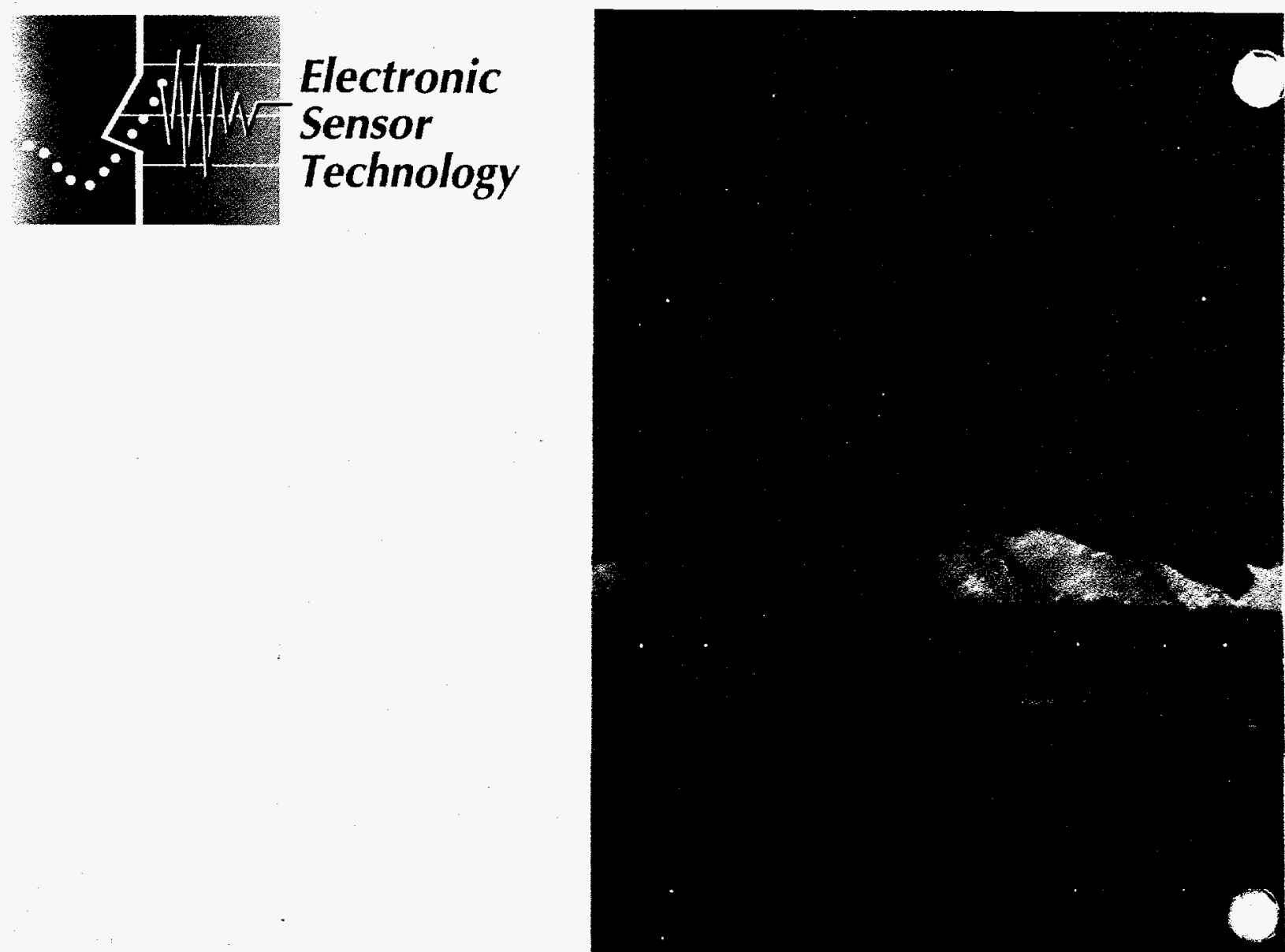


\section{Model 4100 Vapor Detector and Analyzer}

\section{Description}

The $\mathbf{4 1 0 0}$ consists of a portable Gas Chromatograph

(GC), a SAW sensor and a dynamic particle/vapor

sampling head. The components are shock mounted

in a rugged field-portable fiberglass carrying case.

The solid-state resonator sensor has excellent recovery characteristics and provides sensitivity to picogram levels and spans, in dynamic range, more than five orders of magnitude.

\section{Operation}

The $\mathbf{4 1 0 0}$ captures a vapor or particle sample in a cryo-focus chamber. After passing through a GC column, the suspect sample is identified and deposited on the SAW sensor. The SAW sensor determines the mass density and reports it to the database maintained in a $\mathbf{4 8 6}$ laptop computer.

The database identifies the suspect sample by comparison with a library of chemical signatures on file and the Windows based program calculates the mass. The analysis is displayed on a multiple window screen.

\section{Software Selectable Parameters}

- Peak detection values

- Peak alarm values

- Printer drivers

- RS-232 communication parameters

- Remote operation with modem

\section{Specifications}

- $14 \times 20 \times 10$ inches

- 35 pounds $(15.9 \mathrm{Kg})$

- High sensitivity ( 50 pico grams, or parts per billion)

- Wide dynamic signal range (20,000 minimum)

- Variable sampling time from 10 seconds to 2 minutes

- Analysis time from 5 seconds to 2 minutes

- Low detection threshold (parts per trillion)

- Fast column settling time (30 seconds or less)

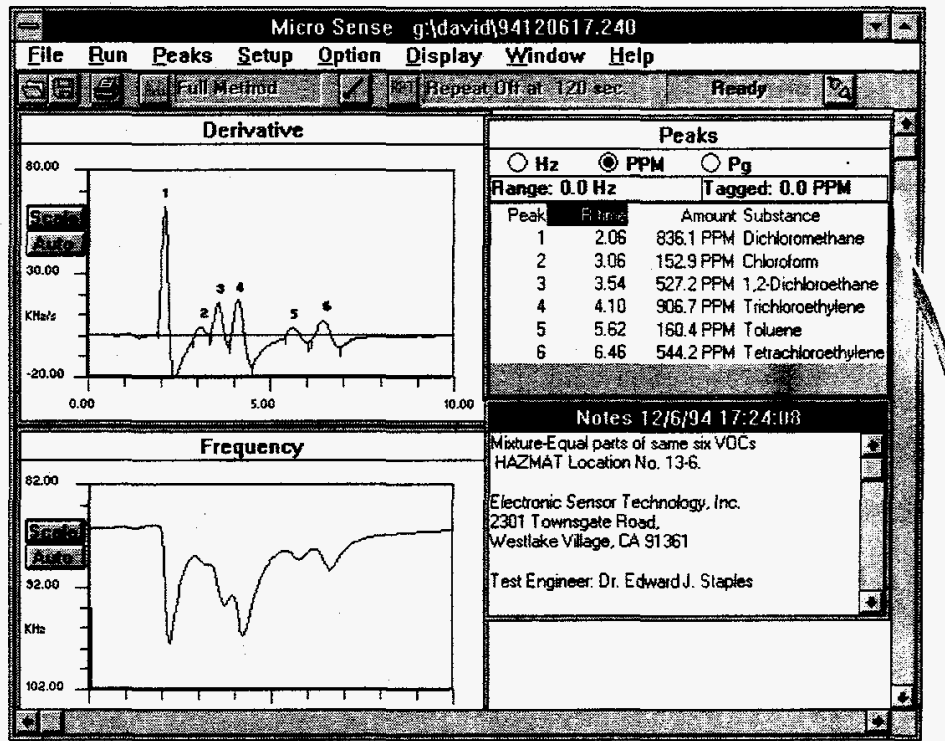




\section{Model 4100 Vapor Detector and Analyzer}

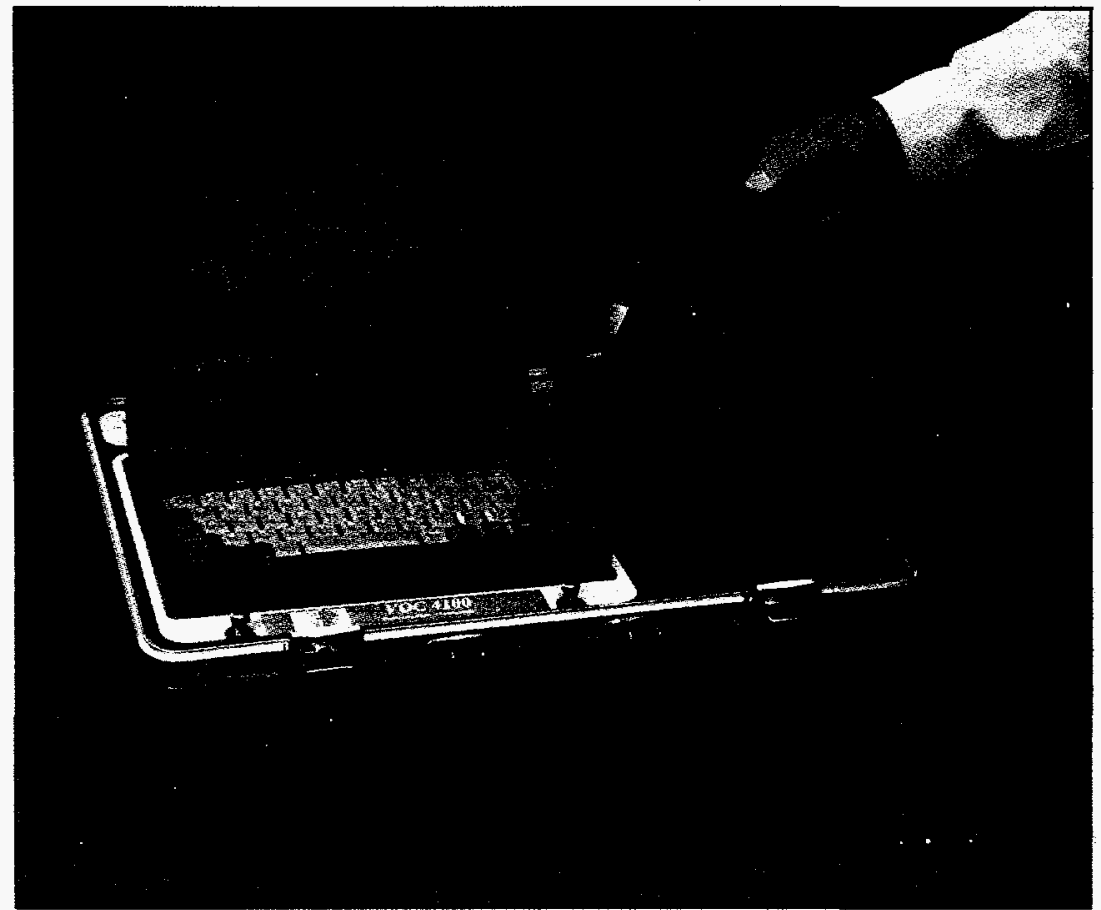

\section{Portable, Fast, Highly Sensitive}

Within 10 seconds, the 4100 identifies vapor concentrations as low as $\mathbf{1 0 0}$ parts per billion in amounts less than $\mathbf{5 0}$ pico grams.

The $\mathbf{4 1 0 0}$ has demonstrated its speed, portability and sensitivity in varied and challenging screening operations. With its proprietary Surface Acoustic Wave (SAW) detector, it has sensitivity and dynamic range previously unattainable in a portable, low-cost package.

\section{Easy to Use}

Windows ${ }^{\circledast}$ based software and extensive on-line help make the 4100 easy to learn and easy to operate. The user interaction mode is selectable for non-technical field use as well as detailed lab analysis.

A range of operator levels can be displayed from simple sunlight legible LCD and audio detection indicators to complete multiple field portable chromatographs.

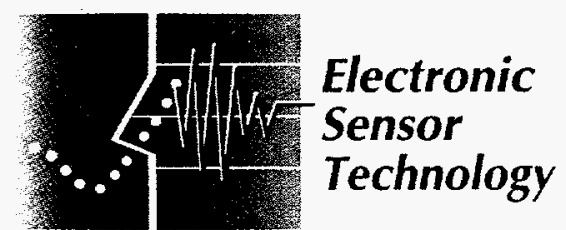




\section{Model 4100 Vapor Detector and Analyzer}

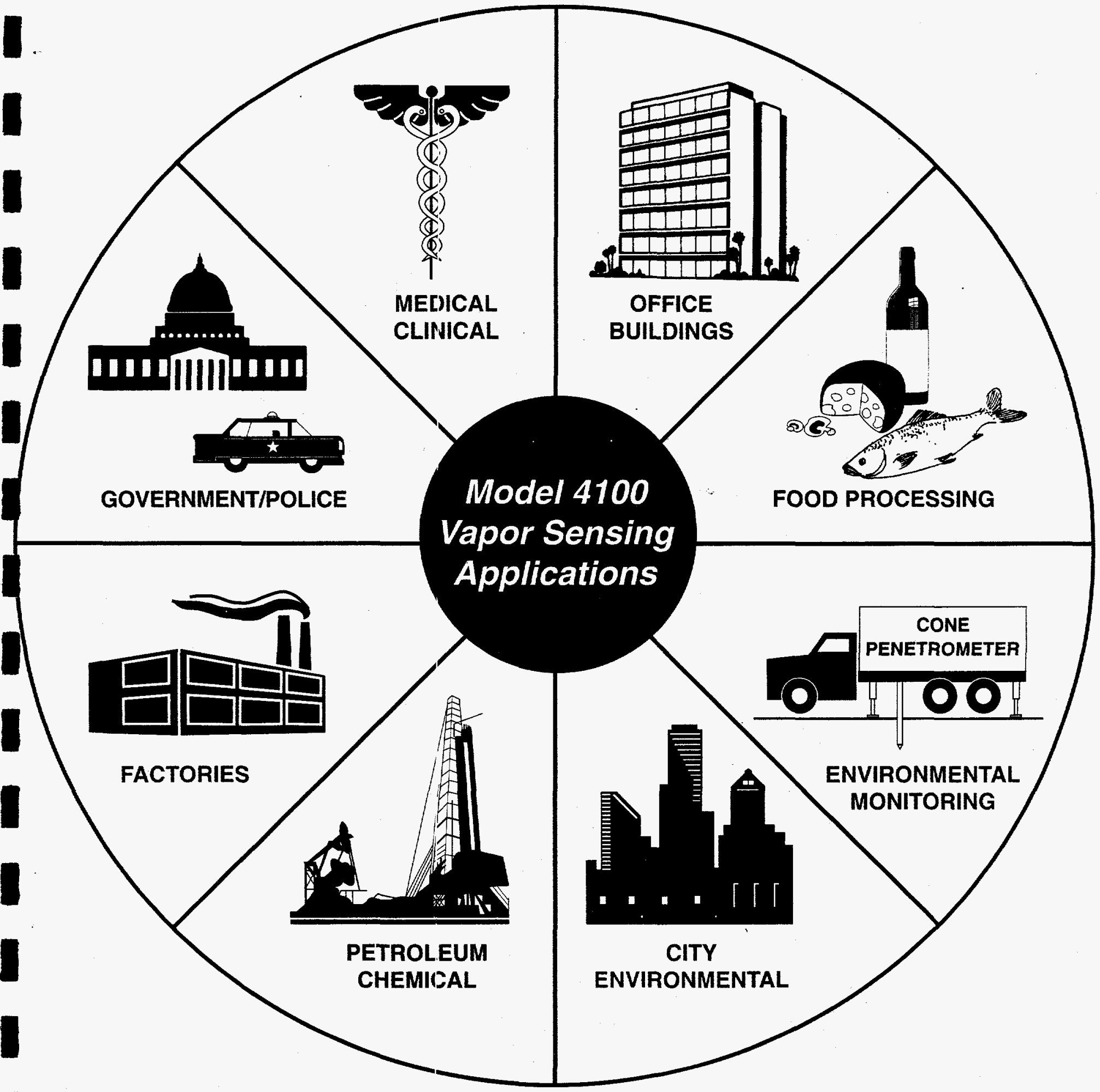

TEST THE AIR, ANY'WHERE, IN JUST 10 SECONDS! 


\section{Model 4100 Applications}

\section{Configuration}

- Process Control

- Food Processing

- Medical Laboratories

- Volatile Organic Compounds

- Military

Chemical/Biological Warfare (CBW) Detection Systems

\section{Environmental}

PRINCIPAL APPLICATIONS

- Stack Emissions Monitoring

- Ambient Air Hazard and Emissions Monitoring

- Underground Tank and Water Contamination

- Fugitive Emissions

- Clean Air Compliance

- Industrial Hygiene-Related Air Monitoring

SELECTED VOC SIGNATURES

- Trichloroethylene - Benzene

- Gasoline / Diesel - Toluene

- Carbon Tetrachloride

Contraband Detection, Drugs of Abuse

SELECTED CHEMICAL SIGNATURES

- Heroin - Marijuana

- Cocaine - PCP

- Meth-Amphetamines

Explosive Detection, Security Systems

SELECTED CHEMICAL SIGNATURES

- Plastic Explosive - RDX - Dynamite

- Semtex - PETN - C-4

- Nitroglycerin • TNT - Taggents

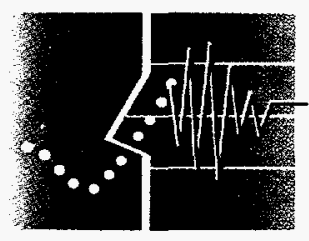

2301 Townsgate Road

Westlake Village, CA 91361

Phone (805) 495-9388

FAX (805) 495-1550

Please feel free to contact us regarding your specific needs.

- Hospital Floor Monitoring and Analysis

- Ethanol Alcohol Testing 



\section{Background}

\section{TechKnow ${ }^{\mathrm{TM}}$ Reference Guide Contents}

\section{What is TechKnow ${ }^{m}$ ?}

TechKnow is not just a database on the World Wide Web. It is a free, easy-to-use tool that can help you learn more or share more - about innovative environmental technologies.

A secure, password-protected database, TechKnow allows you to access, add, and update data highlighting environmental technologies over the Web.

All you need to enter TechKnow ${ }^{\mathrm{T}}$ is a personal computer, access to the World Wide Web, and a frame-compatible Web browser (Netscape ${ }^{\text {TM }}$ or Microsoft Explorer ${ }^{\text {TM }}$ version 3.0 or higher). In order to use TechKnow ${ }^{m}$, you must register and open a free user account.

This reference booklet provides step-by-step instructions to help you use TechKnow'm.

\section{ABOUT TEBHKNOW'M}

Access TechKnow" at www.gnet.org, and click the "About TechKnow" button!

\section{Getting Started}

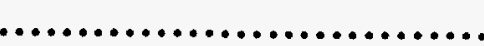

\section{Searching for Information}

\section{Updating Your Technology}

\section{Understanding \\ Keywords and Classifications}

-.............................

Additional Tips 


\section{Getting Started}

Step 1: Set Up Your TechKnow ${ }^{\top M}$ User Account.

1. Go to GNET ${ }^{\mathrm{T} s}$ on the World Wide Web at http://www.gnet.org. From this Main Page, click on the "Technology Center", then click on the TECHXVOW' DAIMUASE button.

2. The TechKnow ${ }^{\text {ma }}$ Main Page will appear. Click on the MEAlsien button.

3. A database entry page will appear. Click on EIIER TECHKMarw' button.

4. A window will appear asking you to log in. Type in "techuser" and "guest"*, then hit enter.

5. TechKnow ${ }^{\mathrm{m}}$ will now appear (it produces frames on your screen)

6. In the top, left-hand corner click on the green REAHIER button. Fill in all fields (you create your own UserID and Password). Keep in mind these fields are case-sensitive.

7. You should receive a confirmation message stating whether your account is approved within $24 \mathrm{hrs}$.

*The guest UserID and Password may only be used to "View" technology information.

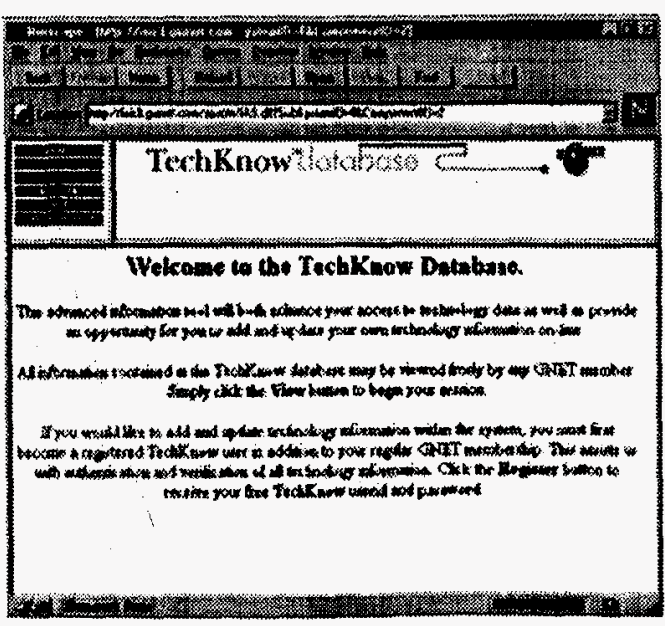

Check to See if Your Technology is Already Listed.

1. While inside the system, click on the green VIFW button. Eight buttons will appear at the top of your screen.

2. Click on the purple MaMn button. The alphabet will appear on the left side of your screen. You may either click on the letter that your technology begins with, or click on "Display All" to browse for your technology.

3. If you find your technology in the system, click on it to view the full profile. Check the "Editor" field (on the right side, third from the top) to see who currently owns the profile.

4. Each technology profile in the system is linked to one TechKnow ${ }^{\mathrm{TM}}$ account. If you are unfamiliar with the "Editor" you will need to send us a request via e-mail to gnet@getf.org so we can assign the profile to you. The profile must be assigned to your account before it can be updated.

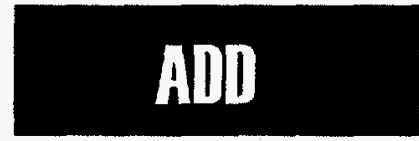

Add Your Technology to TechKnow ${ }^{\mathrm{TM}}$.

1. After your account has been approved, go to TechKnow ${ }^{\text {TM }}$ and $\log$ in with your UserID and Password (Required).

2. Once inside, click on the green ABD/BPIATE/LELETE button in the top, left corner. Three buttons will appear at the top of your screen.

3. Click on the purple All button. Eight buttons will appear on the left side of your screen.

4. Click on the purple BEMERAL Wfo button to begin creating your profile. Fill in all applicable fields. When finished, click the SAVE button.

5. Once you are satisfied with the information, click the green 8EWW IO MOUERAII button. This will send all of your information for inclusion to the public viewing area of TechKnow ${ }^{\mathrm{TM}}$. You will receive a confirmation message of its receipt within 48 hrs.*

*After your technology has been reviewed by the moderator, you will receive a second notification indicating its "approval" status. 


\section{Searching for Information}

Use the Search Feature.

\section{SEARCHI}

1. Go to the GNET ${ }^{\mathrm{TM}}$ Technology Center and log into TechKnow ${ }^{\mathrm{TM}}$ with your UserID and Password or the guest account provided. If you do not have a TechKnow" user account, refer to the "Getting Started" section of this booklet.

2. Once inside TechKnow ${ }^{\text {TM }}$, click on the green VIEW button located in the top-left corner of your screen. Eight buttons will appear at the top of your screen.

3. Click on the grey 8EABEN* button. Search fields and a search guide will appear at the bottom of your screen.

4. Enter your criteria into desired fields. Click on the 8unnuI QuEnY button at the bottom when finished. An alphabet will appear in the bottom-left of your screen.

5. Click on either the desired letter or "Display All" option. A list of technology profiles will appear in the main window.

6. Scroll down through the list and click on the desired technology to view its entire profile.

* You may click on the 8EAnsI button at any time to restart.

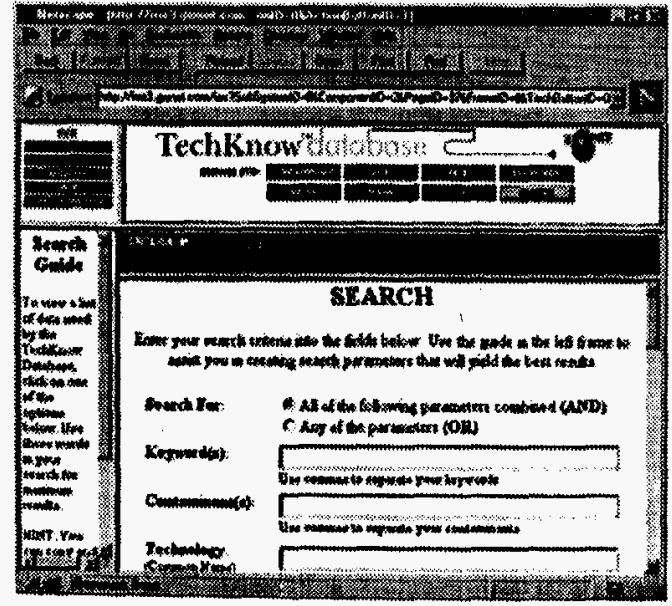

\section{Browse by Keyword. KEYWORLS}

1. While inside the TechKnow" "View" mode, click on the purple REYwarins button. An alphabet will appear in the bottom-left corner of your screen.

2. You may either click on the desired letter, or the "Display All" (which will take a little longer to download). A list of keywords will appear in the bottom-left corner of your screen.

3. Scroll down the list and click on the desired keyword. A list of technologies which match your criteria will appear in the center of your screen (if no matches are found or you wish to try another keyword, just click on another from the list provided).

4. Click on the desired technology to view its full profile.

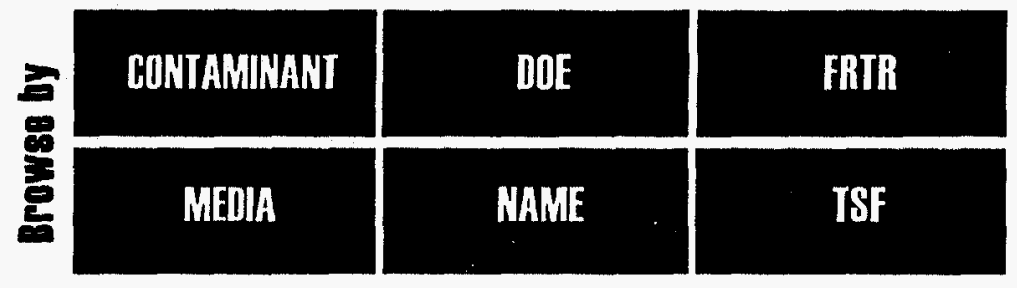

\section{Browse by Classification.}

1. While inside the TechKnow "View" mode, click on any of the following purple buttons: COMTAMIMAMI, MEDIA, DOE, MAME, FRIR, or Isf.* $A$ list of classifications will appear in the bottom-left corner of your screen.

2. Click on the desired classification. A list of applicable technologies will appear in the main portion of your screen.

3. You may scroll through the list of technologies, or click on a letter from the alphabet menu located on the bottom-left corner of your screen.

4. Click on the desired technology to view its full profile.

* These classifications are further described on page 8 of this reference guide 


\section{Updating Your Technology}

Step 1: $\quad$ Locate your technology profile.

1. Enter GNET ${ }^{\mathrm{m}}$ (http://www.gnet.org), click first on the "Technology Center," then click on the IFEAMUm" BAIABnsE button.

2. The TechKnow ${ }^{\mathrm{M}}$ Main Page will appear. Click on the Ellten IEexKNON= button.

3. A window will appear asking you to $\log$ in. Type in your

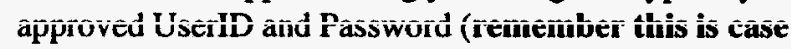
sensitive, it must exactly match) and hit enter.

4. Once inside TechKnow ${ }^{\mathrm{TM}}$, click on the green AM/UPAIE/ DELEIE button, located in the top-left corner of your screen. Three buttons will appear at the top of your screen.

5. Click on the purple upante button. A group of buttons will appear in the bottom-left corner of your screen.

6. Click on the purple IESA LIST button. A listing of your technology profile with keywords will appear. If not, go to the "View" area (button at top-right of screen), locate the technology by name, and check the profile's editor field to see who is listed.

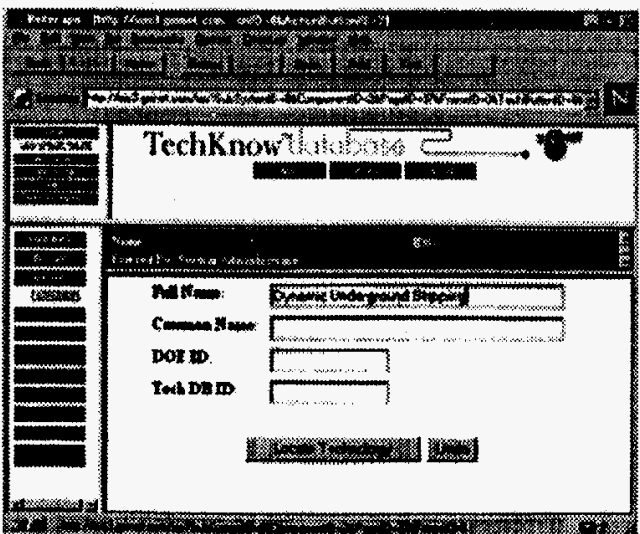

*If someone you are unfamiliar with is named as editor, you will need to notify GNET $^{\text {MM }}$ via e-mail to re-assign the profile to your account.

Update Your Technology Profile.

1. Once you have located your technology, click on it to view the entire profile. The buttons located on the bottom-left of your screen will become active.

2. Choosing from these buttons, click on the desired category*. The center of your screen will change and provide you with options on changing the specific fields.

3. Make changes as desired. At the end of each section you will be asked to save or clear your work.

* If you wish to add a keyword or category that is not included among the TechKnow ${ }^{\mathrm{TM}}$ menu options, send your request via e-mail to GNET ${ }^{\mathrm{T}}$ for consideration.

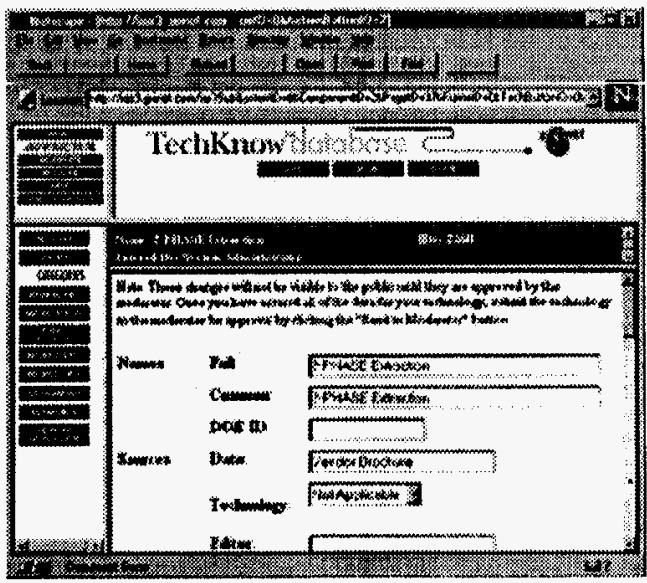

Send Your Updated Technology Profile.

1. When you are finished updating your technology profile review all changes for clerical errors and accuracy (e.g. URL addresses that work)

2. If you are satisfied that your updated profile is ready for public release, click the green SENI TO MABERATER button located at the bottom-left of your screen.

3. A "Send to Moderator" page will appear asking if you are sure you want to upload the updated profile to the public area of TechKnow ${ }^{\text {tM }}$. Click the suBmul IECHNOLasy button to upload the profile.

4. You should receive an e-mail confirmation* within 48 hrs

*After your update has been reviewed, you should receive a second notification stating if the updated profile was approved 


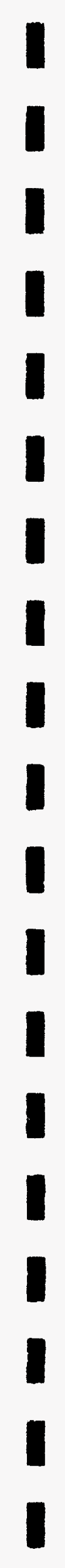




\section{Understanding Keywords and Classifications}

\section{Additional Tips}

\section{Keywords}

TechKnow ${ }^{\text {TM }}$ contains a keyword index of 756 words and phrases which are organized alphabetically. If a keyword is missing that you feel should be included in our index, you may request for its addition via e-mail.

\section{Contaminant}

TechKnow ${ }^{\mathrm{TM}}$ utilizes 16 of the most commonly used contaminant fields. You mayy access them though the "Contaminant" button while in the "View" mode.

\section{Media}

TechKnow ${ }^{\mathrm{TM}}$ allows you to create simple searches based solely on the type of affected media. These basic media categories generate a high-level sort of all technologies which are applicable to a certain field such as soil, or water.

DOE

TechKnow ${ }^{\mathrm{TM}}$ identifies cight Focus and Crosscutting Areas in which the U.S. Department of Energy (DOE) targets their technology development programs. This system provides additional background on how potential technology projects can relate to DOE. Definitions for each Area maybe found in the "Help" section of TechKnow".

\section{FRTR}

TechKnow ${ }^{\mathrm{TM}}$ denotes the 20 work groups of the Federal Remediation Technology Roundtable (FRTR). Definitions are available in the "Help" section of TechKnow"

\section{TSF}

TechKnow ${ }^{\text {MM }}$ offers the White House's taxonomy for technology development from the Technology for a Sustainable Future (TSF) initiative.

\section{Printing Profiles and Lists}

TechKnow ${ }^{\mathrm{TM}}$ allows you to print out information from any portion of the system. When you select the "print" icon, your Web browser will spawn a new browser page. Click the above print button within this new browser to print the screen. When finished, close this browser to get back to your original TechKnow ${ }^{\mathrm{m}}$ screen.

\section{Changing Screen Size}

You may adjust the size of each frame within TechKnow ${ }^{\mathrm{TM}}$ Simply move your mouse over the frames border until your cursor changes to "double arrows." Click and drag the frame across your screen to the desired position.

\section{Clicking on Related URLS}

TechKnow ${ }^{\mathrm{TM}}$ includes hyperlinks to outside white papers, photographs, and other related Web sites. When you click on one of these links, your Web browser will spawn a new browser page containing the requested information. When finished, close this browser to get back to your original TechKnow ${ }^{\mathrm{TM}}$ screen.

\section{Using "Display All"}

TechKnow ${ }^{\mathrm{mm}}$ contains thousands of records in its system. Each time you click for information, the database is generating a custom page in response to your request. Therefore, choosing the "Display All" option may take some time to complete if you are using a modem. 


\title{
Low Quality Naturall Gas Sulfur Removal and Recovery CNG Claus Sulfur Recovery Process
}

\author{
Pilot Plant Test Program
}


Abstract

Acknowledgment

1.0 Introduction $\quad 1$

1.1 CNG Claus Program Objectives 2

1.2 Pilot Plant Program Objectives $\quad 2$

2.0 Conclusions

2.1 CNG Claus Chemistry 3

2.2 Pilot Plant Operation $\quad 4$

3.0 CNG Claus Process and Pilot Plant 5

3.1 CNG Claus Process Description 5

3.1.1 Sulfur Recovery Section

3.1.2 Tail Gas Treating Section 9

3.2 Sulfur Recovery Unit Pilot Plant 12

3.2.1 Design Basis and Process Equipment Description $\quad 12$

3.2.2 Monitoring Equipment Description 24

$\begin{array}{ll}3.2 .3 \text { Commissioning and Operation } & 25\end{array}$

$\begin{array}{ll}4.0 \text { Test Program } & 27\end{array}$

4.1 Experimental Test Plan and Test Matrix 27

4.2 Test Results 39

4.2.1 Field Data

4.3 Data Analysis and Results

4.3.1 Material Balances $\quad 41$

4.3.2 Performance Summary $\quad 42$

$\begin{array}{ll}\text { References } & 51\end{array}$

Appendix A Gas Analysis Results

Appendix B Material Balance Calculations

Appendix C Site Maps and Equipment Photographs 


\begin{abstract}
.
Large, non-producing reserves of Low Quality Natural Gas (LQNG) contaminated with hydrogen sulfide $\left(\mathrm{H}_{2} \mathrm{~S}\right)$, carbon dioxide $\left(\mathrm{CO}_{2}\right)$ and nitrogen $\left(\mathrm{N}_{2}\right)$ exist in identified gas reservoirs in the United States. However, these gas reserves are not suitable for treatment and production using current conventional gas treating methods due to both economic and environmental constraints.

A group of three technologies has tieen identified as candidates for an integrated system which would allow for economical processing of these LQNG reserves. The three processes which make up the integrated system are the 1) Controlled Freeze Zone $(\mathrm{CFZ})^{(1)}$ process for hydrocarbon/acid gas separation; 2) Triple Point Crystallizer (TPC) ${ }^{(2)}$ process for $\mathrm{H}_{2} \mathrm{~S} / \mathrm{CO}_{2}$ separation and the 3) CNG Claus process ${ }^{(3)}$ for conversion and recovery of elemental sulfur from $\mathrm{H}_{2} \mathrm{~S}$. The combined $\mathrm{CFZ/TPC/CNG} \mathrm{Claus} \mathrm{group} \mathrm{of} \mathrm{processes} \mathrm{is} \mathrm{one} \mathrm{program} \mathrm{aimed} \mathrm{at} \mathrm{developing} \mathrm{an} \mathrm{alternative} \mathrm{gas}$ treating technology which is both economically and environmentally suitable for developing these low quality natural gas reserves.
\end{abstract}

Both of the CFZ and TPC technologies have been proven technically feasible during prior plant studies $^{(4,5)}$. However, the CNG Claus process had only been proven on a technical feasibility basis prior to 1996. This report describes the design, construction and operation of a pilot scale plant built to demonstrate the technical feasibility of the CNG Claus process which was designed to take advantage of the unique process conditions available for the integrated process system. 


\section{Acknowledgment}

Funds for this project were provided by the United States Department of Energy, Morgantown Energy Technology Center and the Consolidated Natural Gas Company, Pittsburgh. This support is acknowledged with thanks and appreciation. Global Sulphur Experts Inc. (formerly of BOVAR Corp. and BOVAR Western Research) would also like to acknowledge Acrion Technologies, Cleveland, Ohio and the CNG Producing Company, Ardmore, Oklahoma for their support in completing this work. 


\subsection{Introduction}

Increased use of natural gas (methene) in the domestic energy market will force the development of large non-producing gas reserves now considered to be low quality. Large reserves of low quality natural gas (LQNG) contaminated with hydrogen sulfide $\left(\mathrm{H}_{2} \mathrm{~S}\right)$, carbon dioxide $\left(\mathrm{CO}_{2}\right)$ and nitrogen $\left(\mathrm{N}_{2}\right)$ are available but not suitable for treatment using current conventional gas treating methods due to economic and environmental constraints.

A group of three technologies have been integrated to allow for processing of these LQNG reserves; the Controlled Freeze Zone (CFZ) $)^{(1)}$ process for hydrocarbon / acid gas separation; the Triple Point Crystallizer (TPC) ${ }^{(2)}$ process for $\mathrm{H}_{2} \mathrm{~S} / \mathrm{CO}_{2}$ separation and the CNG Claus process ${ }^{(3)}$ for recovery of elemental sulfur from $\mathrm{H}_{2} \mathrm{~S}$. The combined CFZ/TPC/CNG Claus group of processes is one program aimed at developing an alternative gas treating technology which is both economically and environmentally suitable for developing these low quality natural gas reserves.

The CFZ/TPC/CNG Claus process ${ }^{(4,5)}$ is capable of treating low quality natural gas containing $>10 \%$ $\mathrm{CO}_{2}$ and measurable levels of $\mathrm{H}_{2} \mathrm{~S}$ and $\mathrm{N}_{2}$ to pipeline specifications. The integrated $\mathrm{CFZ} / \mathrm{CNG}$ Claus Process or the stand-alone CNG Claus Process has a number of attractive features for treating LQNG. The processes are capable of treating raw gas with a variety of trace contaminant components. The processes can also accommodate large changes in raw gas composition and flow rates. The combined processes are capable of achieving virtually undetectable levels of $\mathrm{H}_{2} \mathrm{~S}$ and significantly less than $2 \% \mathrm{CO}_{2}$ in the product methane.

The separation processes operate at pressure and deliver a high pressure (ca. 100 psia) acid gas $\left(\mathrm{H}_{2} \mathrm{~S}\right)$ stream for processing in the CNG Claus unit. This allows for substantial reductions in plant vessel size as compared to conventional modified Claus / Tail gas treating technologies. A close integration of the components of the CNG Claus process also allow use of the methane/ $\mathrm{H}_{2} \mathrm{~S}$ separation unit as a Claus tail gas treating unit by recycling the CNG Claus tail gas stream. This allows for virtually 100 percent sulfur recovery efficiency (virtually zero $\mathrm{SO}_{2}$ emissions) by recycling the sulfur laden tail gas to extinction. The use of the tail gas recycle scheme also de-emphasizes the conventional requirement in Claus units to have high unit conversion efficiency and thereby make the operation much less affected by process upsets and feed gas composition changes.

The development of these technologies has been ongoing for many years and both the CFZ and the TPC processes have been demonstrated at large pilot plant scales. On the other hand, prior to this project, the CNG Claus process had not been proven at any scale. Therefore, the primary objective of this portion of the program was to design, build and operate a pilot scale CNG Claus unit and demonstrate the required fundamental reaction chemistry and also demonstrate the viability of a reasonably sized working unit.

The decision to design, construct and evaluate a field scale pilot plant the CNG Claus process was based on a successful theoretical study ${ }^{(6)}$ of the process conducted by BOVAR Western Research under contract to $\mathrm{CNG}$ and the $\mathrm{D} O \mathrm{OE}$ in the Phase 2 portion of this program. 


\subsection{CNG Claus Program Objectives}

In the initial phase of this program, the technical viability of the CNG Claus process was evaluated with respect to the fundamental question:

Would the required Claus reaction chemistry (shown below) proceed to an acceptable level (in terms of unit sulfur conversion) under the unique operating conditions required by the CNG Claus process?

$$
2 \mathrm{H}_{2} \mathrm{~S}+\mathrm{O}_{2}=\mathrm{S}_{2}+2 \mathrm{H}_{2} \mathrm{O}
$$

During this phase of the program it was determined through reaction modeling systems that the $\mathrm{H}_{2} \mathrm{~S}$ oxidation reaction should successfully proceed with an adequate yield to sulfur under the desired operating conditions ${ }^{(\omega)}$.

After completion of this phase of the work the next fundamental question was presented:

Can a pilot plant be successfully designed, built and operated for these unique conditions?

Through review of existing Claus sulfur recovery technology and equipment specification, it was determined that an operating unit could be designed and built successfully. It was determined that much of the commercially proven hardware components used in a conventional modified Claus plant would have equal applicability to the unique operating conditions presented by the CNG Claus process.

Therefore, the primary objective of this portion of the program was to design, build and operate a pilot scale CNG Claus unit, demonstrate the required fundamental reaction chemistry and demonstrate the operational viability of a reasonably sized working unit.

\subsection{Pilot Plant Program Objectives}

The pilot plant phase of the program was designed to realize the following specific objectives:

1. Design and construct a viable pilot scale unit.

2. Demonstrate the operation of the unit under the unique CNG Claus conditions in order to verify the applicability of the pilot plant unit equipment.

3. Demonstrate the operation of the unit under the unique CNG Claus conditions in order to verify the desired reaction chemistry and acceptable conversion efficiency of $\mathrm{H}_{2} \mathrm{~S}$ to sulfur.

4. Identify technical barriers to the design and operation of a commercial CNG Claus sulfur recovery unit. 


\subsection{Conclusions}

\subsection{CNG Claus Chemistry}

1. The Claus reaction $\left(\mathrm{H}_{2} \mathrm{~S}\right.$ oxidation to elemental sulfur) proceeds successfully in a free flame reactor under all of the tested conditions associated with the CNG Claus Process.

2. The $\mathrm{H}_{2} \mathrm{~S}$ oxidation reaction is stable and sustainable in the "free flame" reaction regime.

3. The $\mathrm{H}_{2} \mathrm{~S}$ oxidation reaction continues successfully at the very low oxidation reaction stoichiometries present in the CNG Claus process. The typical reaction stoichiometries were at $1 / 6$ of the full oxidation stoichiometry as compared to $1 / 3$ reaction stoichiometry which is employed in traditional Modified Claus process schemes.

4. The Claus reaction proceeds successfully at pressures of 50 psia and greater. The tests conducted at higher reaction pressure did not indicate any measurable negative effects.

5. The extent of $\mathrm{H}_{2} \mathrm{~S}$ conversion measured during the test runs was consistent with the minimum required value of 50 percent as set out in the test program objectives.

6. The $\mathrm{H}_{2} \mathrm{~S}$ to sulfur conversion yields at the tested conditions closely matched the predicted results as determined by thermodynamic equilibrium calculations for all of the tested conditions. The measured conversion efficiencies ranged between 42 and 68 percent as compared to the predicted efficiencies between 44 to 70 percent. This implies that the $\mathrm{H}_{2} \mathrm{~S}$ oxidation reaction is not unusually hindered by reaction kinetics.

7. The measured process gas compositions in the CNG furnace effluent closely matched the predicted values based on computer simulations. In particular the $\mathrm{SO}_{2}$ concentration was consistent with (and typically less than) the maximum allowed for in the original program objectives. This will ensure successful operation of the downstream tail gas treating section of the process.

8. The measured reaction furnace temperatures $\left(1500-2200^{\circ} \mathrm{F}\right)$ were well within the acceptable range and the measured test run values closely matched the predicted values.

9. The extent of side reactions in the pilot plant indicate that kinetic parameters do affect the extent of formation of the minor reaction product species; $\mathrm{H}_{2}, \mathrm{CO}, \mathrm{COS}$ and $\mathrm{CS}_{2}$. The concentrations of these compounds in the system are not considered detrimental to the overall successful operation of an integrated system. 


\subsection{Pilot Plant Operation}

1. The pilot plant design and equipment was taken directly from conventional technology and performed essentially as planried.

2. The conventional burner and reaction furnace system allowed for successful completion of the $\mathrm{H}_{2} \mathrm{~S}$ oxidation reaction under the required conditions.

3. The measured reaction furnace temperatures were consistently less than the allowable $2500^{\circ} \mathrm{F}$ maximum which ensures that conventional furnace refractory design can be employed.

4. The equipment failure in the pilot plant (leaking wasteheat exchanger) was probably a result of conventional corrosion and was not an artifact of the unconventional CNG Claus operating conditions.

5. The pilot plant was designed with entirely conventional metallurgy and did not suffer any unusual failures due to the CNG Claus operating conditions. 


\subsection{CNG Claus Process and Pilot Plant}

The pilot plant was designed to demonstrate the successful operation of the most critical portion of the CNG Claus unit; the Free Flame Reaction Furnace (RF). It is in this unit that the $\mathrm{H}_{2} \mathrm{~S}$ and $\mathrm{O}_{2}$ react vigorously to produce the desired product, elemental sulfur and other reaction by-products. The subsequent treating of the reaction by-products would be completed using conventional tail gas treating technology. Since all components of the tail gas treating technology have been in wide commercial use for many years, these components were not included in the CNG Claus pilot plant unit.

\subsection{CNG Claus Process Description}

The Sulfur Recovery Section of the CNG Claus process is based on a single stage, free flame reactor system. In this unit the acid gas feed is combusted with an oxygen bearing stream (ambient air or high concentration $\mathrm{O}_{2}$ stream as required) in a reaction furnace unit. This results in the direct oxidation and conversion of $\mathrm{H}_{2} \mathrm{~S}$ to elemental sulfur. The elemental sulfur is then recovered via condensation in a conventional shell and tube heat exchange sulfur condenser unit.

In the Tail Gas Treating Section the CNG Claus tail gas is processed in a conventional catalytic hydrogenation reactor in order to react all remaining sulfur compounds to $\mathrm{H}_{2} \mathrm{~S}$. This stream is then further treated to cool the process gas and remove most of the residual water in a direct contact water contactor and a conventional dehydration unit. The cooled, dehydrated tail gas is then re-compressed to be recycled to the TPC separation system.

The full process flow diagram is given in Figures 3,1-1 and 3.1-2. The primary operating units, their functions and the most important unit details are as follows:

\subsubsection{Sulfur Recovery Section}

\section{Reaction Furnace}

The $\mathrm{H}_{2} \mathrm{~S}$ oxidation reaction occurs in a free flame, single phase, open volume reactor modeled after a conventional modified Claus reaction furnace.

In order to integrate efficiently with the upstream TPC separation unit several novel operation conditions were proposed for the reaction furnace.

1. Oxygen Composition - In order to minimize the flow of unwanted inert components through the system, it was proposed to use a highly enriched air stream as the oxidant in the reaction furnace. For the purpose of the pilot plant design a 90 percent oxygen stream was used. This effectively decreased the total process gas volumes and thereby decreased the required size of all of the processing equipment. 


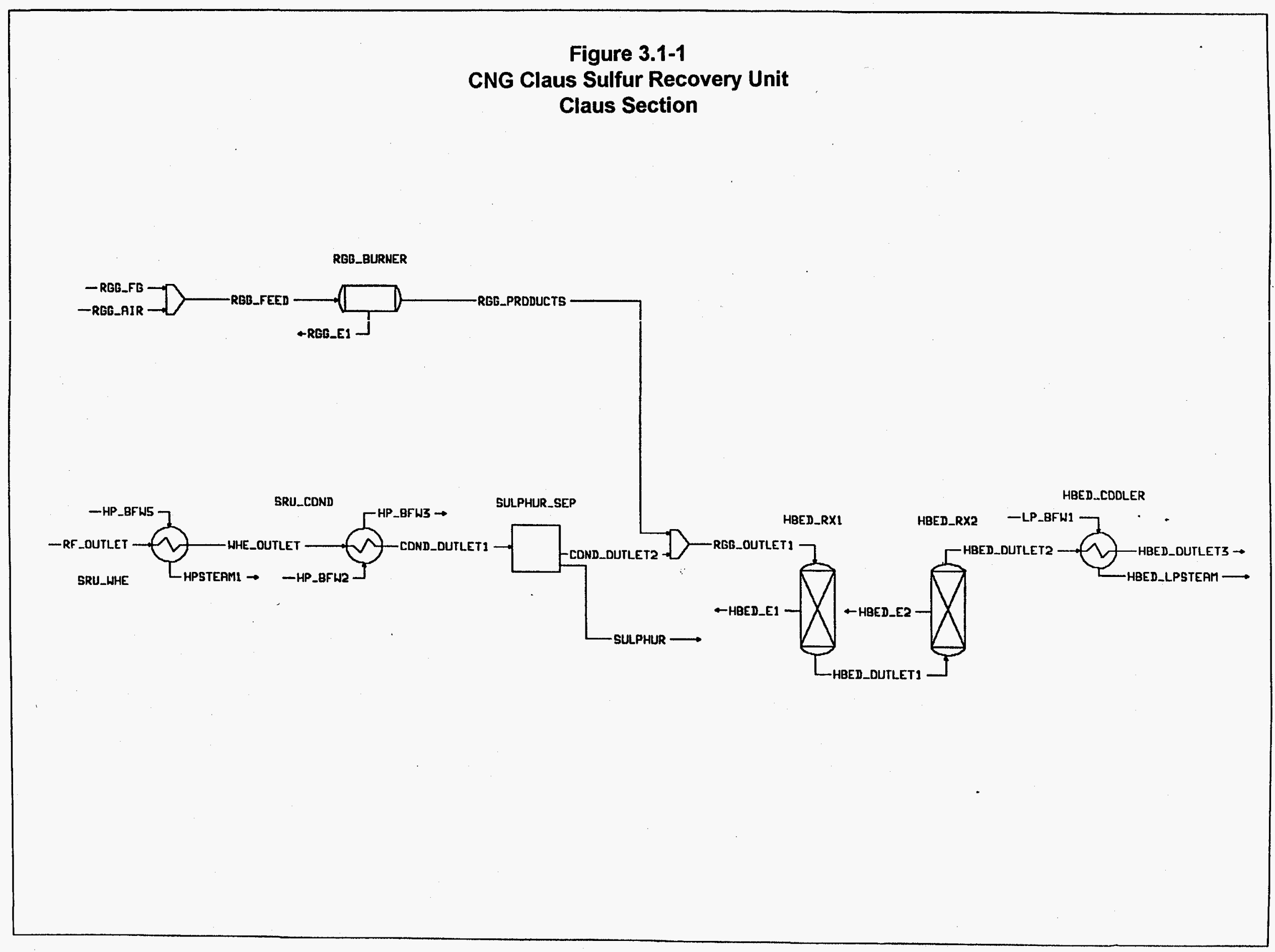




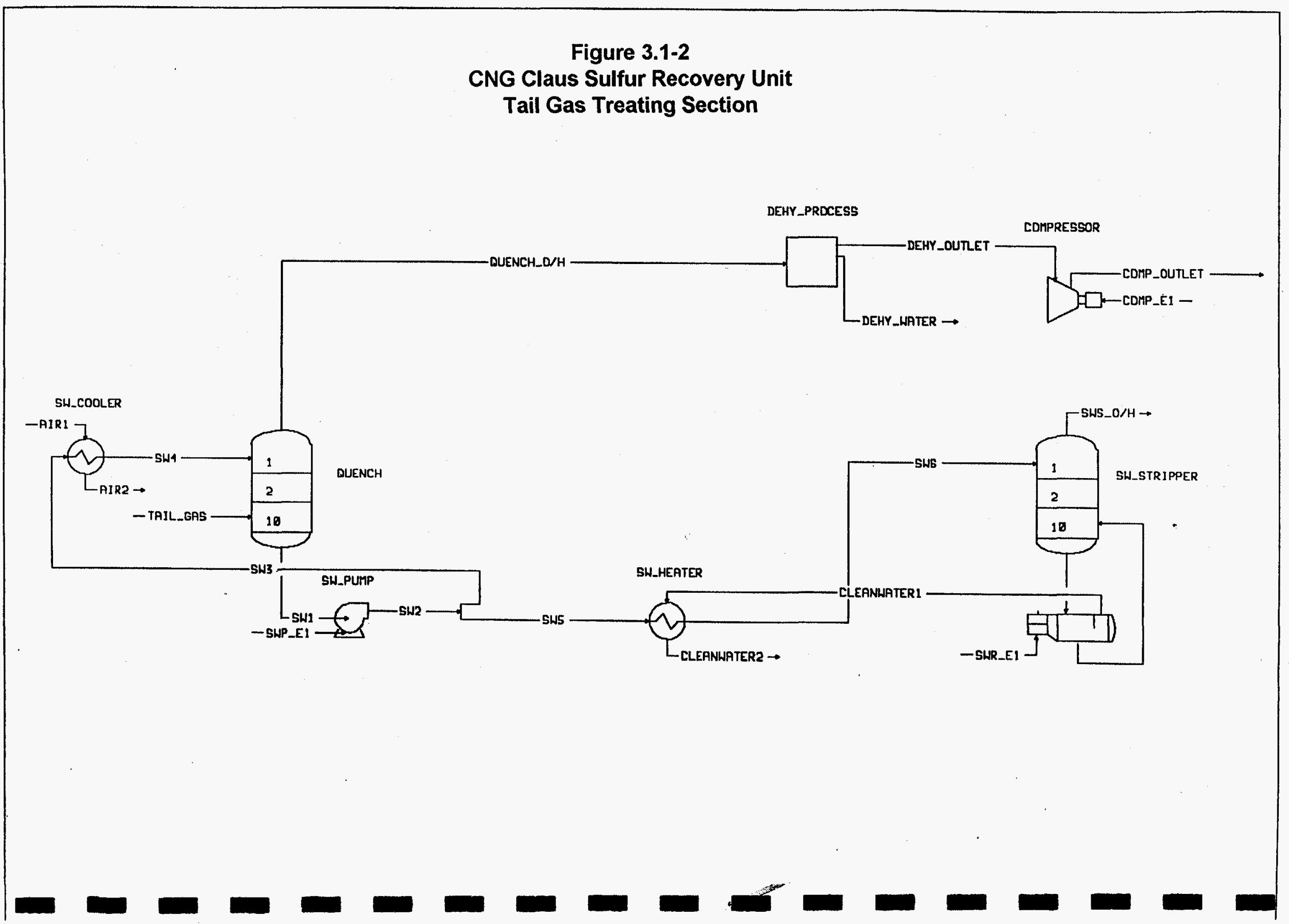


2. Reaction Stoichiometry - A traditional modified Claus system calls for a $1 / 3$ oxidation of the $\mathrm{H}_{2} \mathrm{~S}$ to $\mathrm{SO}_{2}$. The product $\mathrm{SQ}$ then reacts with the remaining ${ }_{2} \mathrm{H} \mathrm{S}$ to form elemental sulfur. In a traditional modified Claus free flame reactor the typical unit conversion (yield) efficiency is 65 to 75 percent.

For the CNG Claus system there was a need to minimize the $\mathrm{SO}_{2}$ production and to control the potentially high reaction temperatures resulting from the use of enriched air as the oxidant. Therefore, it was proposed to operate the CNG Claus reaction furnace with a significantly lower reaction stoichiometry. For the design case, an oxygen deficient operation of approximately 50 percent (of traditional modified Claus stoichiometry) was used. This resulted in a decrease in the predicted unit conversion efficiency to 50 percent and a predicted reaction temperature less than $2000^{\circ} \mathrm{F}$. This also resulted in an $\mathrm{SO}_{2}$ concentration of approximately 1.0 mole percent in the reaction furnace effluent which is appropriate for the subsequent treating in the hydrogenation reactor.

\section{Wasteheat Exchanger}

The partial oxidation of the $\mathrm{H}_{2} \mathrm{~S}$ in the reaction furnace is an extremely exothermic reaction which results in a very large energy release and high process temperatures in the reaction furnace. In order to recover the produced elemental sulfur it is necessary to cool the process gas significantly. This also allows the opportunity to recover a large amount of high quality energy usually in the form of high pressure steam.

The wasteheat exchanger is used to remove the bulk of that energy and cool the process gas to a lower intermediate temperature. This unit is a conventional shell and tube thermosyphon or kettle type boiler which will produce high pressure (600 psia) steam.

\section{Sulfur Condenser / Collection Vessel}

The sulfur condenser is used to further cool the process stream to a temperature $\left(300^{\circ} \mathrm{F}\right)$ where essentially all of the sulfur vapor is condensed to liquid. The sulfur condenser heat exchanger has a traditional shell and tube configuration with the process gas on the tube side. This unit also recovers a significant amount of waste heat by producing steam.

The sulfur condenser vessel was equipped with a disengagement section on the outlet end in order to allow for efficient separation of the product liquid sulfur from the process gas. A collection vessel equipped with continuous level control was used to store and remove the product sulfur from the process. This is effectively the final step in the true sulfur recovery portion of the plant. All of the subsequent units are used to treat the sulfur plant tail gas for recycle back to the TPC process. 


\subsubsection{Tail Gas Treating Section}

In order to allow for a 100 percent recycle of the tail gas stream to the TPC system, it will be necessary to further treat the CNG Claus tail gas. The tail gas stream must meet some critical guidelines in terms of stream content to allow efficient processing in the TPC.

1. $\mathrm{SO}_{2}$ Content - The $\mathrm{SO}_{2}$ content in the tail gas must be essentially zero so that it does not react with $\mathrm{H}_{2} \mathrm{~S}$ to form sulfur in the TPC or its auxiliary systems.

2. Water Content - The tail gas must be dried to a very low dewpoint temperature to ensure that water does not freeze in the TPC system.

3. Process pressure - In order to return the treated tail gas to the TPC it will be necessary to recompress the process gas back up to ca. 100 psia.

The tail gas treating section was designed to perform the following specific process steps :

1. Heat the process gas and introduce reducing compounds into the process.

2. React all of the non- $\mathrm{H}_{2} \mathrm{~S}$ sulfur components back to $\mathrm{H}_{2} \mathrm{~S}$ via various reduction reactions.

3. Cool and remove the excess water.

4. Re-compress the cold, water free process gas which is primarily $\mathrm{H}_{2} \mathrm{~S}$ and $\mathrm{CO}_{2}$ for recycle to the TPC separation process.

All of these functions are performed in units which have been used extensively in existing gas treating processes. Therefore, the design philosophy in general is based completely on existing technology.

\section{Reducing Gas Generator}

This unit performs two functions simultaneously; heating the process gas and introducing reducing compounds $\left(\mathrm{H}_{2}\right.$ and $\left.\mathrm{CO}\right)$ into the process stream. The primary process unit in the reducing gas generator is a direct fired hydrocarbon fuel gas burner. The burn products from this burner are mixed directly with the process gas to raise the process temperature to the desired value.

This burner system utilizes a controlled oxygen source (enriched air) and the burn stoichiometry is controlled such that the unit is 5 to 15 percent deficient in oxygen. This has the result of producing significant amounts of $\mathrm{H}_{2}$ and $\mathrm{CO}$ in the burner which is needed in the subsequent catalytic processing step. The base design calls for a typical mixed outlet temperature of $500^{\circ} \mathrm{F}$. 


\section{Hydrogenation / Hydrolysis Reactor}

The next tail gas treating step is to convert all of the $\mathrm{SO}_{2}, \mathrm{COS}, \mathrm{CS}_{2}$ and sulfur vapor to $\mathrm{H}_{2} \mathrm{~S}$. This is completed in a fixed bed reactor over a cobalt - molybdenum catalyst. The four main reactions which occur in this converter are
1. $\mathrm{SO}_{2}$ conversion:
$\mathrm{SO}_{2}+2 \mathrm{H}_{2}=\mathrm{H}_{2} \mathrm{~S}+\mathrm{H}_{2} \mathrm{O}$
2. $\mathrm{CS}_{2}$ conversion:
$\mathrm{CS}_{2}+2 \mathrm{H}_{2} \mathrm{O}=2 \mathrm{H}_{2} \mathrm{~S}+\mathrm{CO}_{2}$
3. CoS conversion:
$\mathrm{COS}+\mathrm{H}_{2} \mathrm{O}=\mathrm{H}_{2} \mathrm{~S}+\mathrm{CO}_{2}$
4. Sulfur conversion:
$\mathrm{S}_{2}+2 \mathrm{H}_{2} \neq 2 \mathrm{H}_{2} \mathrm{~S}$

This reaction system is utilized extensively in existing gas treating technology and all of the reactions go to completion to ensure no $\mathrm{SO}_{2}, \mathrm{COS}, \mathrm{CS}_{2}$ or $\mathrm{S}_{2}$ residual in the reactor effluent. The only sulfur bearing compound in the reactor effluent stream is $\mathrm{H}_{2} \mathrm{~S}$. The typical reaction temperature in this system is 650 to $750^{\circ} \mathrm{F}$.

\section{Hydrogenation Reactor Cooler}

In order to meet the water specification for the recycle stream it is necessary to remove all of the process water. As a preliminary step in the water removal process, the tail gas is cooled significantly from the $700^{\circ} \mathrm{F}+$ hydrogenation reactor temperature to approximately $300^{\circ} \mathrm{F}$. The initial cooling step is performed by a standard shell and tube heat exchanger with the process gas on the tube side. In a conventional design it is convenient to remove the excess energy in the form of steam.

\section{Direct Water Quench / Water Removal}

The next step in the water removal process is a direct contact water quench tower. In this unit the cooled tail gas is contacted directly with cooling water. The quench tower overhead gas is effectively cooled to $100^{\circ} \mathrm{F}$ and the water content is dropped to the saturated value at that temperature. A typical water content of the quench overhead gas is 2 to 5 percent as compared to 25 to 35 percent in the inlet. This process produces a sutistantial mass of excess water which has a small sour component. This "sour water" must undergo additional treatment in order to allow for safe disposal. The sour water treatment system is described in a later section.

\section{Tail Gas Dehydration}

The final dehydration process must ensure that the water content in the recycled tail gas does not exceed $30 \mathrm{ppmv}$ which translates to a $-50^{\circ} \mathrm{F}$ water dewpoint temperature. This step is completed in a dedicated molecular sieve dehydration system of conventional design. 
- 11

\section{Tail Gas Recompression}

It is expected that the sulfur recovery and tail gas treatment processes will result in a system pressure loss between 5 and $10 \mathrm{psi}$. Therefore, the treated tail gas must be re-compressed to allow reintroduction back into the upstream TPC process. Based on the expected operating conditions of the system, the recompression ratio in this unit will have to be approximately 1.1 to 1 . 


\subsection{Sulfur Recovery Unit Pilot Plant}

The original design concept of the CNG Claus sulfur recovery process is based extensively on existing conventional Claus technology. However, the operating conditions will be substantially different from conventional Claus operations in the following areas :

1. Oxygen source - The primary oxygen source will be a highly $\mathrm{O}_{2}$ enriched air stream in order to minimize the total process gasi volume.

2. Reaction stoichiometry - The reaction will be completed with an oxygen flow of approximately 50 percent of the flow in a conventional Claus plant. This will ensure more moderate reaction temperatures and a low formation rate of $\mathrm{SO}_{2}$.

3. Operating pressure - The operating pressure will be ca. 100 psia as compared to a conventional Claus plant which operates at 15 to 25 psia.

\subsubsection{Design Basis and Equipment Description}

\section{Acid Gas Feed}

Table 3.2-1 summarizes a typical acid gas and combustion "air" stream data cases for the pilot plant study. The acid gas composition was based on a preliminary estimated composition from the specified low quality raw gas stream. The "air" composition was chosen as typical for an enriched air stream from a pressure-swing $\mathrm{O}_{2}$ enrichment plant. This acid gas flow rate and the target 50 percent unit recovery efficiency result in a total sulfur production rate of $10.0 \mathrm{lb} / \mathrm{h}$.

\begin{tabular}{|c|c|c|c|}
\hline \multicolumn{4}{|c|}{$\begin{array}{c}\text { Table 3.2-1 } \\
\text { Pilot Plant Base Case Feed Gas Conditions }\end{array}$} \\
\hline & & Acid Gas & Oxygen \\
\hline Temperature & $\left({ }^{\circ} \mathrm{F}\right)$ & 50.0 & 50.0 \\
\hline Pressure & (psia) & 100.0 & 100.0 \\
\hline Total Flow & $(\mathrm{lbmol} / \mathrm{h})$ & 0.891 & Variable \\
\hline \multirow[t]{6}{*}{ Composition } & (mole \%) & ' & \\
\hline & $\mathrm{H}_{2} \mathrm{~S}$ & 69.7 & \\
\hline & $\mathrm{CO}_{2}$ & 30.0 & \\
\hline & $\cos$ & 0.3 & \\
\hline & $\mathrm{O}_{2}$ & & 90.00 \\
\hline & $\mathrm{N}_{2}$ & & 10.00 \\
\hline
\end{tabular}


The P\&ID for the entire pilot plant is presented in Figure 3.2.1-1.

\section{Feed Gas Control System}

This section of the pilot plant consists of three parallel and nearly identical reactant feed metering trains. The Hydrogen Sulfide $\left(\mathrm{H}_{2} \mathrm{~S}\right)$, transported and stored for use in a liquid form, is vaporized within the storage container through the use of an electric heater blanket wrapped around its exterior surface. This gas is then regulated from a pressure of 250 psig to a delivery pressure of 120 psig by a forward pressure regulator (PCV-21B). The flow rate of the regulated gas is then metered and controlled with a mass flow controller (FT/FV-21B). A manual (un-metered) bypass around the flow controller is available for situations when the mass flow controller is out of service. The metered stream downstream of the flow controller then passes through a dome loaded back pressure (negative bias) regulator. This device maintains a constant back pressure on the flow controller (and thus constant pressure drop across the control valve) enabling accurate steady flow control even with fluctuating downstream pressures. The next components of this section consists of an air operated shut-off valve, for remote (control panel) operation and a check valve.

The Carbon Dioxide $\left(\mathrm{CO}_{2}\right)$ feed metering section is similar to the $\mathrm{H}_{2} \mathrm{~S}$ feed section with the exception that the liquid storage container does not require heating to vaporize the reactant, the mass flow controller (FT/FV-21C) is sized for a lower flow range and the pressure regulators (PCV-21C) have correspondingly lower flow coefficients.

Both feed lines have sample connections on the low pressure side of the feed regulator to allow for controlled flow sampling for reactant feed purity analysis. Block and precision metering valves are supplied at all sample points to provide for pressure let down and safe sampling.

The $\mathrm{H}_{2} \mathrm{~S}$ and $\mathrm{CO}_{2}$ feed streams are each individually metered to allow custom blending of the two streams to any relative amount (within the flow ranges of the mass flow controllers) and are then mixed within a specially fabricated mixing tee $(\mathrm{MX}-1)$. This tee ensures that the two streams create a thoroughly mixed acid gas stream before they are sent to the burner for combustion.

The Oxygen stream as supplied $\left(90 \% \mathrm{O}_{2}, 10 \% \mathrm{~N}_{2}\right)$ is regulated from bottle pressure to a supply pressure of 110 psig and metered in a similar fashion to the $\mathrm{H}_{2} \mathrm{~S}$ and $\mathrm{CO}_{2}$ streams (FT/FV-21A and FCV-21B). Provisions have been made to allow for an external source of nitrogen to be added to this stream if dilution becomes necessary. Also the nitrogen serves as an inert safety gas during system leak testing and emergency shutdowns (oxygen block-in).

After metering, the oxygen flows in one of two directions. During start-up, the stream is diverted (AV-22A on AV-21A) to mix with the fuel gas (methane) for burner ignition. After system warm-up and pressure control is established, the acid gas mixture can be introduced into the system through its metering system. The oxygen stream can then be split between the fuel gas and the acid gas streams (AV-21A on, AV-21B on) to establish combustion of the acid gas. The oxygen and acid gas streams are thoroughly mixed in a second mixing tee (MX-2) and then sent to the burner. 
At this point the fuel gas can be completely shut off and the complete oxygen stream mixed with the acid gas (AV-21A on, AV-22A off) for combustion in the reaction section. To prevent reaction of the acid gas and oxygen stream prior to the burner, both mixing tees as well as the fuel gas metering system will be physically mounted as close as possible to the reaction furnace inlet. This will minimize the length of the inlet process piping. Figure 3.2.1-2 presents the detailed P\&ID for the feed gas control section of the pilot plant.

\section{Reaction Furnace}

The reaction furnace is designed to allow for intimate mixing of the process reactants, initiate a free flame reaction zone and allow continued reaction in an open volume reaction section. This unit is made up of two primary components; 1) the furnace burner unit and 2) the main combustion/reaction chamber.

The furnace burner has a concentric pipe design with a direct mixing flame retaining burner nozzle where the acid gas and oxygen streams are intimately mixed and ignited. The center pipe contains the fuel gas/oxygen mixture required for start-up, while the outer annulus processes the acid gas/oxygen combustion mixture after the fuel gas is shut in. The burner nozzle was of conventional design and metallurgy in order to imitate conventional equipment specifications. The burner was located at the center of the combustion end of the furnace vessel and included a gas pilot burner and electric igniter system.

The reaction furnace vessel is a stainless steel vessel with an inside working diameter of 6 inches and a working length of approximately 30 inches. The vessel design allows for a maximum working pressure of $130 \mathrm{psia}$ at the expecited reaction temperatures. The furnace vessel has an effective reaction volume of $0.49 \mathrm{ft}^{3}$ which allows for reaction residence times between 1 and 4 seconds. The vessel is lined with a custom molded refractory material which allows for working reaction furnaces temperatures up to $3000^{\circ} \mathrm{F}$.

The reaction furnace is equipped with five internal thermocouples, a rear chamber water cooled sample probe and a vessel outer skir high temperature alarm. The internal temperatures are displayed at the control panel on a multi-channel temperature scanner for temperature profile observation. The sample probe will enable capturing of rear chamber reaction furnace samples prior to entering the waste heat exchanger section.

Overall system over-pressure protection is provided by means of a rupture disk mounted on the acid gas feed line to the reaction furnace. This device will protect all downstream equipment from excess pressure in the event of blocked in vents or fire.

Figures 3.2.1-3 and 3.2.1-4 show a working schematic and the detailed equipment drawings of the reaction furnace burner and vessel. 


\section{Waste Heat Exchanger}

The waste heat exchanger initiates the first stage of process gas cooling in the system. The unit is close coupled to the outlet nozzle of the reaction furnace (mounted in a vertical position) and cools the effluent from the furnace temperature to approximately $900^{\circ} \mathrm{F}$. A standard shell and tube design is employed, with four $1 / 2$-inch tubes providing the necessary heat transfer area.

The inlet nozzle contains a pseudo ceramic checker wall for reflecting radiant heat back towards the combustion chamber, also ceramic ferrules at the tube inlets provide additional tube sheet weld protection from the high operating temperatures. The cooling water flows on the shell side of the exchanger. The cooling water is supplied at $60^{\circ} \mathrm{F}$ and the flow rate is controlled through a manual valve located on the shell side outlet nozzle and fine tuned by observation of a local return water temperature indicator.

Figure 3.2.1-5 shows a detailed equipment drawing of the wasteheat exchanger vessel.

\section{Sulfur Condenser and Collector}

After the process gas exits the wasteheat exchanger it passes through a short section of 1 inch tubing, and then enters the sulfur condenser. This vessel is designed to cool the process gas to a temperature less than the sulfur condensation (dewpoint) to condense the sulfur vapor and separate the liquid sulfur from the gas phase onto the tube surface, and gravity drain the sulfur for collection. This vessel is mounted one percent off horizontal, sloping downward from inlet to outlet and is also of tube and shell design. The process gas flows on the tube side and four $1 / 2$-inch tubes provide heat exchange area. An enlarged disengagement zone and mist extractor were built into the outlet end of the condenser to remove any entrained sulfur from the exiting vapor. The produced liquid sulfur is collected and drained into a pressurized sulfur collection vessel. Cooling water flows on the shell side and acts as the cooling medium. The temperature control on this unit is similar to the temperature control on the waste heat exchanger.

Both the waste heat exchanger and the sulfur condenser are equipped with removable flanged end caps to allow for tube cleaning and inspection.

The condensed sulfur is drained from the disengagement section through a heated 1-inch flexible stainless steel line and into the sulfur collection vessel. A full 1 -inch piping cross is provided at a direction transition to allow for rodding of lines. Directly below the cross the sulfur drains into the collection vessel at pressure. This vessel (V-2) has capacity (nominal 6 gallons) to provide for up to six hours worth of sulfur production at design rates. It stands on a load cell transducer (100 lbs. maximum) which instantaneously measures the sulfur production throughout the run. A $1 / 2$-inch balance line provides means for the gas to vent to the pressure control module. 
After a test run is completed and all sulfur produced is recovered, the collection vessel is isolated from the system through hand valves and the liquid sulfur drained under a nitrogen pressure head to a suitable container. Local pressure indication and relief are provided on the vessel for safety.

The vapor exiting from the sulfur condenser passes through a heated $1 / 2$-inch line with a high point and into a surge vessel/knock cut drum (V-1) by means of a dip tube. This vessel has several purposes; first it serves to knock out any residual entrained sulfur in the vapor and drains it to the sulfur collection, second it serves as a pressure balance vessel for the sulfur collection vessel, and third it dampens any flow surges to the downstream system pressure control loop. This vessel as well as all sulfur lines are heat traced $\left(2,60^{\circ} \mathrm{F}\right)$ and insulated to prevent sulfur solidification and plugging. This portion of the system was modified extensively to ensure that there was no plugging of the lines with elemental sulfur. Figures 3.2.1-6 and 3.2.1-7 show the sulfur condenser and sulfur knock-out / collection vessels respectively. 
Figure 3.2.1-3

Reaction Furnace

CS CONNECTOR CLAMPS.

STUD BOLTS, NUTS

17-4 PHSS SEAL RING

(MOS 2 COATING)

MAIN GAS BURNER/IGNITOR

(SEE DETAIL DWG 92C4790-006)
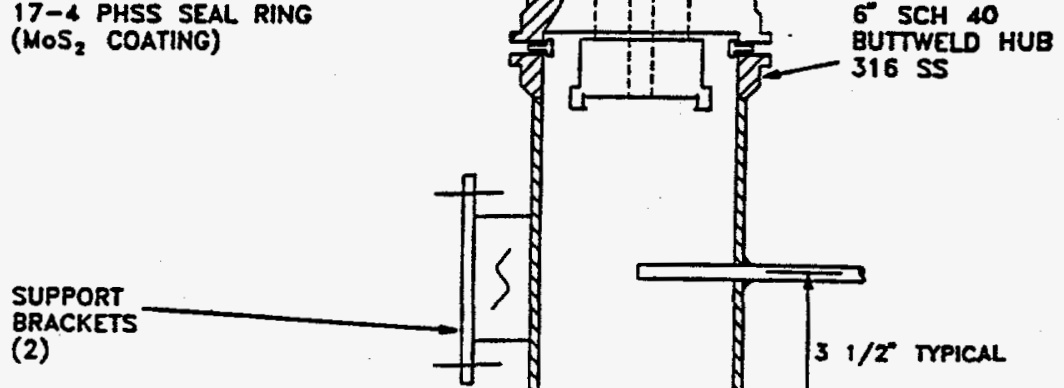

SMLS 316 SS PIPE

$26 i / 2$ WELD-WELD
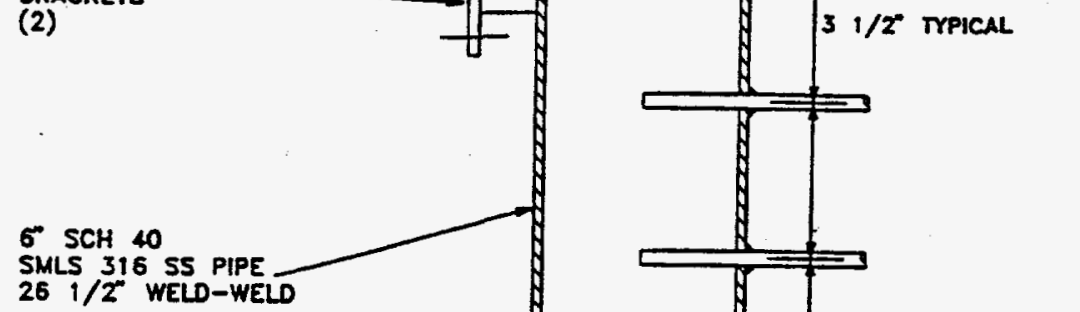

$1 / 2^{*} \times 0.049^{*}$ WALL

316 SS TURING

WITH SEAL WELDS

ON ENO.

ON LONG

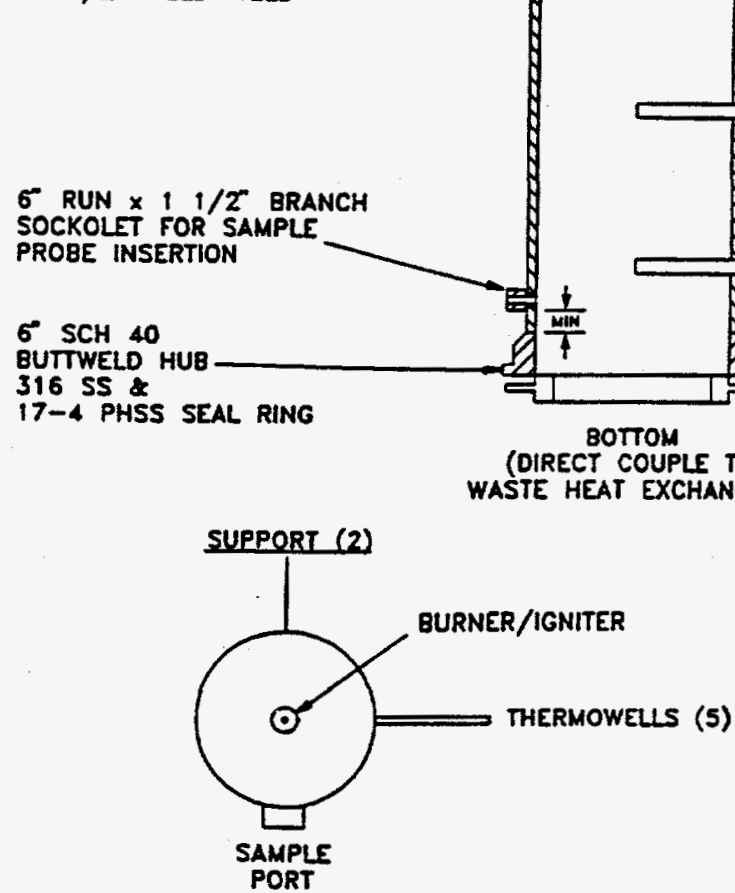

ITE;
1) CERAMIC/REFRACTORY UNING TO ALLOW
FOR 750'F DESIGN WALL TEMPERATURE
2) APPROXIMATE TOTAL WEIGHT IS

180 los (EMPTY)

PRESSURE: 100 PSIG 85 PSIG

TEMP: $750{ }^{\circ 0 \pi}$, 1800\% 
Figure 3.2.1-4

Reaction Furnace Burner

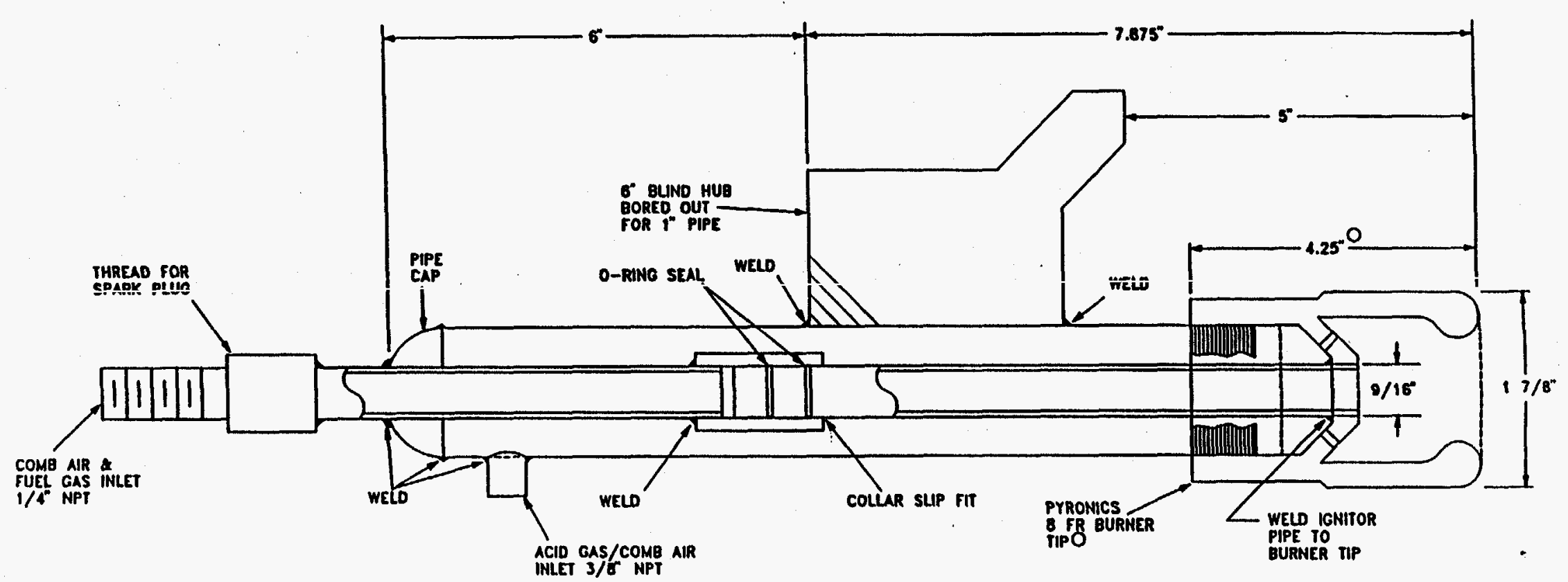

MATLS

PIPE: 316 SS, OUTER: 1" SCH 10, INNER: $1 / 4^{n}$ SCH 10 QURNER TIP: 146 SS

O-RINGS: VITON

SEAL RINGS: 17-A PHSS WITH MOS, COATING

NOIE:

2) CLEARANCE FOR WRENCH FLATS ON THREADED BURNER TIP REQUIRED

1) 6 PORTS STANDARD - DRILL 3 ADDITIONAL 45 MTD (0.082") PORTS EQUALLY SPACED 
Figure 3.2.1-5

Wasteheat Exchanger

IIEM QUAN DESCRIPTION

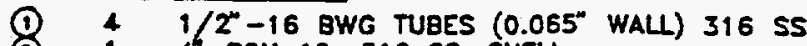

(2) $14 \mathrm{SCH} 10,316$ SS, SHELL

(3) 4 4"-150" S.O. FLANGE, 316 SS

(4) $16 \times 4^{-} \mathrm{SCH} 10$ REDUCING HUB, 316 SS (OTECO TYPE)

FERRULE DETAIL

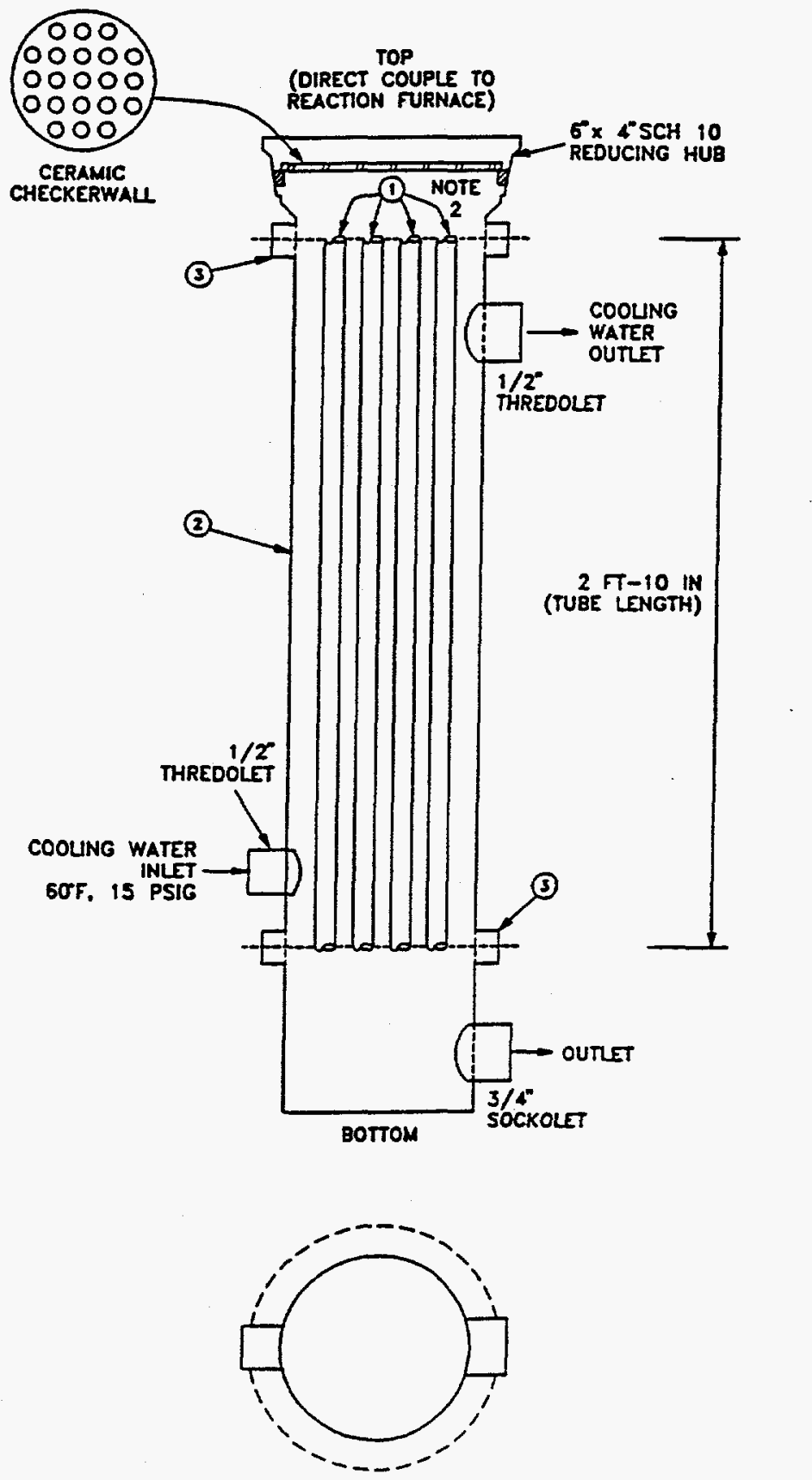

DESIGN

TUEES: 125 PSIG 2000\% SHELL: 100 PSIG $750^{\circ} \mathrm{F}$
NOTE:

3) SHEU BAFFLS AS REOUIRED

2) TUBE INLETS WILL REOUIRE

REFRACTORY UNING AND

CERAMIC FERRULES FOR HIGH

TEMP. PROTECTION (SEE DETAIL)

1) UNIT WILL BE INSTALLE

VERTICALLY 
Figure 3.2.1-6

Condenser
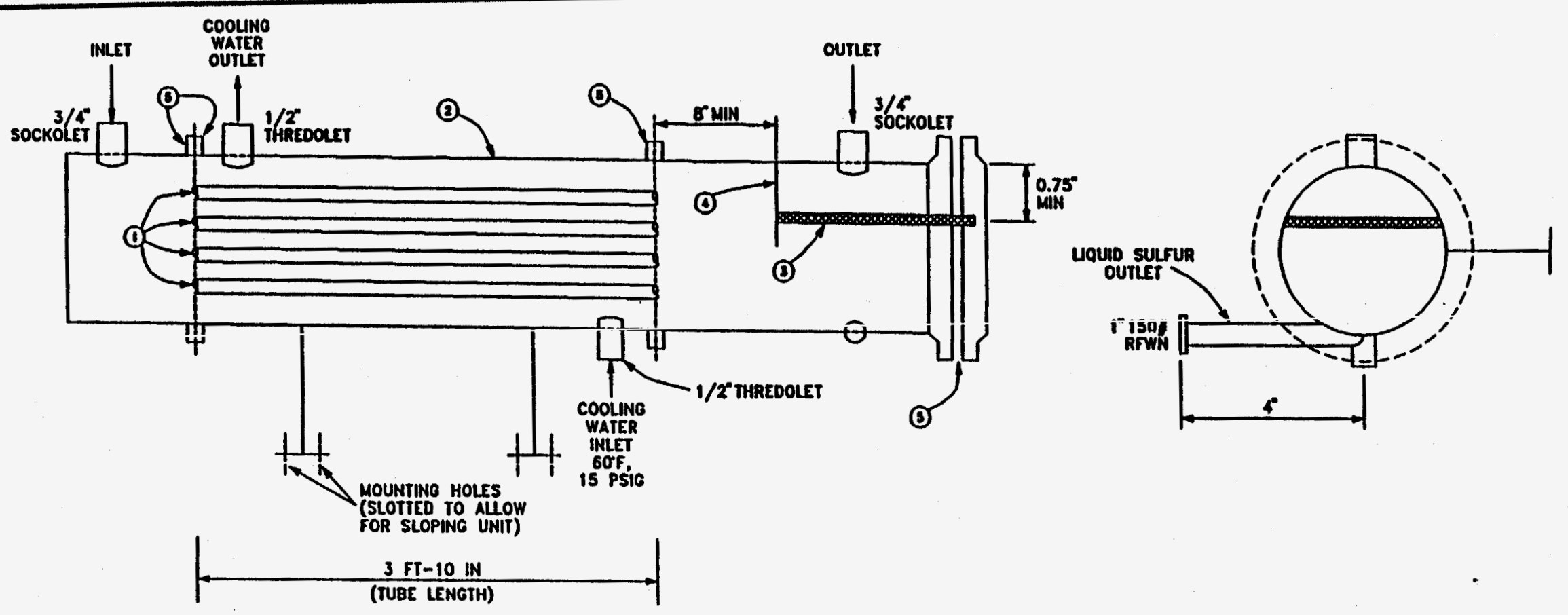

IIEM QUAN DESCRIPIION

(1) $41 / 2^{\prime \prime}-16$ BWO TUBES (0.065"WALL THKNESS) 316 SS

(2) 1 SCH 10.316 SS, SHELL (ASME SECT 1)(4.26"1.D.)

(3) YORK STYLE 326 OR EQUIVALENT, 316 SS (REMOVABLE)(98\% VOID)(1/2n SURFACE AREA MINIMUM)

(3) 6 -150 S.0. FLANGE, 316 SS

TUBES: 125 PSIG $1000 \mathrm{~F}$

SHELL: 100 PSIG $500^{\circ} F$

NOIE:

3) SHELL BAFFLES AS NECESSARY

2) GENERAL ORIENTATION OF UNIT IS HORIZONTAL

1) SLOPE UNIT 1T INLET TO OUTLET WITH MOUNTING BRACKETS 
Figure 3.2.1-7

Sulfur Knock-Out and Collector
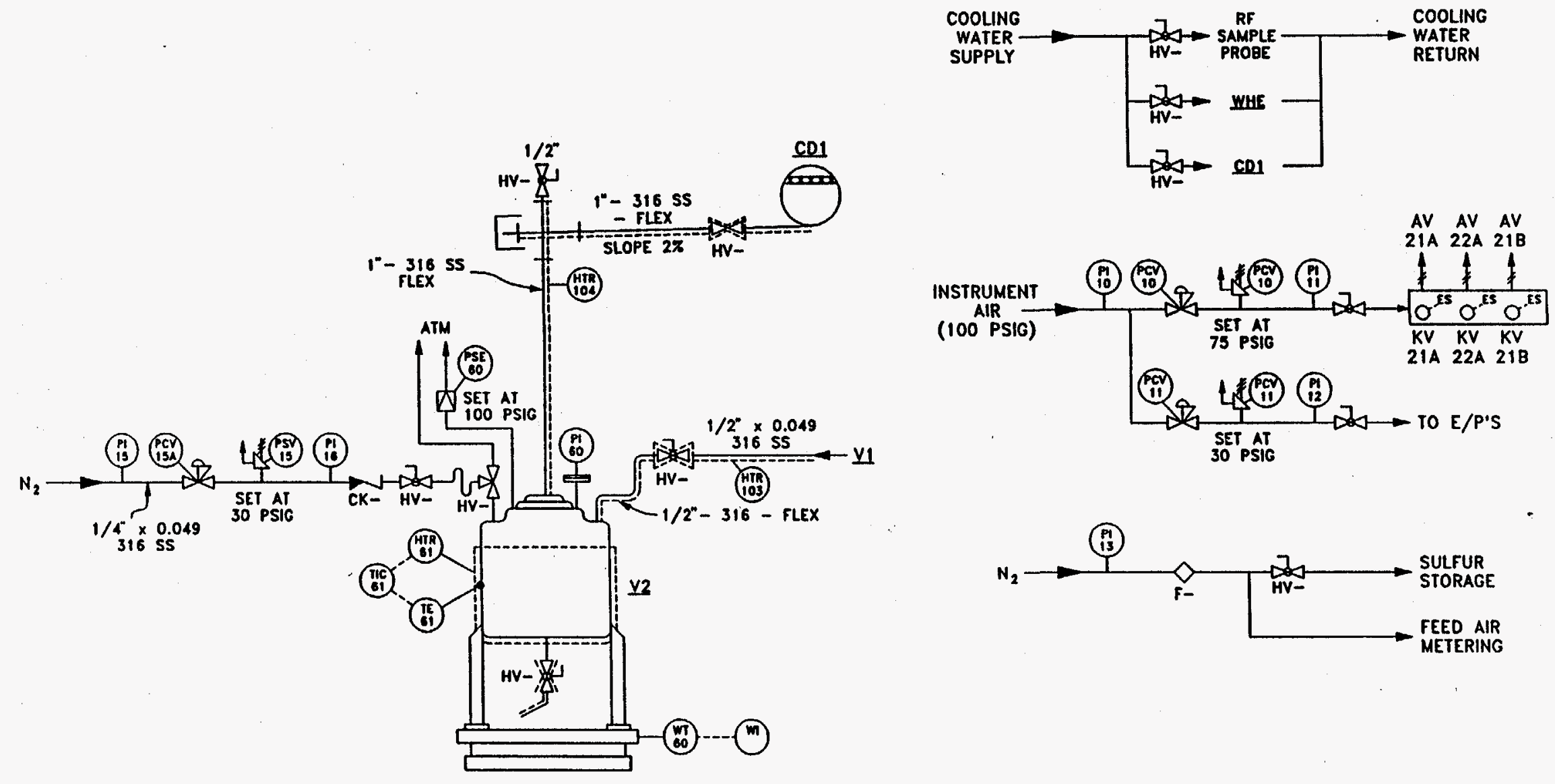


\subsubsection{Monitoring Equipment Description}

The fundamental issues to be addressed in the pilot plant program were related to the $\mathrm{H}_{2} \mathrm{~S}$ oxidation reaction chemistry. Therefore, the data gathering requirements were related primarily to accurate measurement of the temperature, pressure, flow rate and composition of the process streams in question. The data gathered during the test runs were expected to be similar to data typically generated from the operation of a traditional modified Claus process. Therefore, the monitoring systems used in the CNG Claus pilct plant were patterned after conventional data monitoring systems.

\section{Pressure and Temperature Monitoring Systems}

One of the primary objectives of the pilot plant project was to operate the $\mathrm{H}_{2} \mathrm{~S}$ oxidation reactions at somewhat elevated pressures as compared to the conventional modified Claus process. In the modified Claus process the typicial operating pressures in the system are 15 to 25 psia. The test program for the CNG Claus project called for system pressures up to 100 psia.

The pressures expected for the test runs fall well within the pressures which can be adequately handled by conventional pressure measuring devices and the pilot plant was well equipped with continuous pressure measurement at key process locations.

Similarly, the reaction furnace temperatures were expected to be consistent with conventional Claus furnace conditions. However, extensive experience with conventional Claus furnaces has shown that standard in situ thermocouples do not have acceptable longevity. Therefore, non-invasive (infrared) types of temperature detection have become the norm. This was considered for the CNG system however, space and size limitations precluded the use of these devices.

In response to this, a modified air purged thermocouple system was installed in the critical flame zone of the reaction furnace. These devices gave good performance during the test runs. The P\&I diagrams in Section 3.2.1 indicate the lociation and type of pressure and temperature monitoring devices installed on the CNG Claus pilot plant.

\section{Gas Analysis Equipment}

The other primary required data from the pilot plant was the composition of the process gas streams at the various points in the process. This data allowed for completion of the detailed heat and material balances which were required for evaluating all of the performance parameters in the system.

The modeling work conducted in the earlier phases of this project indicated that the expected process gas compositions would be consistent with those often observed in traditional modified Claus processes. Therefore, the gas analysis equipment and methodologies were adopted directly from the existing procedures used in sour gas systems. 
Of primary interest was the accurate and reliable measurement of the sulfur bearing components expected in the system; $\mathrm{H}_{2} \mathrm{~S}, \mathrm{SO}_{2}, \mathrm{COS}$ and $\mathrm{CS}_{2}$. In order to complete rigorous material balances on this system however, additional compounds were also measured: $\mathrm{N}_{2}, \mathrm{Ar}, \mathrm{O}_{2}, \mathrm{CO}_{2}, \mathrm{CO}, \mathrm{H}_{2}$ and an array of light hydrocarbon compounds. For this application, gas chromatography was the analytical system of choice. A full description of the analytical methods employed for this work are included in Appendix A.

\subsubsection{Commissioning and Operation}

The pilot plant was designed to be assembled as a transportable skid mounted unit. After fabrication of the major components the pilot plant was assembled at a fabrication shop in Houston, Texas. The fully assembled unit underwent extensive functionality testing in the shop under controlled conditions.

After initial functionality testing in the shop, the unit was shipped to the pilot plant operations site.

\section{Test Site and Site Selection}

During the Phase 2 work a review of possible test sites was completed. The primary criterion for selecting the site were as follows:

1. Existing experience with handling sour gas processes.

2. Available utilities (power, cooling water).

3. Capability to allow for (via an existing flare system) the disposal of the tail gas waste stream.

4. Reasonable access to the support trades (welding, electricians, etc.)

During the initial Phase $2^{(5)}$ portion of the program, an extensive site selection procedure was used to select an acceptable site. The final choice for the pilot plant site was an existing CNG Producing oil and gas processing plant in Davis, Oklahoma. The site met all of the designated criteria and also had the advantage of already dealing with sour gas streams. A full description of the site selection process and all of the associated operating considerations is dealt with in the National Environmental Policy Act (NEPA) documentation provided in the Phase 2 report $^{(5)}$.

Photographs and maps showing the pilot plant site are included in Appendix D. Additional photographs of the pilot plant equipment are presented in Appendix E. 


\section{Pilot Plant Installation}

After siting the pilot plant unit, all of the plant support facilities were also sited and connected to the pilot plant. These facilities included:

- feed gas supply; liquid $\mathrm{H}_{2} \mathrm{~S}$, liquid $\mathrm{CO}_{2}$, compressed $\mathrm{O}_{2}, \mathrm{~N}_{2}$ and methane.

- exchanger cooling water systern

- electrical supply

Prior to starting the full Claus test runs, the plant was started up and run on fuel gas (methane). This was done to allow for complete functionality tests on all of the major and associated equipment. The unit was operated with a fuel gas combustion in order to ensure proper operation of the following systems:

- feed gas delivery systems

- plant pressure control system

- furnace and heat exchanger temperature measurement systems

- sample ports and probes

- exchanger cooling systems

- tail gas disposal to the flare

These initial test runs revealed many problems with the unit which had to be rectified prior to operating the unit with $\mathrm{H}_{2} \mathrm{~S}$. Most of these problems were related to excessive heat losses in the vessels and the associated problems with maintaining proper temperature profiles through the process units. There were also significant problems with excessive system pressure drop in the feed gas delivery systems. Various minor field modifications were made on the unit to overcome these problems. The P\&ID diagrams presented in Section 3.2.1 represent final configuration of the pilot plant as it entered the test phase. 


\subsection{Test Program}

\subsection{Experimental Test Plan and Test Matrix}

The fundamental questions to be answered by the experimental program were whether a viable pilot scale plant could be designed, built and operated successfully and whether the Claus $\mathrm{H}_{2} \mathrm{~S}$ oxidation reactions would proceed to a sufficient degree under the proposed operating conditions.

The pilot plant design was taken largely from existing industrial technology and as such no significant technical barriers were anticipated. The final plant design utilized completely conventional unit equipment, properly scaled for the proposed feed gas flow rates.

For the experimental test plan, a full review of conventional modified Claus chemistry was used as a base line reference. It is well known from the operation of conventional Claus Process Reaction Furnaces, at or near one atmosphere of pressure ( 15 psia), that one-third of the $\mathrm{H}_{2} \mathrm{~S}$ can be oxidized within 1 to 2 seconds at temperatures above $1700^{\circ} \mathrm{F}$ with acceptable yields according to the $\mathrm{H}_{2} \mathrm{~S}$ oxidation reaction:

$$
2 \mathrm{H}_{2} \mathrm{~S}+\mathrm{O}_{2}=\mathrm{S}_{2}+\mathrm{H}_{2} \mathrm{O}
$$

This highly exothermic reaction is fully sustainable and controllable in a free flame reactor.

However, it is also known that although all the $\mathrm{O}_{2}$ is consumed in the reaction furnace, the equilibrium yield of sulfur is not always achieved, particularly at lower temperatures. This indicates that the reaction is to some extent, kinetically limited, usually as a result of the mechanical aspects of the furnace design (mixing and residence time).

Since the proposed strategy for the CNG Claus process is to oxidize only one-sixth of the $\mathrm{H}_{2} \mathrm{~S}$ at a higher system pressure (ca. 100 psia or 6 atmospheres) and a lower temperature ( $c a .1500$ to $2000^{\circ} \mathrm{F}$ ) the experiments were designed to determine if, indeed, the proposed strategy was practicable.

The reaction furnace operation has been devised to allow for stable operation while meeting the following criteria to ensure that a conventional furnace design (metallurgy etc) is adequate and that the downstream tail gas treating section can adequately handle the hydrogenation of $\mathrm{SO}_{2}$ in a conventional manner.

1. The adiabatic reaction temperature must be maintained at or below $2500^{\circ} \mathrm{F}$.

2. The overall conversion efficiency must be maintained at $50+$ percent.

3. The $\mathrm{SO}_{2}$ in the furnace outlet must be maintained at less than 2.0 mole percent.

4. The system pressure would be at approximately 100 psia. 


\section{Critical Operating Variables}

The critical operating parameters are related to two well-defined concepts; the chemical equilibria of the reaction system and the kinetic effects of the mechanical system. For the pilot plant test program it was necessary to determine the impact of these parameters on the key reaction.

\section{Chemical Equilibrium Effects}

The chemical equilibrium of the reaction system is affected and determined by :

- reaction pressure

- reaction temperature

- reactant composition

The reaction pressure was determined by the system pressure as defined in the process design. While it may be possible to determine the effect of reaction pressure on the reaction equilibrium, this parameter has not been identified as critical to the successful operation of the process.

The pilot plant was designed for adiabatic operation in the reaction furnace (while heat losses to some extent were fully expected). Therefore the reaction temperature is set by the reactant composition and the extent of reaction of those reactants. This leaves the reactant composition as the most significant process variable and was the focus of the pilot plant test plan. The information in the Test Plan Matrix discusses the composition variables which will be evaluated and presents the results from an array of simulated reaction runs which were completed using an equilibrium model based on a Gibbs free energy calculation technique.

\section{Kinetic Reaction Effects}

The reaction equilibrium can also be significantly affected by kinetic effects in the thermal reactor. The kinetics of the reaction system can be affected by the following physical conditions:

- reaction residence time

- reaction temperature

- extent of mixing in the reaction section

It is assumed that the kinetic effects could have a measurable impact on the outcome of the reaction. It is expected that the effect of some kinetic limitation on the $\mathrm{H}_{2} \mathrm{~S}$ oxidation will not significantly affect the overall feasibility of the process, however, the test plan included some studies to determine the kinetics of the new operating conditions.

The furnace design allowed for a maximum residence time of 4 seconds which is significantly longer than in conventional Claus furnace design. The design also allows for decreasing the residence time substantially by altering the reactant flow rates which would allow for some evaluation of residence time on the overall reaction. The mixing characteristics of the burner were identical for all of the tests, therefore it was possible to determine the effects of mixing and turbulence on the reaction. 


\section{Pilot Plant Test Matrix}

The work completed in the original technical feasibility study ${ }^{(6)}$ was used to evaluate the appropriate test variable matrix for the pilot plant tests. Those simulation results define the range of potential reactant compositions.

The most significant reactant components are $\mathrm{H}_{2} \mathrm{~S}$ and $\mathrm{O}_{2}$. There will also be $\mathrm{CO}_{2}$ and $\mathrm{N}_{2}$ in the feed gas which may have an effect on the reaction equilibrium. The original test matrix allowed for "acid gas" feed compositions varying in $\mathrm{H}_{2} \mathrm{~S}$ content from 50 to 90 mole percent. The balance of the acid gas is $\mathrm{CO}_{2}$. The test matrix also allowed for "air" compositions varying in $\mathrm{O}_{2}$ content between 21 and 90 mole percent. The balance of the combustion air was $\mathbf{N}_{2}$.

Table 4.1-1 on the following pages summarizes the extensive set of equilibrium calculations completed for a range of inlet reactant compositions. This simulation matrix encompasses the full range of potential operating conditions proposed for the acid gas and air compositions for the experimental test runs. Figures 4.1-1 through 4.1-6 illustrate in graphical form the range of operating conditions and expected results for the most critical performance parameters. 


\begin{tabular}{|c|c|c|c|c|c|c|}
\hline \multicolumn{7}{|c|}{$\begin{array}{c}\text { Table } 4.1-1 \\
\text { Experimental 'Test Plan - Original Simulation Results Summary } \\
\end{array}$} \\
\hline $\begin{array}{c}\text { Acid Gas } \\
\text { Compositio } \\
\mathrm{n} \mathrm{H}_{2} \mathbf{S} \\
(\text { mole } \%) \\
\end{array}$ & $\begin{array}{c}\text { Air } \\
\text { Composition } \\
\mathbf{O}_{2} \\
(\mathrm{~mole} \%) \\
\end{array}$ & $\begin{array}{c}\mathrm{H}_{2} \mathrm{~S} / \mathrm{O}_{2} \\
\text { Flow Ratio }\end{array}$ & $\begin{array}{c}\text { Excess Air } \\
\text { (\%) }\end{array}$ & $\begin{array}{c}\mathbf{H}_{2} \mathrm{~S} \\
\text { Equilibrium } \\
\text { Conversion } \\
(\%) \\
\end{array}$ & $\begin{array}{c}\text { Reaction } \\
\text { Temp. } \\
\left({ }^{\circ} \mathrm{F}\right) \\
\end{array}$ & $\begin{array}{c}\mathrm{SO}_{2} \\
\text { Residual } \\
(\text { mole \%) } \\
\end{array}$ \\
\hline 50 & 21 & 2.11 & 0 & 62.0 & 1719 & 3.21 \\
\hline 50 & 21 & 2.77 & -25 & 56.1 & 1498 & 1.79 \\
\hline 50 & 21 & 4.06 & -50 & 43.8 & 1241 & 0.70 \\
\hline 50 & 50 & 2.28 & 0 & 64.9 & 1987 & 4.53 \\
\hline 50 & 50 & 2.92 & -25 & 58.6 & 1710 & 2.20 \\
\hline 50 & 50 & 4.14 & -50 & 44.3 & 1382 & 0.84 \\
\hline 50 & 90 & 2.36 & 0 & 65.6 & 2070 & 5.26 \\
\hline 50 & 90 & 3.00 & -25 & 59.2 & 1776 & 2.48 \\
\hline 50 & 90 & 4.19 & -50 & 44.6 & 1432 & 0.88 \\
\hline 70 & 21 & 2.16 & 0 & 65.8 & 1975 & 3.45 \\
\hline 70 & 21 & 2.84 & -25 & 59.8 & 1743 & 1.77 \\
\hline 70 & 21 & 4.14 & -50 & 45.2 & 1456 & 0.68 \\
\hline 70 & 50 & 2.40 & 0 & 68.9 & 2335 & 5.30 \\
\hline 70 & 50 & 3.10 & -25 & 62.2 & 2009 & 2.33 \\
\hline 70 & 50 & 4.38 & -50 & 46.2 & 1649 & 0.75 \\
\hline 70. & 90 & 2.51 & 0 & 69.6 & 2454 & 6.42 \\
\hline 70 & 90 & 3.22 & -25 & 62.7 & 2091 & 2.67 \\
\hline 70 & 90 & 4.49 & -50 & 46.5 & 1708 & 0.80 \\
\hline 90 & 21 & 3.18 & 0 & 68.7 & 2195 & 3.53 \\
\hline 90 & 21 & 2.89 & -25 & 62.4 & 1945 & 1.68 \\
\hline 90 & 21 & 4.24 & -50 & 46.4 & 1642 & 0.57 \\
\hline 90 & 50 & 2.45 & 0 & 72.6 & 2714 & 5.66 \\
\hline 90 & 50 & 3.21 & -25 & 65.2 & 2305 & 2.23 \\
\hline 90 & 50 & 4.59 & -50 & 47.4 & 1883 & 0.62 \\
\hline 90 & 90 & 2.58 & 0 & 73.7 & 2905 & 7.05 \\
\hline 90 & 90 & 3.36 & -25 & 65.9 & 2424 & 2.66 \\
\hline 90 & 90 & 4.74 & -50 & 47.7 & 1956 & 0.66 \\
\hline
\end{tabular}


-Figure 4.1-1

Test Plan Simulation Study

Sulfur Conversion vs. Reaction Stoichiometry

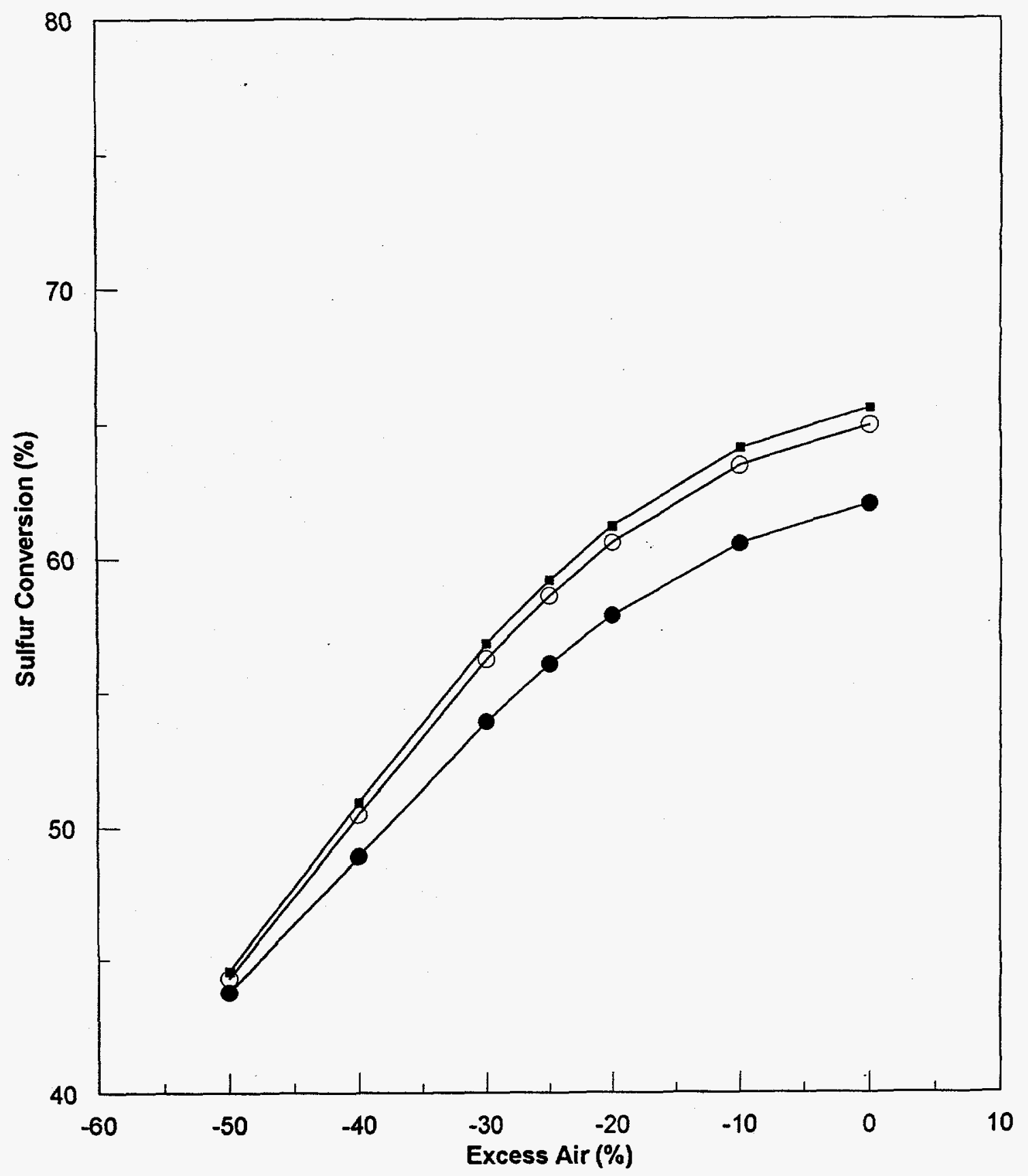

Thermodynamic Simulation Thermodynamic Simulation Thermodynamic Simulation Air $50 \%$ Oxygen $90 \%$ Oxygen

1. Feed gas: $50 \%$ H2S

2. Various "Air" Compositions 
Figure 4.1-2

Test Plan Simulation Study

Sulfur Conversion vs. Reaction Stoichiometry

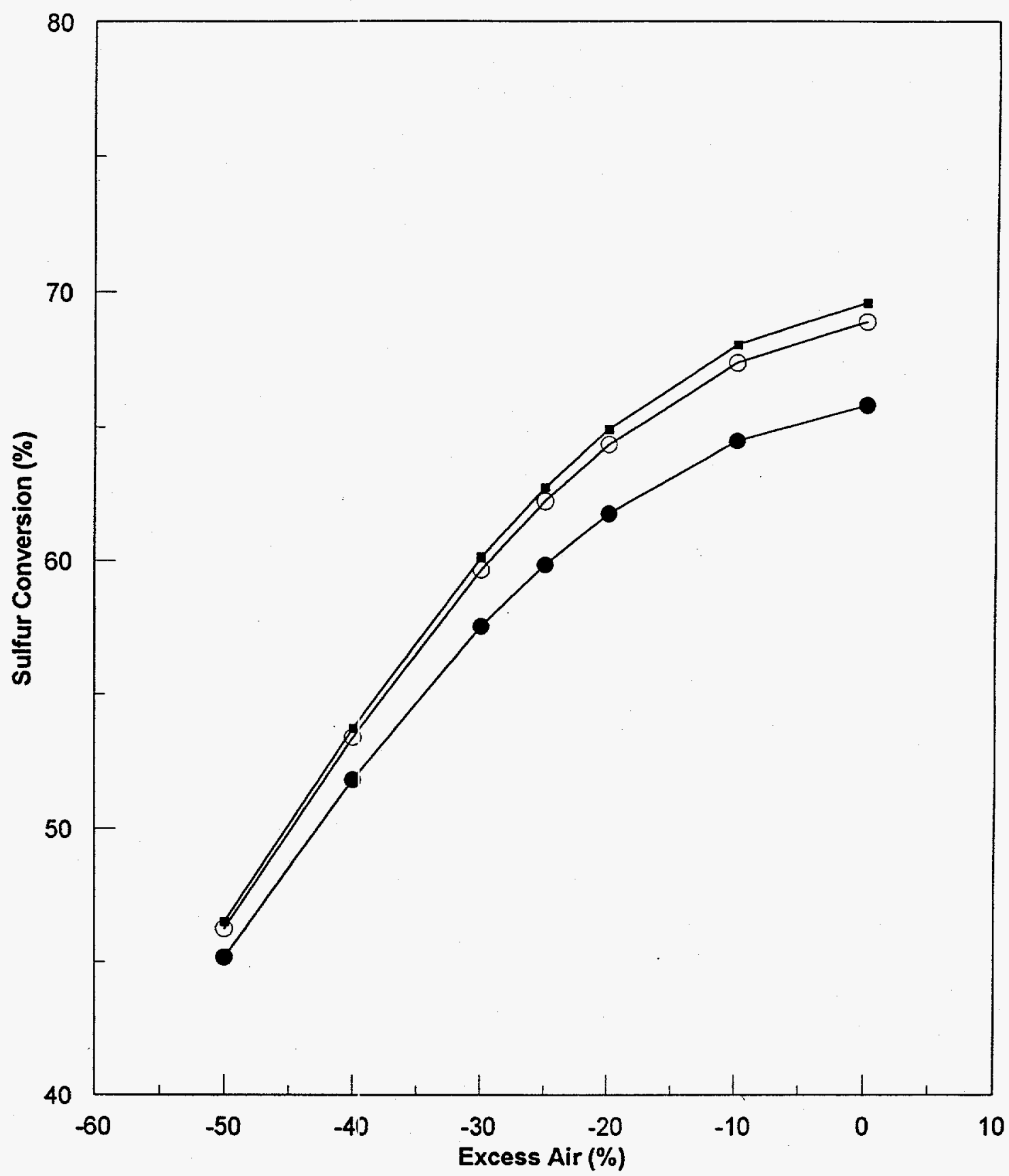

Thermodynamic Simulation Thermodynamic Simulation Thermodynamic Simulation Air $50 \%$ Oxygen $90 \%$ Oxygen

1. Feed gas : $70 \% \mathrm{H} 2 \mathrm{~S}$

2. Various "Air" Compositions 
Figure 4.1-3

Test Plan Simulation Study

Sulfur Conversion vs. Reaction Stoichiometry

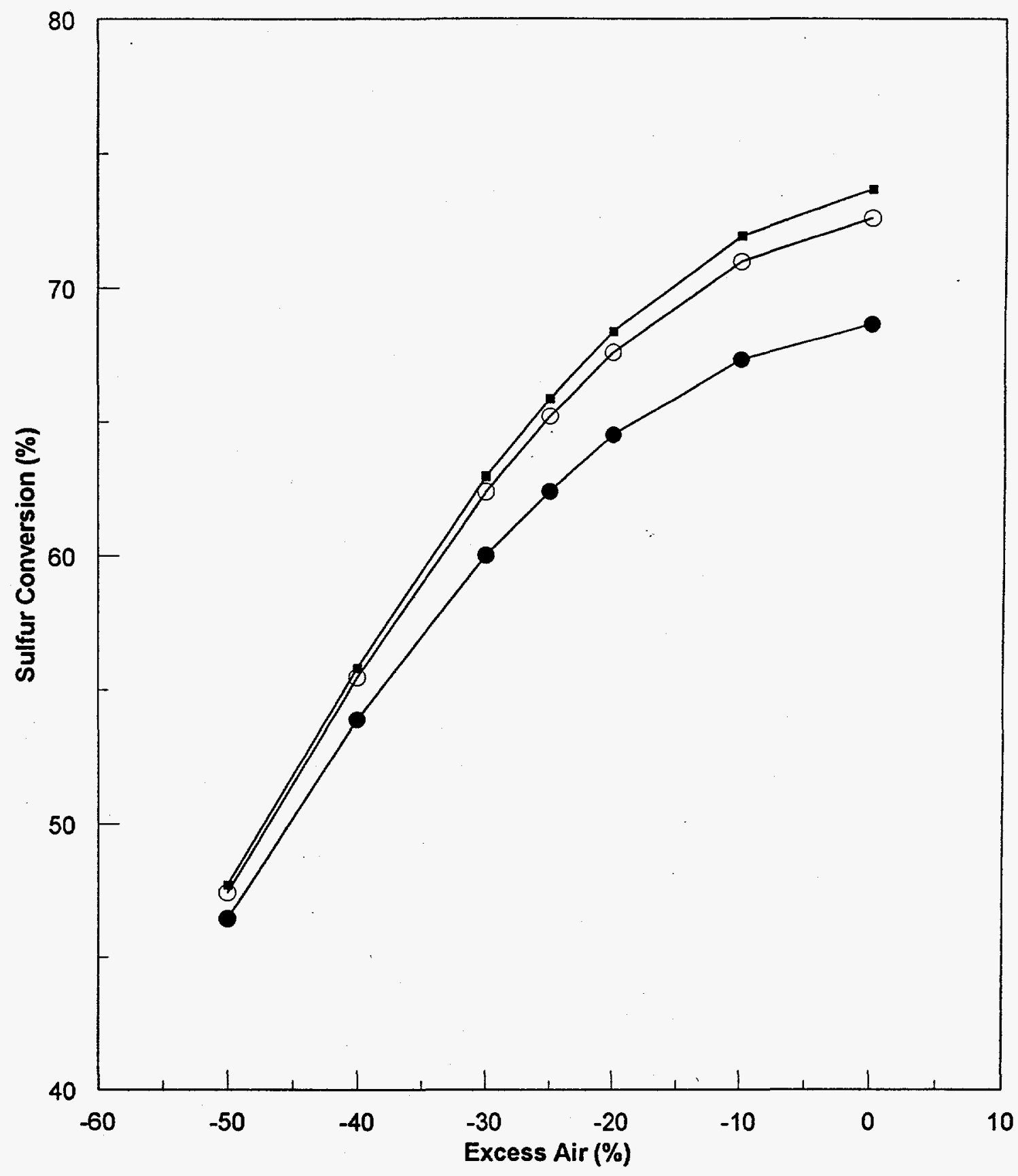

Thermodynamic Simulation Thermodynamic Simulation Thermodynamic Simulation Air $50 \%$ Oxygen $90 \%$ Oxygen

1. Feed gas : $90 \% \mathrm{H} 2 \mathrm{~S}$

2. Various "Air" Compositions 
Figure $4.1-4$

Test Plan Simulation Summary

Reaction Furnace Temperature vs. Reaction Stoichiometry

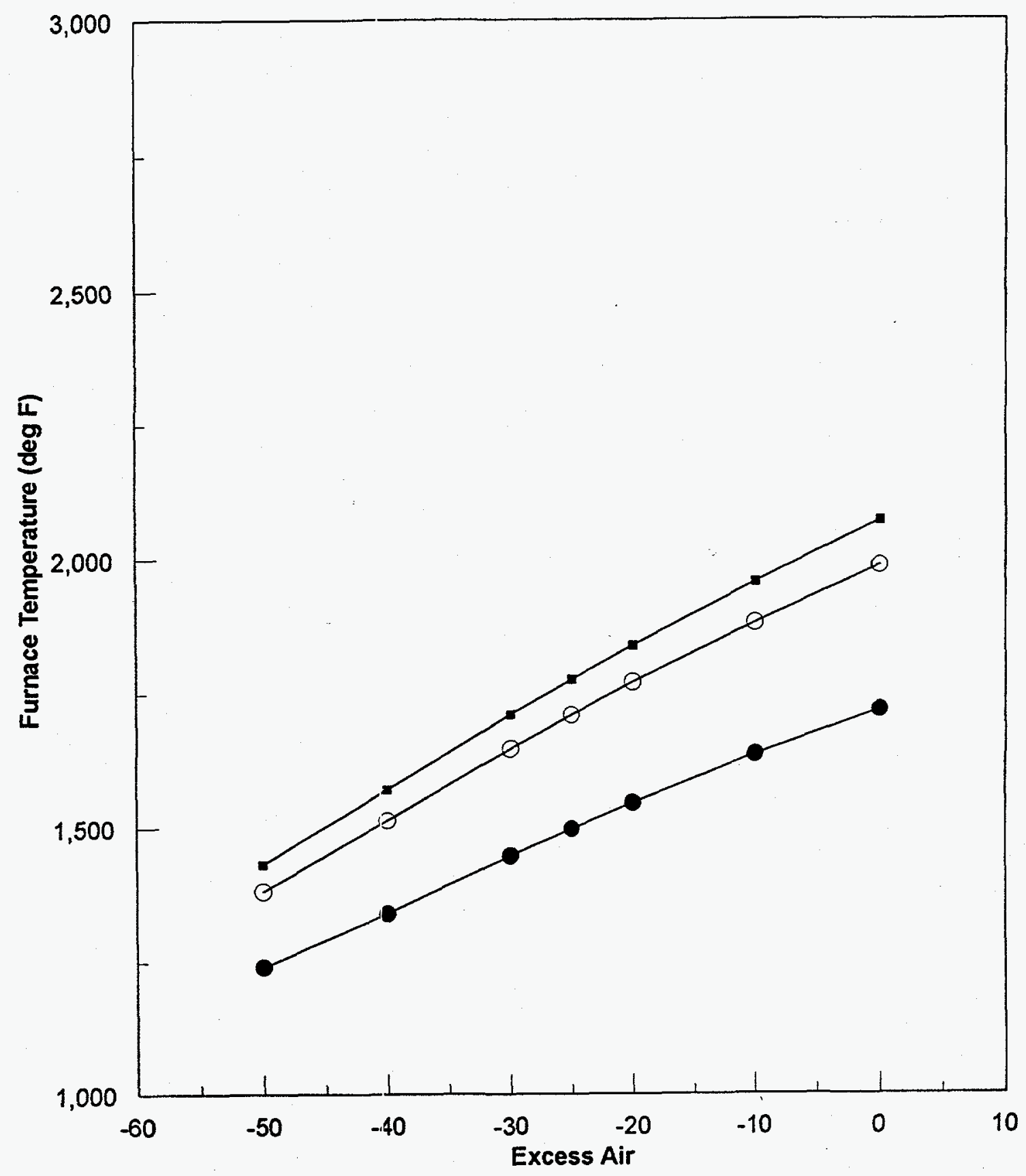

Thermodynamic Simulation Thermodynamic Simulation Thermodynamic Simulation Air $\quad 50 \%$ Oxygen $90 \%$ Oxygen

1. Feed gas: $50 \% \mathrm{H} 2 \mathrm{~S}$

2. Various "Air" Compostions 
Figure 4.1-5

Test Plan Simulation Summary

Reaction Furnace Temperature vs. Reaction Stoichiometry

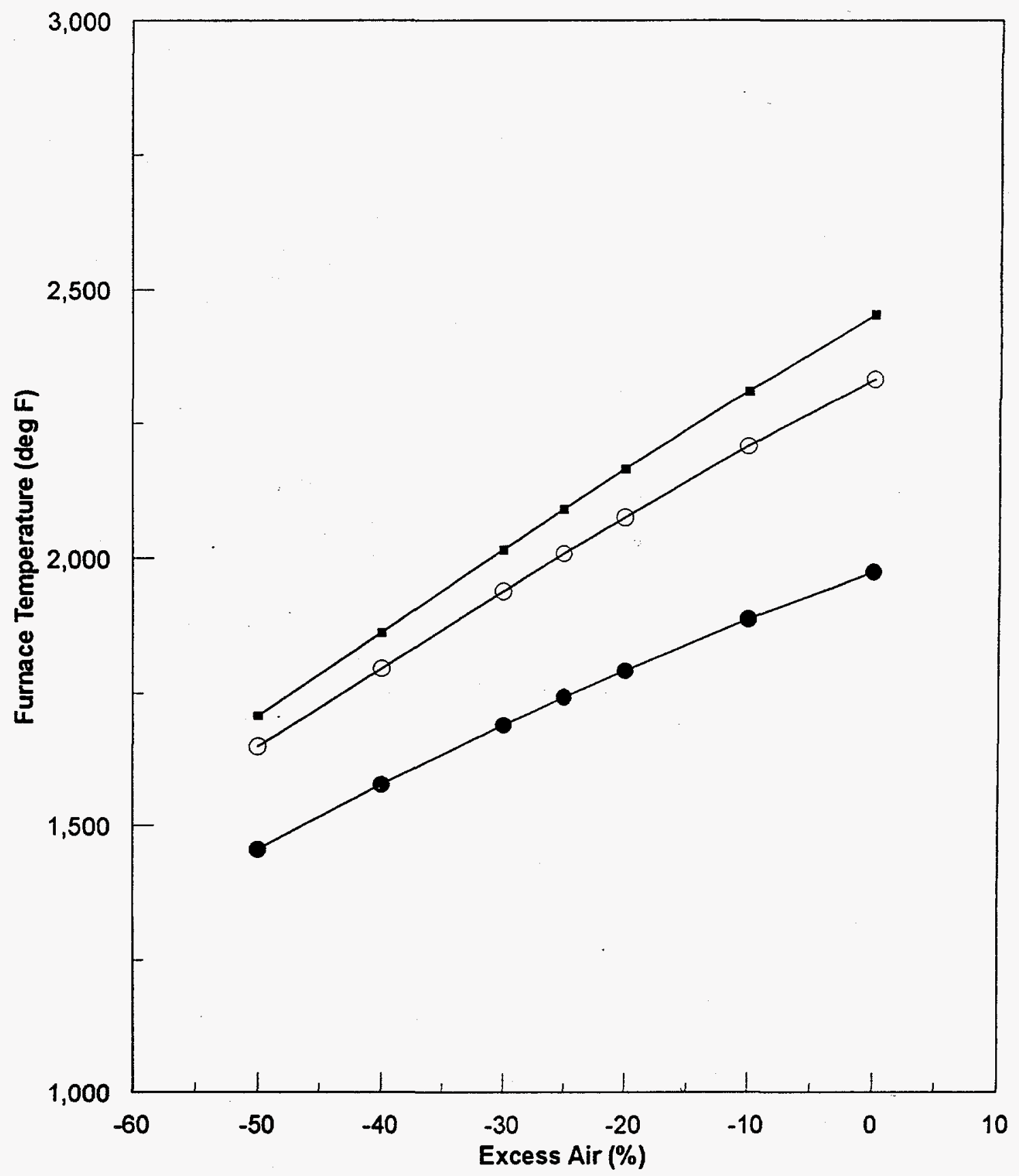

Thermodynamic Simulation Thermodynamic Simulation Thermodynamic Simulation Air $50 \%$ Oxygen $90 \%$ Oxygen

1. Feed gas : $70 \% \mathrm{H} 2 \mathrm{~S}$

2. Various "Air" Compostions 
Figure 4.1-6

Test Plan Simulation Summary

Reaction Furnace Temperature vs. Reaction Stoichiometry

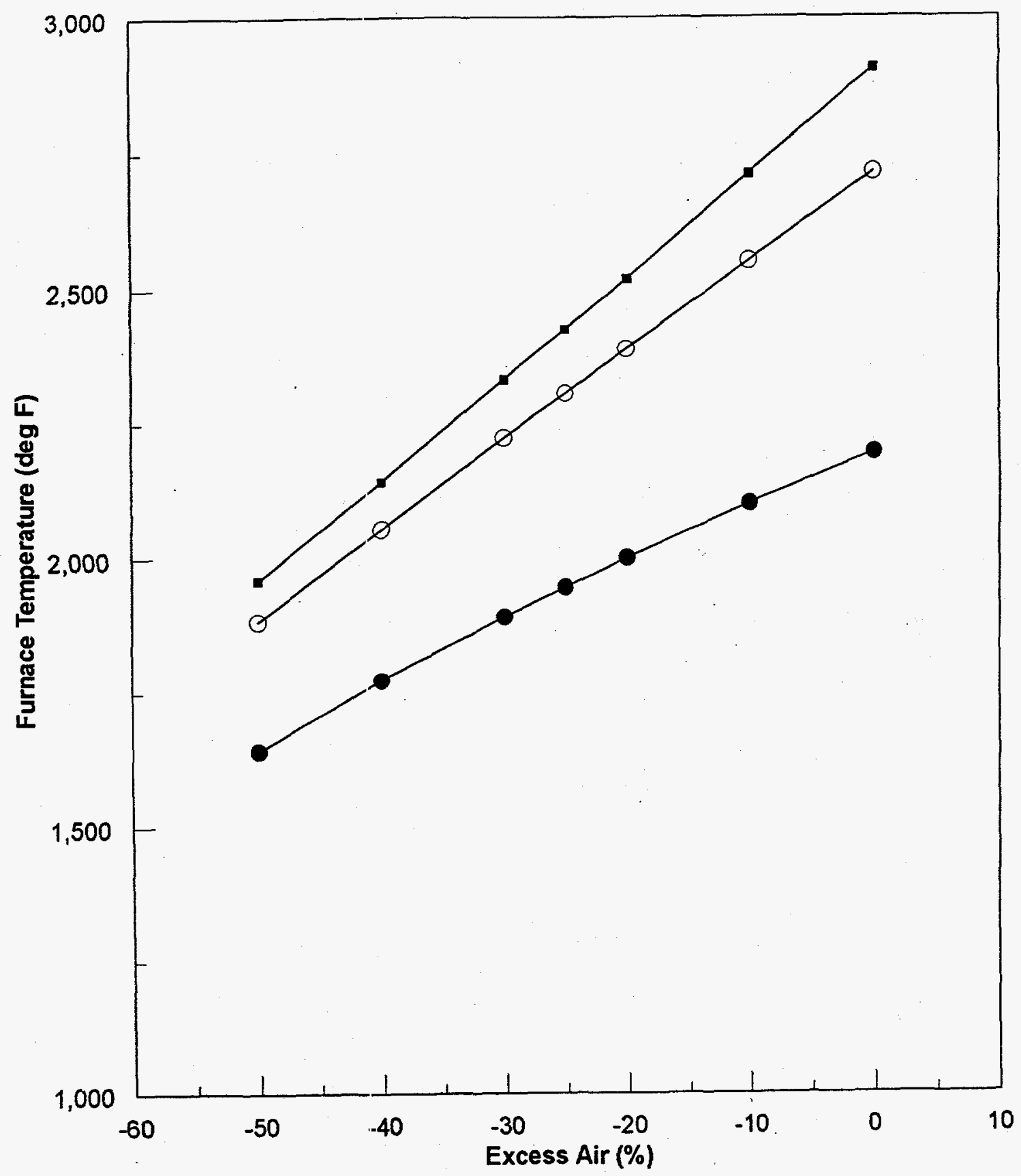

Thermodynamic Simulation Thermodynamic Simulation Thermodynamic Simulation Air $50 \%$ Oxygen $90 \%$ Oxygen

1. Feed gas : $90 \% \mathrm{H} 2 \mathrm{~S}$

2. Various "Air" Compositions 


\section{Test Run Procedure}

\section{Chemical Equilibrium Tests}

The pilot unit will be started up using sufficient $\mathrm{O}_{2}$ to oxidize between one-third and one-half of the $\mathrm{H}_{2} \mathrm{~S}$ with a target residence time in the reaction furnace of 2 seconds. The temperature will be monitored to ensure that the Reaction furnace does not become overheated. If necessary, the flow rates of the Acid Gas and $\mathrm{O}_{2} /$ Air Feeds, and/or their ratio, will be adjusted to prevent overheating. When stable operation is achieved, a routine sample set will be taken and analyzed to confirm the performance of the Reaction furnace.

Once the operability of the pilot unit is established, the ratio of $\mathrm{O}_{2}$ /Air Feed to Acid Gas Feed will be adjusted, step wise, towards oxidation of one-sixth of the $\mathrm{H}_{2} \mathrm{~S}$ while monitoring the temperature and maintaining the residence time in the Reaction furnace between 2 and 3 seconds. At each step, the unit will be allowed to stabilize (between 20 to 30 minutes should be sufficient) as indicated by stable Reaction furnace temperature(s) and a routine sample set will be taken and analyzed. When the target of one-sixth oxidation of the $\mathrm{H}_{2} \mathrm{~S}$ is reached (increasing the residence time if necessary), duplicate routine sample sets will be taken.

In addition, for each routine sample set, a set of quenched samples directly from the furnace will be taken and analyzed. The analytical data from the routine sample set will be used to evaluate overall performance while the analytical data from the quenched samples set will be used for comparison with equilibrium-calculation results to determine the degree of approach to equilibrium in the Reaction furnace.

Within the range of operating variables described above, tests will be carried out at the maximum and minimum attainable $\mathrm{CO}_{2} / \mathrm{H}_{2} \mathrm{~S}$ ratios for the Acid Gas and the maximum and minimum attainable $\mathrm{O}_{2} / \mathrm{N}_{2}$ ratios for the "Air" Feed Streams. For these tests, the "Air" to Acid Gas ratio will be for one-sixth oxidation of the $\mathrm{H}_{2} \mathrm{~S}$ and the residence time in the Reaction furnace will be that which in prior tests achieved the closest approach to equilibrium. Both a routine sample set and a quenched samples set will be taken and analyzed for each condition.

\section{Kinetic Reaction Tests}

Assuming that the feasibility and practicability of the fundamental operating strategy are established by the foregoing, the "kinetics" of the pilot unit equipment will be characterized by the following series of tests.

Holding the $\mathrm{O}_{2}$ /Air to Acid Gas Feed ratio constant at one-sixth oxidation of the $\mathrm{H}_{2} \mathrm{~S}$, the residence time in the Reaction furnace will be varied from 1 to 4 seconds in one-second steps. Routine sample sets and quenched samples sets will be taken and analyzed at each step. If equilibrium is approached at 1 second residence time, a test will be run at 0.5 seconds residence time. 
Holding the residence time constant at the value indicated by the foregoing as sufficient to reach equilibrium, the $\mathrm{O}_{2} / \mathrm{Air}$ to Acid $\mathrm{Gas}$ Feed ratio will be reduced step wise to determine the practical lower limit of operation as indicated by analytical results, the Reaction furnace temperature and stability of operation. Routine sample sets and quenched samples sets will be taken and analyzed at each step.

This set of tests will be repeated at twice the residence time indicated as sufficient to reach equilibrium at one-sixth oxidation of the $\mathrm{H}_{2} \mathrm{~S}$. 


\subsection{Test Results - Data, Analysis and Methods}

As described earlier, the actual number of test runs completed was significantly less than described in the original test run matrix due to a major mechanical failure in one of the primary units. Fortunately, the small number of test runs completed occurred with a set of operating conditions that covered a significant number of the fundamental parameters. More importantly, the test runs which were completed clearly demonstrated the critical performance of the reaction system.

\subsubsection{Field Data}

\section{Operating Conditions}

The test runs were completed under the following primary conditions:

- Acid Gas with $\sim 90$ percent $\mathrm{H}_{2} \mathrm{~S}$ only.

- Combustion air with $\sim 21$ percent $\mathrm{O}_{2}$ only.

- Excess air ranging between 21 and 55 percent of "normal" modified Claus stoichiometry.

- Furnace residence times ranging between 1.3 and 3.6 seconds.

- Furnace temperatures ranging between 1620 and $1870^{\circ} \mathrm{F}$.

This clearly represented only a small fraction of the originally planned test runs. However, after the failure of the wasteheat exchange unit (which would require substantial repair time and costs) a review of the data gathered to that point was completed. This review indicated that the runs completed to that point had substantially demonstrated many of the critical performance parameters and therefore, a decision was made to discontinue further testing pending completion of the full report and a determination whether testing was warranted. Table 4.2-1 on the following page summarizes the primary operating data for the completed test runs.

\section{Process Gas Analysis Results}

For each test run set, a detailed set of gas analyses were completed on each of the following sample locations:

- Acid gas furnace feed (combined $\mathrm{H}_{2} \mathrm{~S}$ and $\mathrm{CO}_{2}$ feed streams)

- Reaction furnace product

- Wasteheat exchanger process gas

In essence, the reaction furnace products and the wasteheat exchanger process gas are normally considered to be of the same composition. However, experience with industrial modified Claus furnaces has shown that often there is a change in gas composition between these two points due to continued reaction in the exchanger unit. The analysis of the actual reaction products in the furnace was of primary interest with regard to determining the performance of the reaction system. However, the analysis of the wasteheat exchanger process gas allowed for direct measurement of the gas which would be treated further in the tail gas treating section of the CNG Claus process. Analysis of both of these streams allowed for a complete review of the "thermal stage" reaction system. A complete set of gas analysis results is presented in Appendix A. 


\begin{tabular}{|c|c|c|c|c|c|c|c|}
\hline \multicolumn{8}{|c|}{$\begin{array}{c}\text { Table 4.2-1 } \\
\text { Pilot Plant Test Data - Session } 1 \\
\end{array}$} \\
\hline \multicolumn{3}{|c|}{ Test } & 1 & $2 a$ & $\mathbf{2 b}$ & 3 & 4 \\
\hline \multirow[t]{2}{*}{ Ambient } & Temperature & $\left({ }^{\circ} \mathrm{F}\right)$ & 52 & 52 & 52 & 52 & 52 \\
\hline & Pressure & (psia) & 14.3 & 14.3 & 14.3 & 14.3 & 14.3 \\
\hline \multirow[t]{5}{*}{ Acid Gas } & Flow & $(\mathrm{lb} \cdot \mathrm{mol} / \mathrm{h})$ & 0.583 & 0.695 & 0.695 & 0.600 & 0.600 \\
\hline & Flow & (scfim) & 3.68 & 4.386 & 4.439 & 3.782 & 4.810 \\
\hline & Temperature & $\left({ }^{\circ} \mathrm{F}\right)$ & 60 & 60 & 60 & 60 & 60 \\
\hline & Pressure & (psia) & 76.3 & 76.3 & 76.3 & 76.3 & 76.3 \\
\hline & {$\left[\mathrm{H}_{2} \mathrm{~S}\right]$} & (mole \%) & 89.4 & 89.4 & 89.4 & 89.4 & 89.4 \\
\hline \multirow[t]{5}{*}{ Air } & Flow & $(\mathrm{b}$ mol/h) & 0.851 & 1.210 & 1.192 & 0.658 & 0.579 \\
\hline & Flow & (scim) & 5.388 & 7.661 & 7.547 & 4.166 & 3.666 \\
\hline & Temperature & $\left({ }^{\circ} \mathrm{F}\right)$ & 60 & 60 & 60 & 60 & 60 \\
\hline & Pressure & (psia) & 114.3 & 114.3 & 114.3 & 114.3 & 114.3 \\
\hline & {$\left[\mathrm{O}_{2}\right]$} & (mole \%) & 20.81 & 20.81 & 20.81 & 20.81 & 20.81 \\
\hline \multirow[t]{6}{*}{ Furnace } & Flow & $(\mathrm{lb}$ mol/h) & 1.273 & 1.672 & 1.680 & 1.134 & 1.091 \\
\hline & Flow & (sc:im) & 8.060 & 10.587 & 10.637 & 7.180 & 6.908 \\
\hline & Temperature & $\left({ }^{\circ} \mathrm{F}\right)$ & 1570 & 1644 & 1873 & 1618 & 1620 \\
\hline & Temperature & $\left({ }^{\circ} \mathrm{F}\right)$ & --- & 1651 & 1857 & 1583 & $\cdots$ \\
\hline & Temperature & $\left({ }^{\circ} \mathrm{F}\right)$ & -- & 1521 & 1709 & 1454 & $\cdots$ \\
\hline & Pressure & (psia) & 28.8 & 31.3 & .63 .3 & 54.3 & 49.8 \\
\hline \multirow[t]{2}{*}{ Wasteheat Exc. } & Temperature & $\left({ }^{\circ} \mathrm{F}\right)$ & 541 & 541 & 632 & 555 & 555 \\
\hline & Pressure & (psia) & 19.8 & 21.3 & 58.8 & 50.3 & 45.3 \\
\hline \multirow[t]{2}{*}{ Condenser } & Temperature & $\left({ }^{\circ} \mathrm{F}\right)$ & 275 & 275 & 289 & 284 & 284 \\
\hline & Pressure & (psia) & 16.3 & 16.3 & 55.3 & 48.3 & 44.3 \\
\hline
\end{tabular}




\subsection{Data Analysis and Results}

\subsubsection{Material Balances}

The primary method for compiling and reviewing the test run data was to construct detailed multicomponent material and heat balances. Compilation of these balances for each and every sample set allow for direct calculation of the following performance parameters:

- $\mathrm{H}_{2} \mathrm{~S}$ conversion efficiency (reaction yield) and approach to equilibrium

- Reaction stoichiometry (extent of "deficient" oxygen in the reaction system)

- Adiabatic reaction temperature

- Evaluation of the extent of side reactions in the system

Table 4.3-1 illustrates a typical material balance for one of the test run sets. Full material balances for all of the test run sets are presented in Appendix B-1.

\begin{tabular}{|c|c|c|c|c|}
\hline \multicolumn{5}{|c|}{$\begin{array}{c}\text { Table 4.3-1 } \\
\text { Material Balance - Test } 1 \\
\end{array}$} \\
\hline $\begin{array}{l}\text { Process Location } \\
\text { Sample No. } \\
\end{array}$ & $\begin{array}{c}\text { Acid Gas } \\
15 \\
\end{array}$ & Air & $\begin{array}{c}\text { Reaction Furnace } \\
07 \\
\end{array}$ & $\begin{array}{c}\text { Tail Gas } \\
08 \\
\end{array}$ \\
\hline $\mathrm{H}_{2}$ & 0.0000 & 0.0000 & 0.0259 & 0.0155 \\
\hline $\mathrm{Ar}$ & 0.0001 & 0.0079 & 0.0080 & 0.0078 \\
\hline $\mathrm{O}_{2}$ & 0.0000 & 0.1771 & 0.0030 & 0.0002 \\
\hline $\mathrm{N}_{2}$ & 0.0065 & 0.6604 & 0.6666 & 0.6549 \\
\hline $\mathrm{CH}_{4}$ & 0.0000 & 0.0000 & 0.0000 & 0.0000 \\
\hline $\mathrm{CO}$ & 0.0000 & 0.0000 & 0.0022 & 0.0014 \\
\hline $\mathrm{CO}_{2}$ & 0.0530 & 0.0003 & 0.0518 & 0.0539 \\
\hline $\mathrm{H}_{2} \mathrm{~S}$ & 0.5213 & 0.0000 & 0.1590 & 0.1863 \\
\hline $\cos$ & trace & 0.0000 & 0.0014 & 0.0015 \\
\hline $\mathrm{SO}_{2}$ & 0.0001 & 0.0000 & 0.0021 & 0.0084 \\
\hline $\mathrm{CS}_{2}$ & 0.0000 & 0.0000 & 0.0034 & 0.0019 \\
\hline $\mathrm{H}_{2} \mathrm{O}$ & 0.0000 & 0.0057 & 0.3493 & 0.3323 \\
\hline $\mathrm{C}_{3}^{+}$ & 0.0018 & 0.0000 & 0.0000 & 0.0000 \\
\hline Total & 0.5828 & 0.8511 & 1.2727 & 1.2641 \\
\hline$S$ vapor (as $S_{1}$ ) & $-\cdots$ & $\ldots$ & 0.3522 & 0.0008 \\
\hline Temperature $\left({ }^{\circ} \mathrm{F}\right)$ & 60 & 60 & 1888 & 271 \\
\hline Pressure (psig) & 62.0 & 100.0 & 5.5 & 2.0 \\
\hline
\end{tabular}




\subsubsection{Performance Summary}

\section{Chemical Equilibrium Results}

A thorough review was completed on all of the material balances generated from the February, 1997 test runs. Table 4.3-2 summarizes the most important performance parameters from the test runs.

\begin{tabular}{|c|c|c|c|c|c|c|}
\hline \multicolumn{7}{|c|}{$\begin{array}{c}\text { Table 4.3-2 } \\
\text { Test Run Results }\end{array}$} \\
\hline Sample & $\begin{array}{c}\text { Acid Gas } \\
\mathbf{H}_{2} \mathrm{~S} \\
(\text { mole \%) }\end{array}$ & $\begin{array}{c}\text { Combustion } \\
\text { Air } \mathbf{O}_{2} \\
\text { (mole \%) } \\
\end{array}$ & $\begin{array}{c}\text { Ercess Air } \\
(\%)\end{array}$ & $\begin{array}{c}\mathrm{H}_{2} \mathbf{S} \\
\text { Conversion } \\
(\%) \\
\end{array}$ & $\begin{array}{c}\mathrm{SO}_{2} \text { Residual } \\
\text { (mole \%) }\end{array}$ & $\begin{array}{c}\text { Temperature } \\
\text { Meas. / Theo. } \\
\left({ }^{\circ} \mathbf{F}\right)\end{array}$ \\
\hline \multicolumn{7}{|c|}{ Results Based on Furnace Samples } \\
\hline RF09 & 89.40 & 20.81 & -18.6 & 79.47 & 0.013 & $1644 / 2047$ \\
\hline RF07 & 89.40 & 20.81 & -30.1 & 67.55 & 0.163 & $1770 / 1888$ \\
\hline RF11 & 89.40 & 20.81 & -49.2 & 49.70 & 0.157 & $1620 / 1702$ \\
\hline RF13 & 89.40 & 20.81 & -53.7 & 42.16 & 0.670 & $1618 / 1627$ \\
\hline \multicolumn{7}{|c|}{ Results Based on Tail Gas Samples } \\
\hline TG10 & 89.40 & 20.81 & -21.3 & 65.17 & 1.657 & $1873 / 2127$ \\
\hline TG08 & 89.40 & 20.81 & -33.4 & 61.64 & 0.668 & $1770 / 1946$ \\
\hline TG14 & 89.40 & 20.81 & -48.9 & 47.65 & 0.523 & $1620 / 1764$ \\
\hline TG12 & 89.40 & 20.81 & -55.2 & 43.72 & 0.168 & $1618 / 1652$ \\
\hline
\end{tabular}

For base line comparison, each of these test sets was also simulated on Sulsim ${ }^{\otimes}$ to determine the expected thermodynamic equilibrium behavior for these particular test runs. The full material balances for these runs are included in Appendix B-2 and are summarized in Table 4.3-3.

\begin{tabular}{|c|c|c|c|c|c|c|}
\hline \multicolumn{7}{|c|}{$\begin{array}{c}\text { Table } 4.3-3 \\
\text { Test Run Comparison - Thermodynamic Equilibrium }\end{array}$} \\
\hline Test & $\begin{array}{c}\text { Acid Gas } \\
\mathbf{H}_{2} \mathbf{S} \\
(\text { mole \%) }\end{array}$ & $\begin{array}{c}\text { Combustion } \\
\text { Air } \mathbf{O}_{2} \\
\text { (mole \%) }\end{array}$ & $\begin{array}{c}\text { Excess Air } \\
(\%)\end{array}$ & $\begin{array}{c}\mathbf{H}_{2} \mathbf{S} \\
\text { Conversion } \\
(\%) \\
\end{array}$ & $\begin{array}{c}\mathrm{SO}_{2} \text { Residual } \\
\text { (mole \%) }\end{array}$ & $\begin{array}{c}\text { Temperature } \\
\left({ }^{\circ} \mathbf{F}\right)\end{array}$ \\
\hline 2 & 89.40 & 20.81 & -12.5 & 70.23 & 2.096 & 2042 \\
\hline 1 & 89.40 & 20.81 & -27.2 & 64.39 & 1.129 & 1895 \\
\hline 3 & 89.40 & 20.81 & -47.6 & 49.08 & 0.497 & 1694 \\
\hline 4 & 89.40 & 20.81 & -53.2 & 44.41 & 0.367 & 1624 \\
\hline
\end{tabular}




\section{$\underline{\mathrm{H}}_{2}$ S Conversion Efficiency}

As illustrated in Tables 4.3-2 and 4.3-3 and Figure 4.3.2-1, the conversion of $\mathrm{H}_{2} \mathrm{~S}$ to elemental sulfur varied between 42 and 68 percent. These results were marginally lower than the equivalent values determined by the thermodynamic equilibrium calculations. These values were however, consistent with the expected results and indicated that the $\mathrm{H}_{2} \mathrm{~S}$ oxidation reaction proceeded adequately even under these conditions which were severely deficient in oxygen.

The test runs were also conducted at furnace pressures varying between 16 and $55 \mathrm{psia}$. These tests did not cover the full range of the initial test plan and did not reach the expected maximum test pressure of 100 psia. However, the test runs did indicate that the $\mathrm{H}_{2} \mathrm{~S}$ oxidation reaction was not measurably affected by system pressure in a negative manner. It is expected that based on these results, further increases in system pressure would not be expected to have any detrimental effects on the reaction system. Indeed, as with most homogeneous gas phase reaction systems, increasing pressure could be expected to improve the overall mixing in the system which would have a net positive effect on the approach to equilibrium in this system.

In general, these conversion efficiencies were also consistent with the target value of 50 percent as stipulated in the original program objectives. The test results demonstrated that the conversion efficiency could be maintained at 50 percent as long as the reaction stoichiometry was maintained at no less than 50 percent of traditional modified Claus stoichiometry.

Therefore, the pilot plant runs demonstrated that the $\mathrm{H}_{2} \mathrm{~S}$ oxidation reaction will proceed successfully under the operating conditions imposed by the CNG Claus process.

\section{Reaction Temperature}

The criterion in the original program objectives required that the reaction system be maintained below $2500^{\circ} \mathrm{F}$. This would ensure that the CNG Claus furnace could be of conventional design with commercially available vessel refractory systems.

The test results (Figure 4.3.2-2) clearly indicated that the furnace temperatures were less than the benchmark value and were also remarkably consistent with the predicted equilibrium results. The measured furnace temperatures were actually less than the predicted values largely as a result of heat losses from the furnace vessel. The level of heat loss observed in the pilot plant runs was consistent with what is typically observed in industrial systems.

Due to the mechanical failure in the exchanger system, full test runs were not completed with the higher level oxygen concentrations prescribed in the original test run matrix. However, the test runs did demonstrate that the actual furnace temperatures for the completed runs were consistent with the equilibrium values. Therefore, by extrapolation and review of the original simulation studies conducted, it is a reasonable assumption that the furnace temperatures would be consistent with the equilibrium simulation results. The simulated results indicated that the furnace temperature could be maintained below the prescribed $2500^{\circ} \mathrm{F}$ value even with extremely rich acid gas feeds and very high oxygen concentrations in the combustion air ( 90 percent $\mathrm{H}_{2} \mathrm{~S}$ and 90 percent $\mathrm{O}_{2}$ respectively). 
Figure 4.3.2-1

Test Run Data vs Theoretical Model

Sulfur Conversion vs. Reaction Stoichiometry

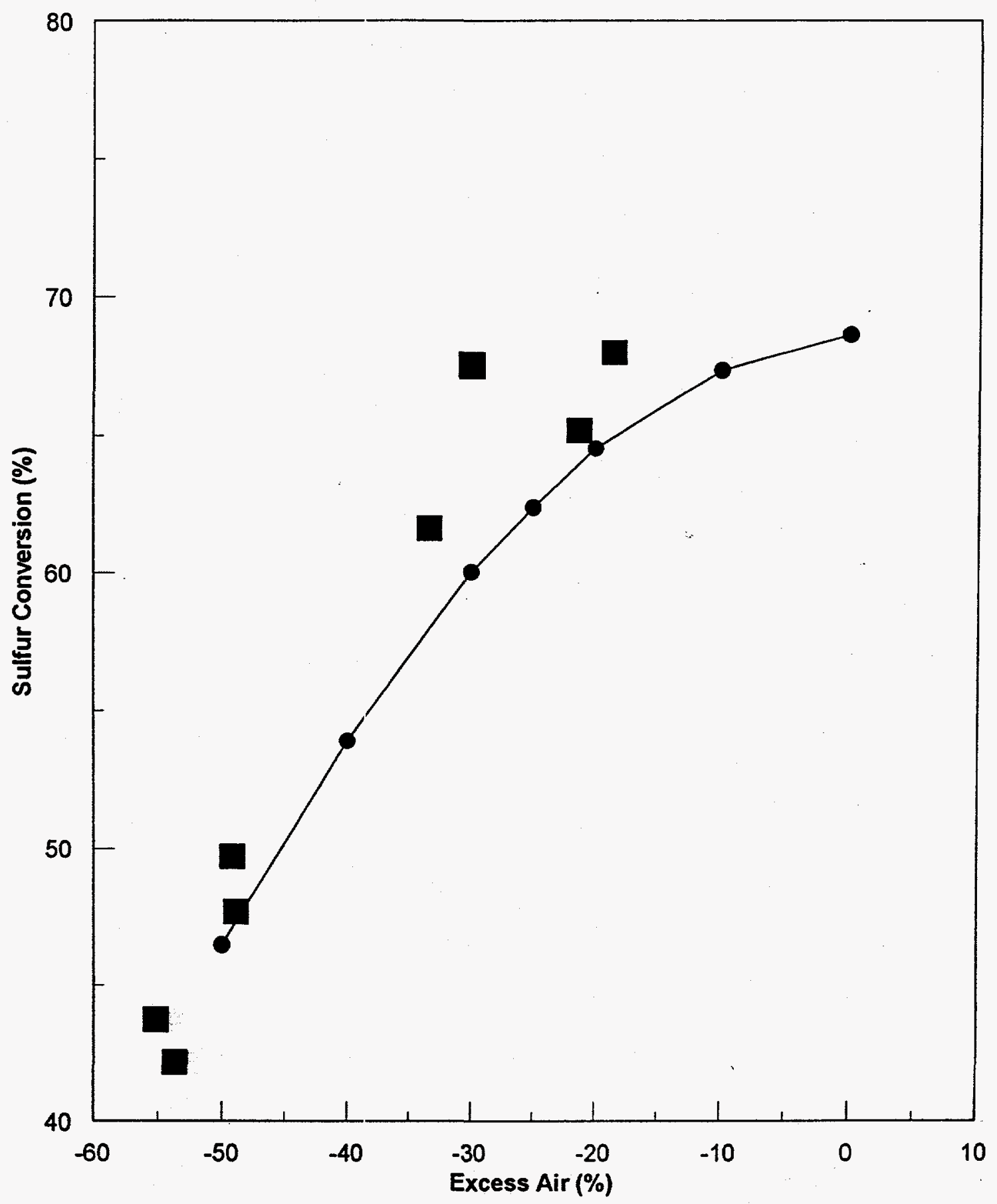

Themodynamic Simulation Test Data

1. Feed gas : $90 \% \mathrm{H} 2 \mathrm{~S}$ 


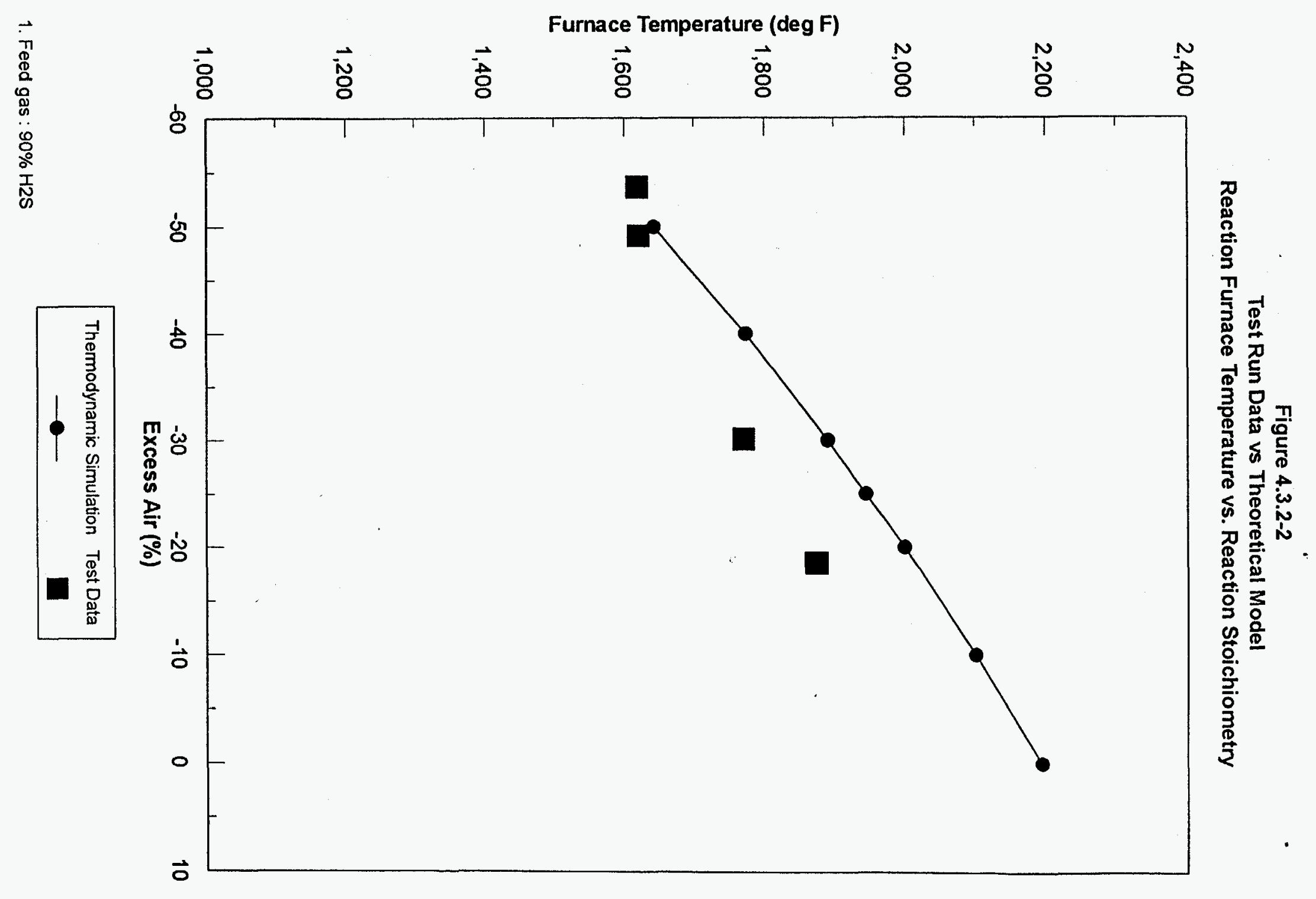




\section{$\underline{\text { Reactant Composition }}$}

The test results clearly indicated that the performance of the furnace with respect to $\mathrm{H}_{2} \mathrm{~S}$ conversion met the program objectives. By inference therefore, the composition of the reaction product stream was also consistent with the expected results. However, there were two additional considerations regarding reaction product composition which were reviewed:

1. $\mathrm{SO}_{2}$ concentration in the reaction effluent stream

2. Concentration of other sulfur bearing compounds in the reaction effluent stream

As discussed in Section 3.1, a further requirement on the CNG Claus process was that the $\mathrm{SO}_{2}$ concentration be maintained at a prescribed maximum level. This would ensure successful operation of the downstream tail gas clean-up section of the process. The maximum desired $\mathrm{SO}_{2}$ concentration was set at 2.0 mole percent to ensure that the downstream hydrogenation reaction would not be overloaded with respect to $\mathrm{SO}_{2}$. The results shown in Table 4.3-2 indicate that the $\mathrm{SO}_{2}$ concentrations were less than the prescribed 2 mole percent for all test cases. Even in the cases at relatively high reaction stoichiometry (Test 2) the $\mathrm{SO}_{2}$ concentration was less than the prescribed level.

The role of side reactions in traditional Claus furnaces is well documented and ultimately can affect the conversion performance of the: system in addition to creating new compounds which can affect the downstream operations. These side reactions are generally predicted in thermodynamic equilibrium models and have been shown to be affected by kinetic limitations also.

The most commonly documented products of these side reactions in industrial Claus furnaces are $\mathrm{H}_{2}$, $\mathrm{CO}, \mathrm{COS}$ and $\mathrm{CS}_{2}$. The formation of these compounds is consistently predicted by the equilibrium model however, the extent of formation of these compounds is often affected significantly by kinetic limitations.

Both $\mathrm{H}_{2}$ and $\mathrm{CO}$ exist in fairly high concentrations in these $\mathrm{H}_{2} \mathrm{~S}$ oxidation systems and the test results confirmed the extent of these side reactions in the pilot plant. Generally, the measured concentrations of these species was less than predicted by thermodynamic equilibrium. This indicated some level of kinetic limitation in the pilot plant furnace which is entirely consistent with industrial Claus furnaces. Generally, low reaction furnace temperatures result in $\mathrm{H}_{2}$ and $\mathrm{CO}$ formation rates less than equilibrium in the furnace. The oxygen deficient conditions used for the pilot plant studies resulted in relatively low furnace temperatures $\left(<2000^{\circ} \mathrm{F}\right)$ and comparatively low formation rates also.

The formation of $\mathrm{H}_{2}$ and $\mathrm{CO}$ does not affect the $\mathrm{H} \mathrm{S}$ conversion efficiency and is therefore not important to overall sulfur recovery. However, they do affect the "air demand" of the system and can have some effect on the reaction. temperature and material balance through the system. For this system, however, the effects on overall performance of the process were not deemed significant. 
Of more interest are those reactants and reactions which lead to other sulfur bearing compounds in the reaction product stream; primarily the carbon-sulfur compounds $\mathrm{COS}$ and $\mathrm{CS}_{2}$. Because these compounds contain sulfur, they can have a measurable effect on the furnace conversion efficiency and also require that the overall process system be designed to ultimately eliminate these compounds from the process stream or risk adding to the sulfur emissions from the process.

$\operatorname{COS}$ is formed in a system that contains both sulfur and carbon from any source. In the test system the acid gas stream contained a significant level of $\mathrm{CO}_{2}(\sim 10$ mole percent $)$ and therefore, formation of COS was expected. The thermodynamic models predict relatively low levels of COS formation; typically less than $1000 \mathrm{ppm}$ for the pilot plant feed streams. However, kinetic limitations can lead to higher levels as was observed in the pilot plant tests which had COS levels in the 1000 to 3000 ppm range.

The levels of COS formation in the CNG Claus system were in the range observed in industrial Claus furnaces as expected. The tail gas treating system proposed for the CNG Claus process is fully capable of dealing with this level of COS in the hydrogenation reactor. Therefore, no detrimental effects due to COS formation are expected for the CNG Claus process.

$\mathrm{CS}_{2}$ is formed in a system that contains both sulfur and carbon from hydrocarbon compounds. In the test system it was originally expected that there would be no hydrocarbon in the acid gas. However, analysis of the liquid $\mathrm{H}_{2} \mathrm{~S}$ indicated nominal levels of propane (approximately $300 \mathrm{ppm}$ ) and therefore formation of $\mathrm{CS}_{2}$ was expected. The thermodynamic model predicts very low levels of $\mathrm{CS}_{2}$ formation; typically less than $50 \mathrm{ppm}$ for the pilot plant feed streams. However, kinetic limitations can lead to higher levels as was observed in the pilot plant tests which had $\mathrm{CS}_{2}$ levels in the 1700 to $4300 \mathrm{ppm}$ range.

The levels of $\mathrm{CS}_{2}$ formation in the pilot plant were in the range observed in industrial Claus furnaces. The tail gas treating system proposed for the CNG Claus process is fully capable of dealing with this level of $\mathrm{COS}$ in the hydrogenation reactor. Therefore, no detrimental effects due to $\mathrm{CS}_{2}$ formation are expected for the CNG Claus process.

\section{Kinetic Limitations}

Industrial Claus reaction furnaces systems are known to have some level of kinetic limitations which cause the reaction products to vary from those predicted by thermodynamic equilibrium. These kinetic limitations are directly affected by reaction residence time, reaction temperature and the extent of mixing in the burner and reaction zone.

It was assumed that the pilot plant burner/furnace system would suffer some level of kinetic limitation and a portion of the test matrix was dedicated to measuring the effects of residence time and reaction temperature on the reaction system. Due to the mechanical problems encountered during the pilot plant test runs, these specific test runs were not completed. However, a thorough review of the completed test runs indicated that a range of residence times and reaction temperatures was achieved. Table 4.3-3 on the following page summarizes the effect of the measured kinetic parameters from the completed test runs. 


\begin{tabular}{||l|c|c|c|c|c|c||}
\hline \multicolumn{7}{|c|}{ Test Run Results - Kinetic Effects } \\
\hline \hline Sample & $\begin{array}{c}\text { Process } \\
\text { Flow Rate } \\
(\text { acfm) }\end{array}$ & $\begin{array}{c}\text { Residence } \\
\text { Time } \\
(\mathbf{s})\end{array}$ & $\begin{array}{c}\mathbf{H}_{2} \mathbf{S} \\
\text { Conversion } \\
(\%)\end{array}$ & $\begin{array}{c}\mathbf{H}_{2} \mathbf{S} \\
\text { Conversion } \\
\text { Theo. }(\%)^{1}\end{array}$ & $\begin{array}{c}\text { Approach to } \\
\text { Equilibrium } \\
(\%)\end{array}$ & $\begin{array}{c}\text { Temperature } \\
\text { Measured } \\
\left({ }^{\circ} \mathbf{F}\right)\end{array}$ \\
\hline \hline TG10 & 22.63 & 1.30 & 65.17 & 70.23 & 93 & 1644 \\
\hline RF07 & 20.06 & 1.47 & 67.55 & 64.39 & 95 & 1770 \\
\hline RF11 & 8.68 & 3.39 & 49.70 & 49.08 & 100 & 1620 \\
\hline RF13 & 8.07 & 3.64 & 42.16 & 47.23 & 89 & 1618 \\
\hline
\end{tabular}

'Based on thermodynamic equilibrium sinulations.

${ }^{2}$ Measured $\mathrm{H}_{2} \mathrm{~S}$ conversion/ Theoretical $\mathrm{H}_{2} \mathrm{~S}$ conversion.

These results indicated that the pilot plant fumace generally had a very close approach to equilibrium for all of the test cases. It also indicated that the residence time did not have a significant impact on the approach to equilibrium and lower residence times did not have a significant detrimental effect on the conversion efficiency. Similarly, the lower reaction temperatures measured in the very low reaction stoichiometry cases did not adversely affect the approach to equilibrium conversion. This is consistent with observations in industrial furnaces which show a good approach to equilibrium for $\mathrm{H}_{2} \mathrm{~S}$ conversion regardless of measured kinetic parameters. It is generally agreed in the industry that this lack of kinetic limitations on the $\mathrm{H}_{2} \mathrm{~S}$ oxidation reaction is largely a function of the extremely fast reaction times associated with this reaction.

As described earlier, the concentrations of $\mathrm{H}_{2}, \mathrm{CO}, \mathrm{COS}$ and $\mathrm{CS}_{2}$ were measurably different than the equilibrium predictions which does indicate measurable kinetic limitation with respect to side reactions in the furnace. This is also consistent with observations in industrial furnaces and is attributed to the fact that all of the side reactions in question have considerably slower overall reaction rates and are therefore much more susceptible to kinetic limitation in the reaction zone. 
In summary, the following conclusions were drawn for the test run results:

\section{Reaction Considerations}

- the $\mathrm{H}_{2} \mathrm{~S}$ oxidation reaction proceeds successfully at the fundamental CNG Claus conditions; specifically with very low reaction stoichiometry and high reaction pressures.

- the oxidation reaction is stable and sustainable in the "free flame" reaction regime.

- the extent of $\mathrm{H}_{2} \mathrm{~S}$ conversion to elemental sulfur measured during the test runs was consistent with the required values set out in the test program objectives ( $>50$ percent).

- the extent of $\mathrm{H}_{2} \mathrm{~S}$ conversion to elemental sulfur measured during the test runs was comparable to the predicted results using thermodynamic equilibrium reaction models. This implies that the $\mathrm{H}_{2} \mathrm{~S}$ oxidation reaction is not unusually hindered by reaction kinetics at the CNG Claus conditions.

- the increased pressure associated with the CNG Claus process had no discernable effect on the $\mathrm{H}_{2} \mathrm{~S}$ oxidation reaction. Traditional homogeneous gas phase reaction theory suggests that the reactions would actually be enhanced under higher pressure conditions.

- the concentration of the reaction products (primarily $\mathrm{SO}_{2}<2.0$ mole percent) were consistent with the values required for successful operation of a conventional downstream tail gas treating process.

- the measured and calculated reaction temperatures $\left(1500-2200^{\circ} \mathrm{F}\right)$ were consistent with the values required to ensure that the process can be operated in furnace of conventional design.

- the measured and calculated reaction temperatures were consistent with the predicted results using thermodynamic equilibrium reaction models.

- the extent of side reactions in the pilot plant indicate that kinetic parameters do affect the extent of formation of the minor reaction product species; $\mathrm{H}_{2}, \mathrm{CO}, \mathrm{COS}$ and $\mathrm{CS}_{2}$. The concentrations of these compounds in the system are not considered detrimental to the overall successful operation of an integrated system. 


\section{Equipment Considerations}

- the pilot plant design and equipment was taken directly from conventional technology and performed essentially as planned.

- the conventional burner and reaction furnace system allowed for successful completion of the $\mathrm{H}_{2} \mathrm{~S}$ oxidation reaction under the required conditions.

- the measured reaction furnace temperatures were consistently less than the allowable $2500^{\circ} \mathrm{F}$ maximum which ensures that conventional furnace refractory design can be employed.

- the equipment failure in the pilot plant (leaking wasteheat exchanger) was probably a result of conventional corrosion and was not an artifact of the unconventional CNG Claus operating conditions.

- the pilot plant was designed with entirely conventional metallurgy and did not suffer any unusual failures due to the CNG Claus operating conditions. 


\section{References}

1. Victory, D.J., and Valencia, J.A., : "The CFZ Process: Direct Methane - Carbon Dioxide Fractionation", Hydrocarbon Processing, 66(5) 1987.

2. Brown, W.R., et al. : "Triple-Point Crystallization Separates and Concentrates Acid Gas", Presented at AIChE Spring National Meeting (March 27-31, 1983), Houston.

3. Siwajek, L.A., et al. "CNG Acid Gas Removal Process" Final Technical report, US Department of Energy, Morgantown Energy Technology Center, Contract No. DE-AC21-83MC20230 (July 1986.)

4. Cole, E.T, and Cook, W.J., et al. : "Evaluation of the Exxon CFZ and CNG-Claus Process for the Treatment of Sub-Quality Natural Gas", Final report, Gas Research Institute, Gas Processing and Chemical Process Research, Contract No. 5090-222-2011 (June, 1992).

5. Cook, W.J., and Klint, B.W. et al. : "Low Quality Natural Gas Sulfur Removal/Recovery", Task 2 report, US Department of Energy, Morgantown Energy Technology Center, Contract No. DEAC21-92MC29470 (August, 1993).

6. Klint, B.W., et al : "Low Quality Natural Gas Sulphur Removal/Recovery - CNG Claus Sulphur Recovery Process", Report to CNG Research and Acrion Technologies (May, 1993). 
I

1.

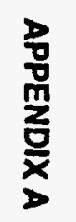

I

I

I

I

,

I

I

I

I

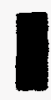

I

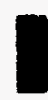


Appendix A

Gas Analysis Results 
TABLE A-1.

Gas Chromatographic Analyses

(Mole Percent)

Test 1

Consolidated Natural Gas Davis, Oklahoma

\begin{tabular}{|c|c|c|c|}
\hline \multirow{2}{*}{$\begin{array}{r}\text { Sample No: } \\
\text { site: }\end{array}$} & 15 & 7 & 8 \\
\hline & $\begin{array}{r}\text { ACID } \\
\text { GAS }\end{array}$ & WHB & $\begin{array}{r}\text { TAIL } \\
\text { GAS }\end{array}$ \\
\hline Time: & $12: 41$ & $12: 58$ & $12: 58$ \\
\hline $\begin{array}{r}\mathrm{H}_{2} \\
\mathrm{Ar} \\
\mathrm{O}_{2} \\
\mathrm{~N}_{2} \\
\mathrm{CH}_{4} \\
\mathrm{CO} \\
\mathrm{CO}_{2} \\
\mathrm{C}_{2} \mathrm{H}_{4} \\
\mathrm{C}_{2} \mathrm{H}_{6} \\
\mathrm{H}_{2} \mathrm{~S} \\
\mathrm{COS} \\
\mathrm{C}_{3} \mathrm{H}_{8} \\
\mathrm{SO}_{2} \\
\mathrm{CS}_{2} \\
i \mathrm{C}_{4} \mathrm{H}_{10} \\
\mathrm{nC}_{4} \mathrm{H}_{10} \\
i \mathrm{C}_{5} \mathrm{H}_{12} \\
\mathrm{nC}_{5} \mathrm{H}_{12} \\
\mathrm{C}_{6} \mathrm{H}_{14}+\end{array}$ & $\begin{array}{r}0.000 \\
0.013 \\
0.000 \\
1.110 \\
0.000 \\
0.000 \\
9.101 \\
0.000 \\
0.000 \\
89.454 \\
0.005 \\
0.307 \\
0.010 \\
0.000 \\
0.000 \\
0.000 \\
0.000 \\
0.000 \\
0.000\end{array}$ & $\begin{array}{r}2.924 \\
0.850 \\
0.343 \\
71.080 \\
0.000 \\
0.246 \\
5.845 \\
0.000 \\
0.000 \\
1.7 .942 \\
0.153 \\
0.000 \\
0.235 \\
0.382 \\
0.000 \\
0.000 \\
0.000 \\
0.000 \\
0.000\end{array}$ & $\begin{array}{r}1.728 \\
0.827 \\
0.019 \\
69.116 \\
0.000 \\
0.158 \\
6.020 \\
0.000 \\
0.000 \\
20.810 \\
0.170 \\
0.000 \\
0.943 \\
0.209 \\
0.000 \\
0.000 \\
0.000 \\
0.000 \\
0.000\end{array}$ \\
\hline & 100.000 & $\overline{100.000}$ & $\overline{100.000}$ \\
\hline
\end{tabular}

Zero means not detected.

Sampled water- and sulfur-free.
Global Bulphur Experts Inc.

Tyler, Texas 
TABLE A-2 .

Gas Chromatographic Analyses

(Mole Percent)

Test 2

Consolidated Natural Gas

Feb 25, 1997

Davis, Oklahoma

File Number: 4309

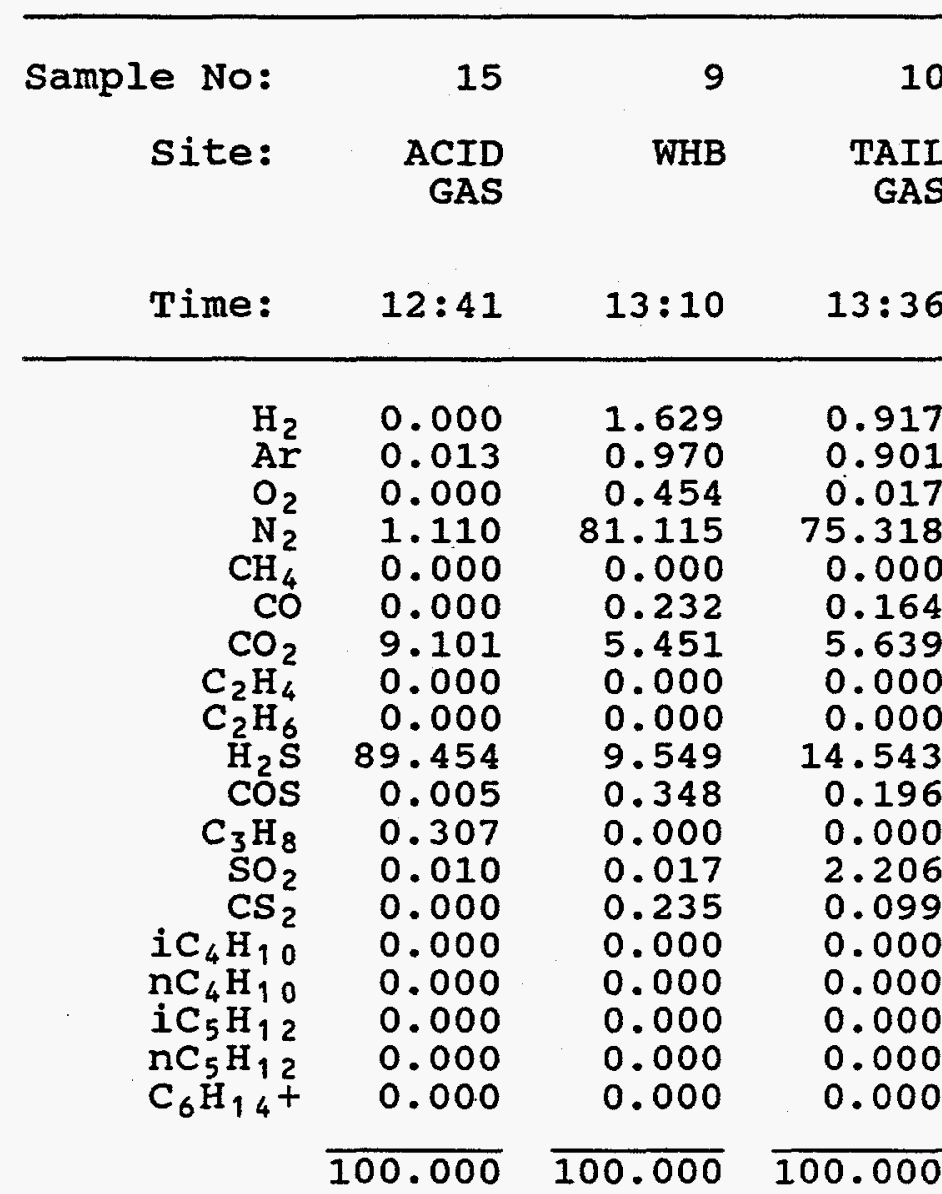

Zero means not detected. 
TABLE A-3

Gas Chromatographic Analyses

(Mole Percent)

Test 3

Consolidated Natural Gias

Feb. 25, 1997

Davis, Oklahoma

File Number: 4309

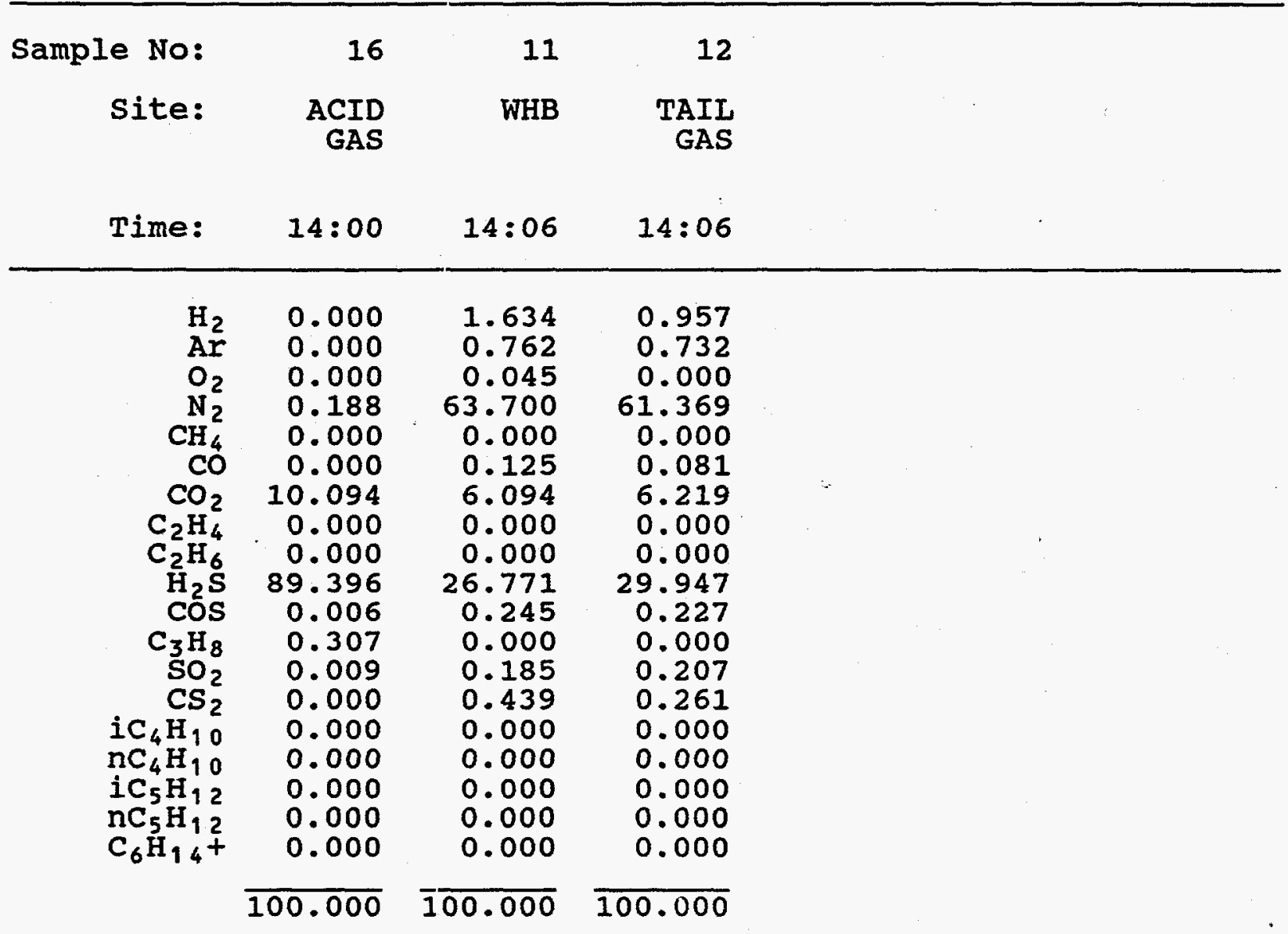

Zero means not detected.

Sampled water- and

sulfur-free.

Global sulphur Experts Inc.

Tyler, Texas 
TABLE A-4.

Gas Chromatographic Analyses

(Mole Percent)

Test 4

Consolidated Natural Gas

Davis, Oklahoma

Feb 25, 1997

File Number: 4309

\begin{tabular}{|c|c|c|c|}
\hline Sample No: & 16 & 13 & 14 \\
\hline Site: & $\begin{array}{r}\text { ACID } \\
\text { GAS }\end{array}$ & WHB & $\begin{array}{r}\text { TAIL } \\
\text { GAS }\end{array}$ \\
\hline Time: & $14: 00$ & $14: 08$ & $14: 08$ \\
\hline $\begin{array}{r}\mathrm{H}_{2} \\
\mathrm{Ar}^{2} \\
\mathrm{O}_{2} \\
\mathrm{~N}_{2} \\
\mathrm{CH}_{4} \\
\mathrm{CO} \\
\mathrm{CO}_{2} \\
\mathrm{C}_{2} \mathrm{H}_{4} \\
\mathrm{C}_{2} \mathrm{H}_{6} \\
\mathrm{H}_{2} \mathrm{~S} \\
\mathrm{COS}^{-} \\
\mathrm{C}_{3} \mathrm{H}_{8} \\
\mathrm{SO}_{2} \\
\mathrm{CS}_{2} \\
\mathrm{iC}_{4} \mathrm{H}_{10} \\
\mathrm{nC}_{4} \mathrm{H}_{10} \\
\mathrm{iC}_{5} \mathrm{H}_{12} \\
\mathrm{nC}_{5} \mathrm{H}_{12} \\
\mathrm{C}_{6} \mathrm{H}_{14}\end{array}$ & $\begin{array}{r}0.000 \\
0.000 \\
0.000 \\
0.188 \\
0.000 \\
0.000 \\
10.094 \\
0.000 \\
0.000 \\
89.396 \\
0.006 \\
0.307 \\
0.009 \\
0.000 \\
0.000 \\
0.000 \\
0.000 \\
0.000 \\
0.000\end{array}$ & $\begin{array}{r}1.699 \\
0.730 \\
0.016 \\
61.019 \\
0.000 \\
0.115 \\
5.847 \\
0.000 \\
0.000 \\
29.169 \\
0.202 \\
0.000 \\
0.732 \\
0.471 \\
0.000 \\
0.000 \\
0.000 \\
0.000 \\
0.000\end{array}$ & $\begin{array}{r}0.901 \\
0.755 \\
0.030 \\
63.087 \\
0.000 \\
0.086 \\
6.308 \\
0.000 \\
0.000 \\
27.730 \\
0.226 \\
0.000 \\
0.626 \\
0.251 \\
0.000 \\
0.000 \\
0.000 \\
0.000 \\
0.000\end{array}$ \\
\hline & $\overline{100.000}$ & $\overline{100.000}$ & $\overline{100.000}$ \\
\hline
\end{tabular}

zero means not detected. 
TABLE A-5

Gas Chromatographic Analyses

(Mole Percent)

Fuel Gas Runs

Consolidated Natural Gas

Davis, Oklahoma

Feb 23, 1997

File Number: 4309

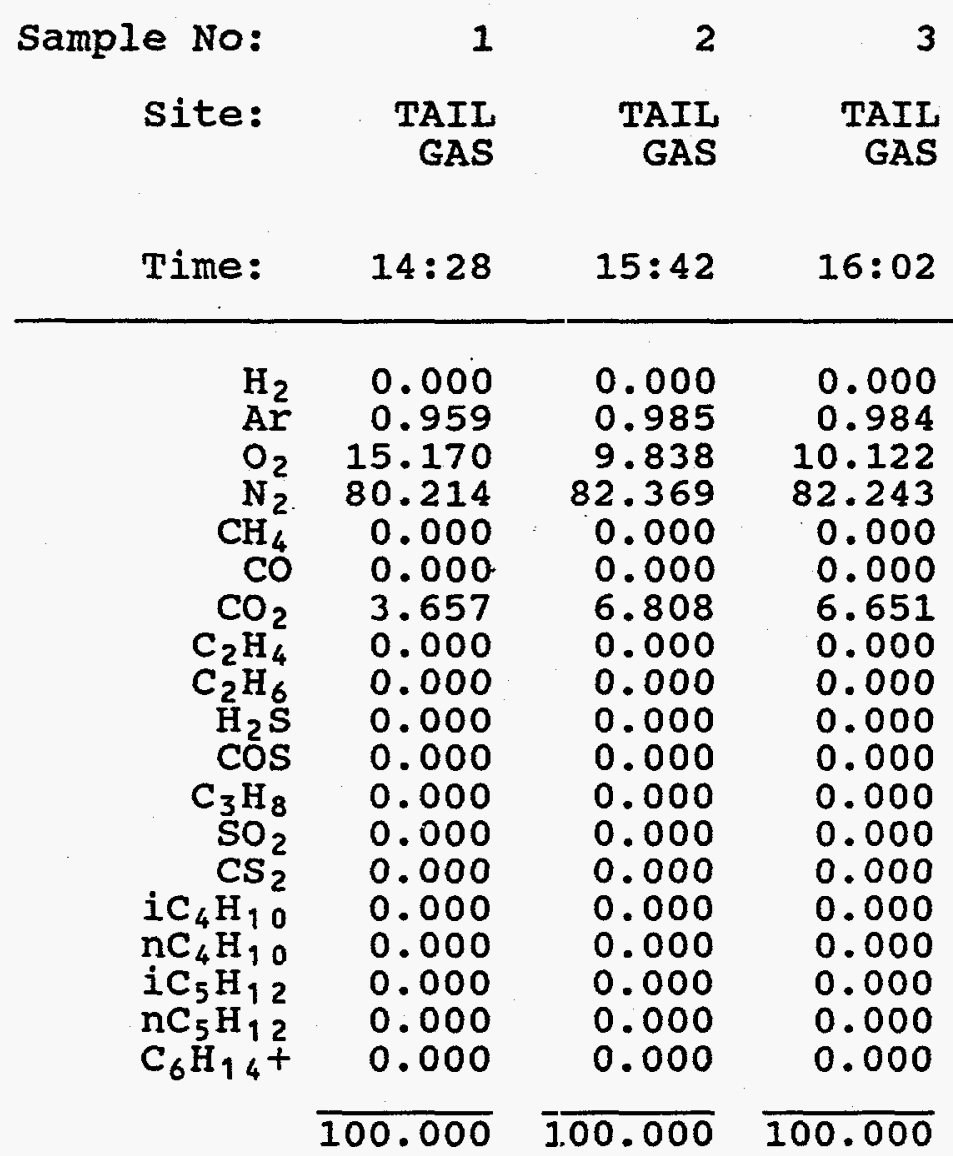

Zero means not detected.

Sampled water- and sulfur-free.
Global Sulphur Experts Inc.

Tyler, Texas 
TABLE A-6.

Gas Chromatographic Analyses

(Mole Percent)

Acid Gas Flow Test

Consolidated Natural Gas

Feb 24, 1997

Davis, Oklahoma

File Number: 4309

\begin{tabular}{|c|c|c|c|}
\hline \multirow{2}{*}{$\begin{array}{r}\text { Sample No: } \\
\text { Site: }\end{array}$} & 4 & 5 & 6 \\
\hline & $\begin{array}{r}\text { ACID } \\
\text { GAS }\end{array}$ & $\begin{array}{r}\text { ACID } \\
\text { GAS }\end{array}$ & $\begin{array}{r}\text { TAIL } \\
\text { GAS }\end{array}$ \\
\hline Time: & $15: 41$ & $16: 02$ & $16: 35$ \\
\hline $\begin{array}{r}\mathrm{H}_{2} \\
\mathrm{Ar}^{2} \\
\mathrm{O}_{2} \\
\mathrm{~N}_{2} \\
\mathrm{CH}_{4} \\
\mathrm{CO}^{2} \\
\mathrm{CO}_{2} \\
\mathrm{C}_{2} \mathrm{H}_{4} \\
\mathrm{C}_{2} \mathrm{H}_{6} \\
\mathrm{H}_{2} \mathrm{~S} \\
\mathrm{COS}^{-} \\
\mathrm{C}_{3} \mathrm{H}_{8} \\
\mathrm{SO}_{2} \\
\mathrm{CS}_{2} \\
\mathrm{iC}_{4} \mathrm{H}_{10} \\
\mathrm{nC}_{4} \mathrm{H}_{10} \\
\mathrm{iC}_{5} \mathrm{H}_{12} \\
\mathrm{nC}_{5} \mathrm{H}_{12} \\
\mathrm{C}_{6} \mathrm{H}_{14}\end{array}$ & $\begin{array}{r}0.000 \\
0.000 \\
0.000 \\
0.000 \\
0.000 \\
0.000 \\
66.500 \\
0.000 \\
0.000 \\
33.389 \\
0.002 \\
0.109 \\
0.000 \\
0.000 \\
0.000 \\
0.000 \\
0.000 \\
0.000 \\
0.000\end{array}$ & $\begin{array}{r}0.000 \\
0.000 \\
0.000 \\
0.020 \\
0.000 \\
0.000 \\
75.454 \\
0.000 \\
0.000 \\
24.440 \\
0.001 \\
0.085 \\
0.000 \\
0.000 \\
0.000 \\
0.000 \\
0.000 \\
0.000 \\
0.000\end{array}$ & $\begin{array}{r}0.184 \\
0.992 \\
7.812 \\
82.946 \\
0.000 \\
0.045 \\
5.603 \\
0.000 \\
0.000 \\
0.414 \\
0.011 \\
0.000 \\
1.991 \\
0.002 \\
0.000 \\
0.000 \\
0.000 \\
0.000 \\
0.000\end{array}$ \\
\hline & 100.000 & $\overline{100.000}$ & $\overline{100.000}$ \\
\hline
\end{tabular}

Zero means not detected. 
TABLE A-7 .

Gas (hromatographic Analyses

(Mole Percent)

lJtility Gas Analysis

Consolidated Natural Gas

Feb 26, 1997

Davis, Oklahoma

File Number: 4309

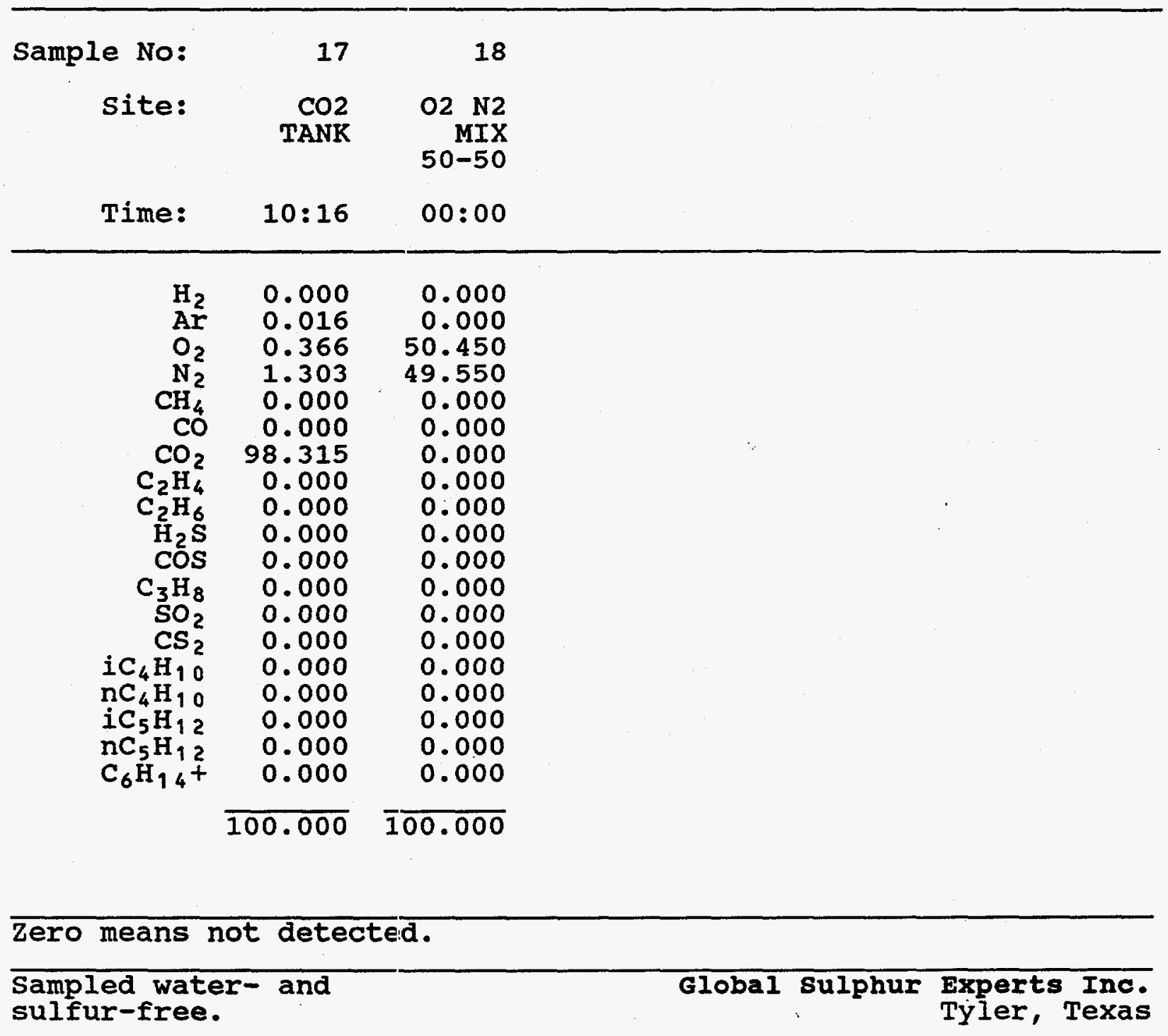


I

I

I

I

I

1

I

I

1

I

I

I

I

I

I

I

I 
Appendix B-1

Material Balance Calculations

Test Run Results 


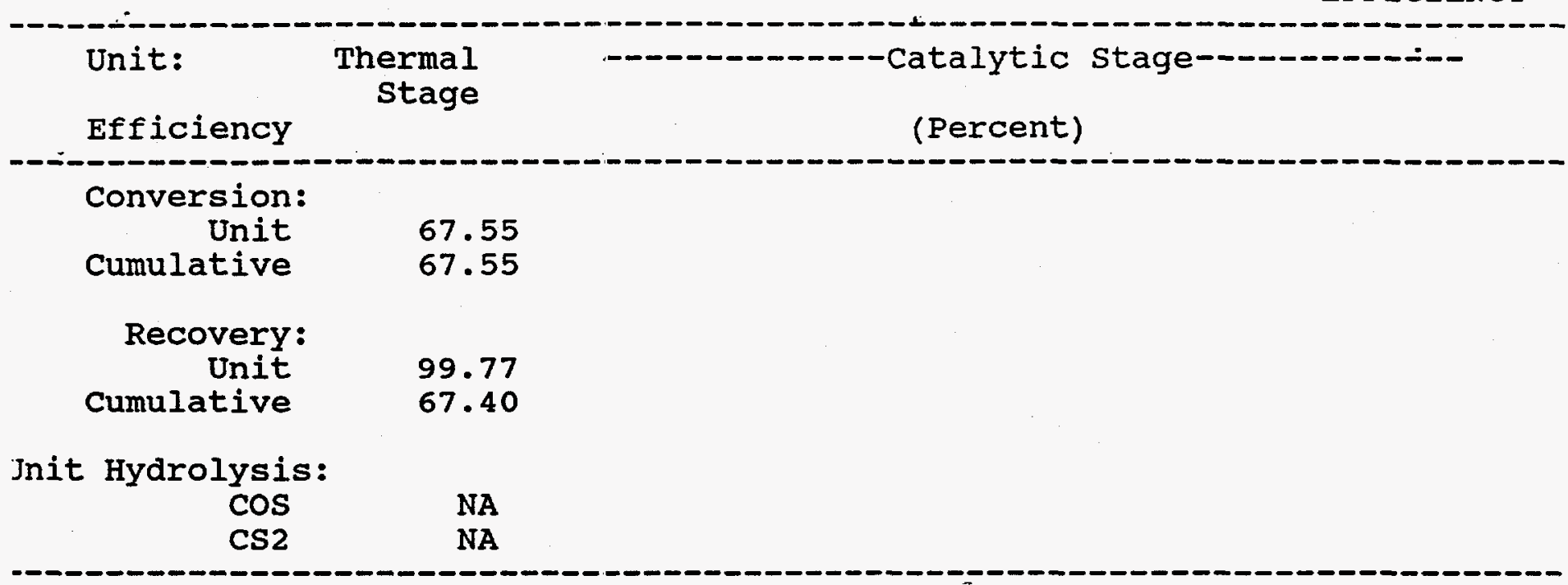

Jverall Recovery Efficiency . . . . . . . . . . . . . . . 67.40

$\begin{gathered}\text { Thermal } \\ \text { Stage } \\ \text { Production }\end{gathered}$
$\begin{gathered}\text { Conversion: } \\ \text { Unit }\end{gathered}$
$\begin{gathered}\text { Cumulative } \\ \text { Recovery: } \\ \text { Unit }\end{gathered}$
$\begin{gathered}11.30 \\ \text { Cumulative }\end{gathered}$
11.27

lotal Inlet Sulphur . . . . . . . . . . . . . . . . . . 16.72 
O/L Known Reaction Furnace

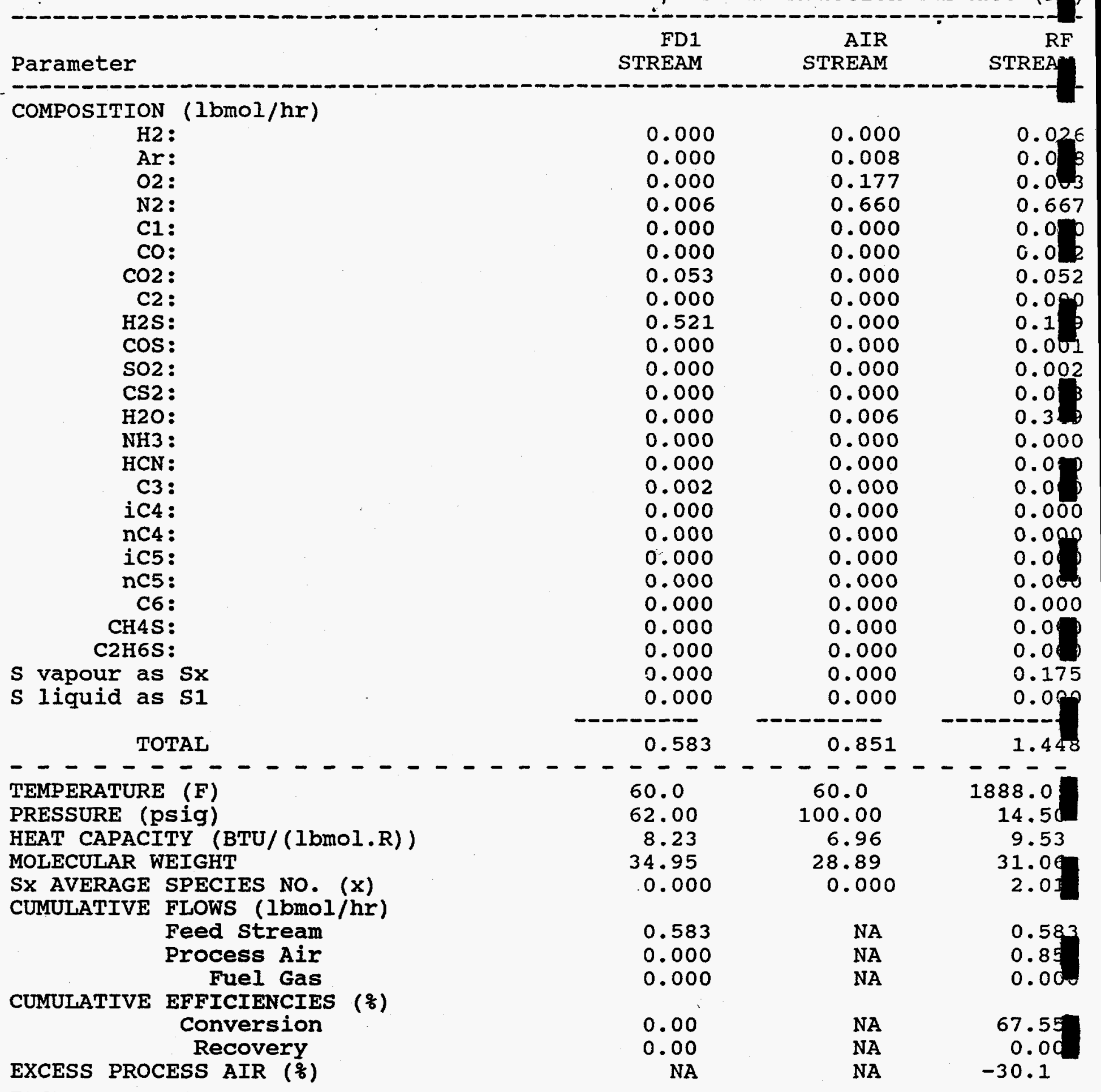

Cumulative Sulphur Conversion as $\mathrm{Sl}$ (Ibmol/hr) 


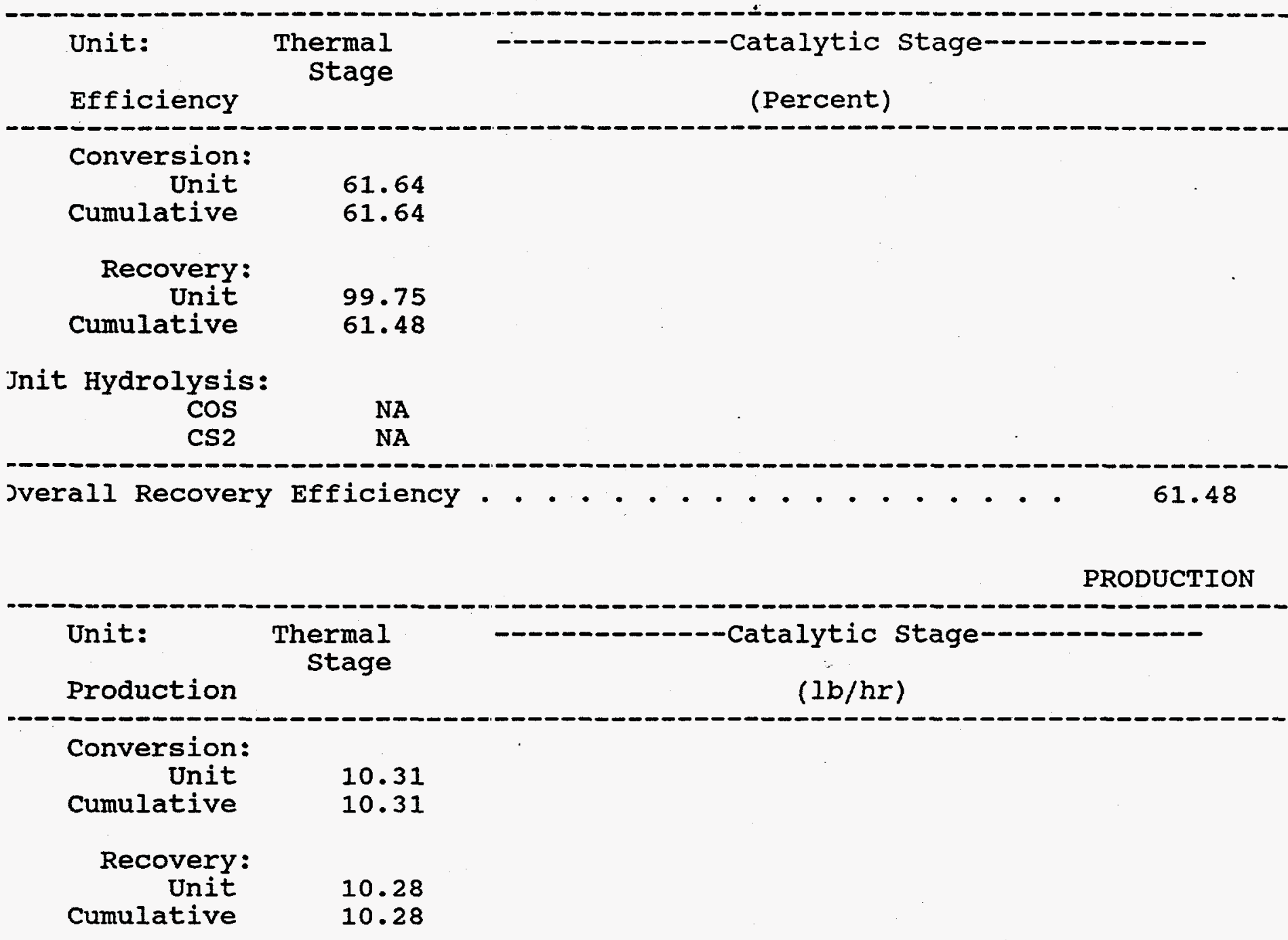

cotal Inlet sulphur . . . . . . . . . . . . . . . . . 16.72 
Q/I known Reaction Furnace (RF

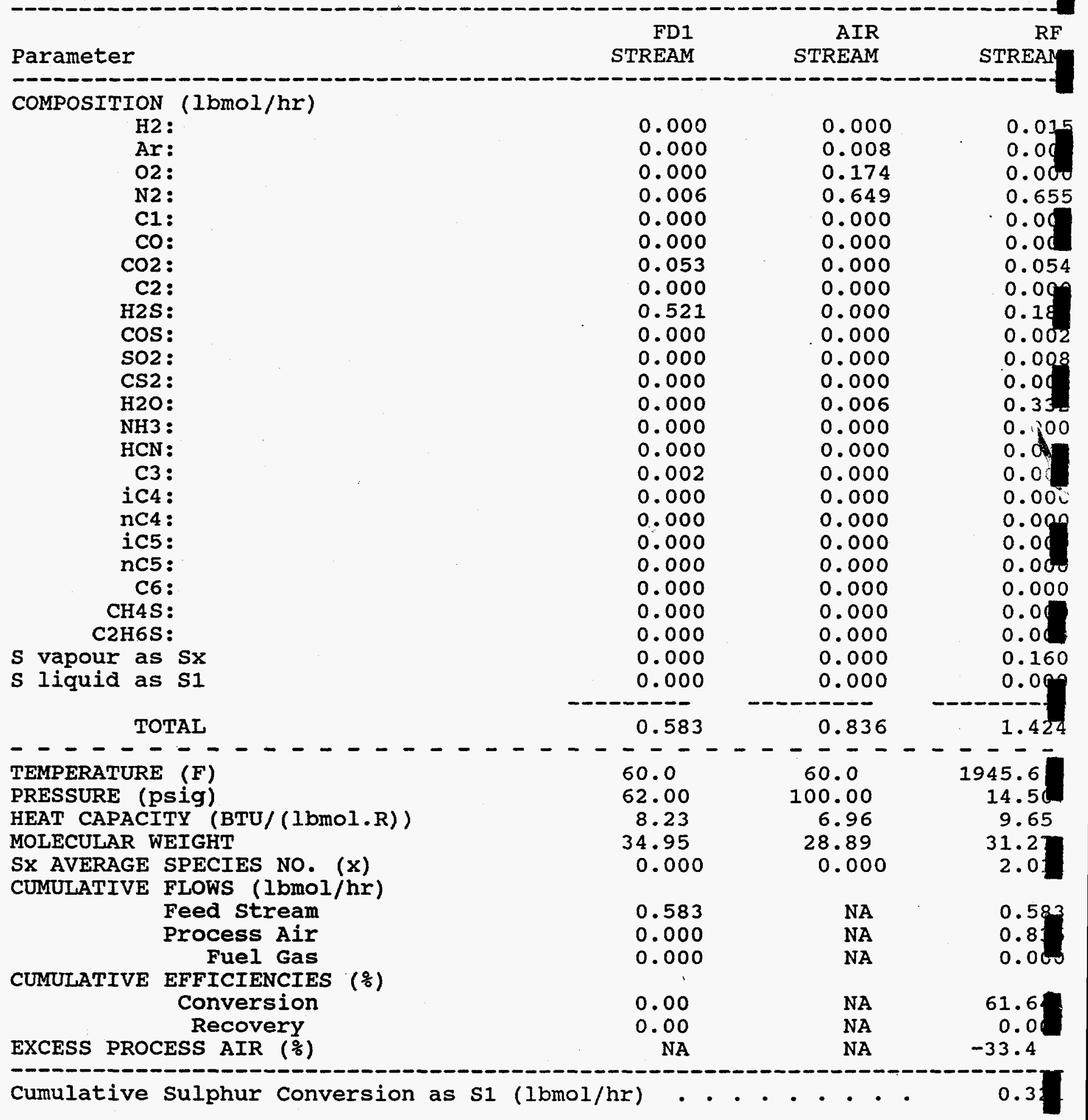


Unit:

Efficiency

Conversion:

Unit
Cumulative

Unit
Cumulative

Thermal

stage
Catalytic

(Percent)

79.47

Recovery:

Unit

Cumulative

79.47

99.76

79.27

Unit Hydrolysis:

$\begin{array}{ll}\cos & \text { NA } \\ \text { Cs2 } & \text { NA }\end{array}$

Jverall Recovery Efficiency

79.27

PRODUCTION

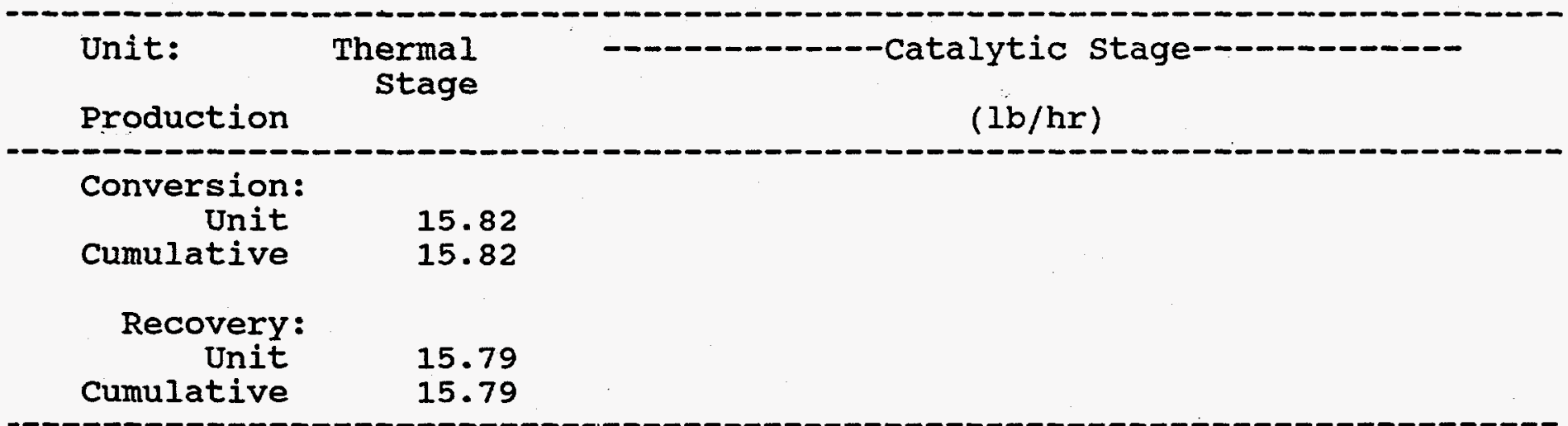

rotal Inlet Sulphur . 
O/L Known Reaction Furnace (RH

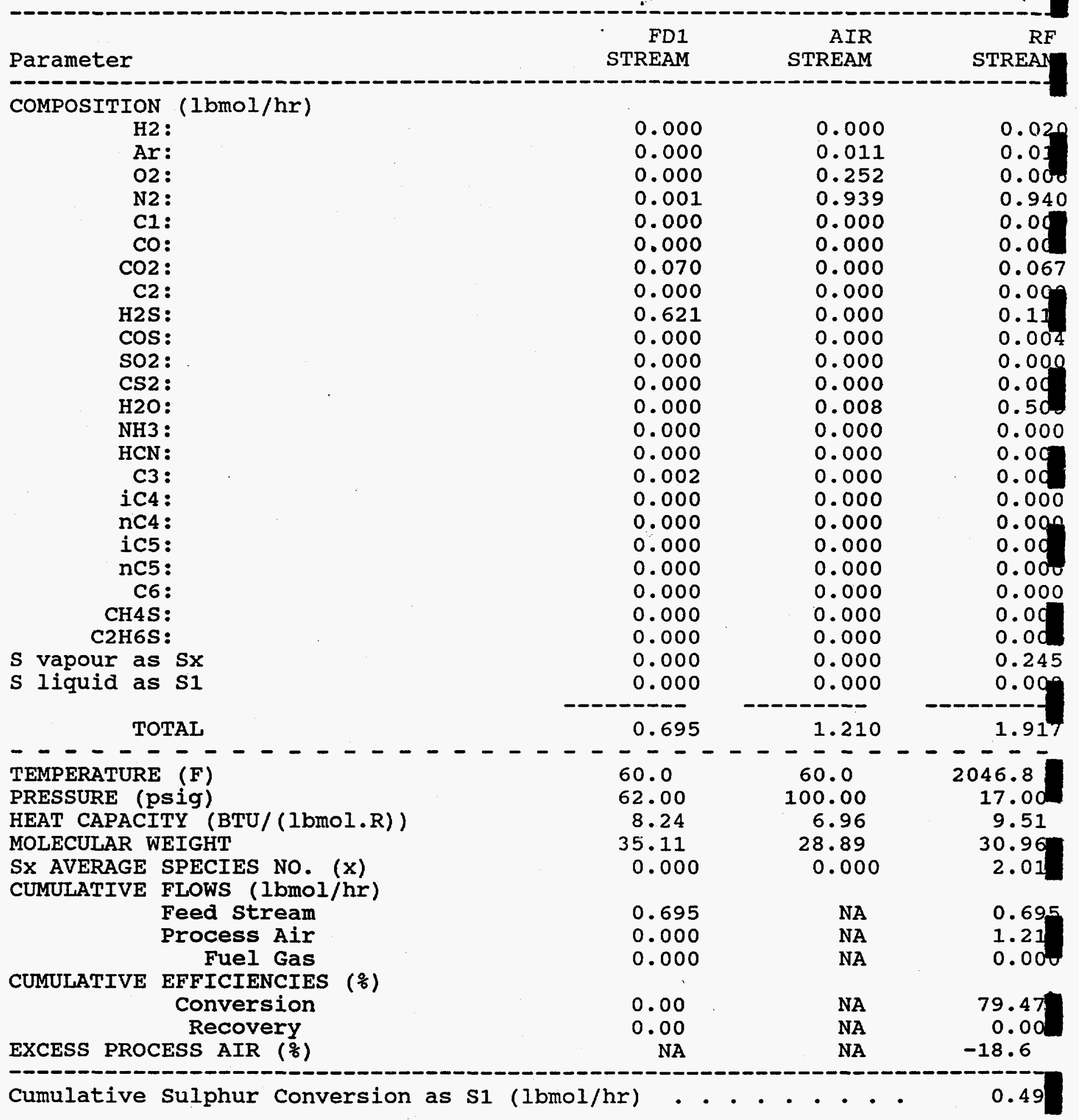




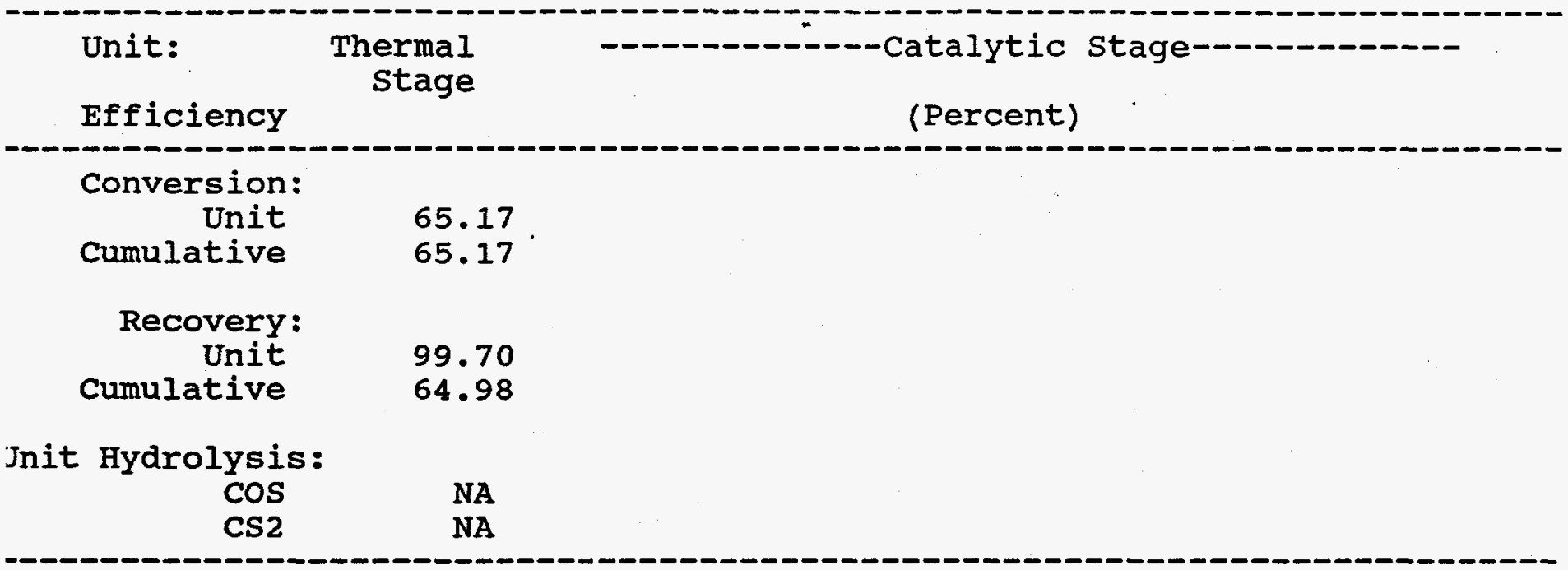

Jverall Recovery Efficiency

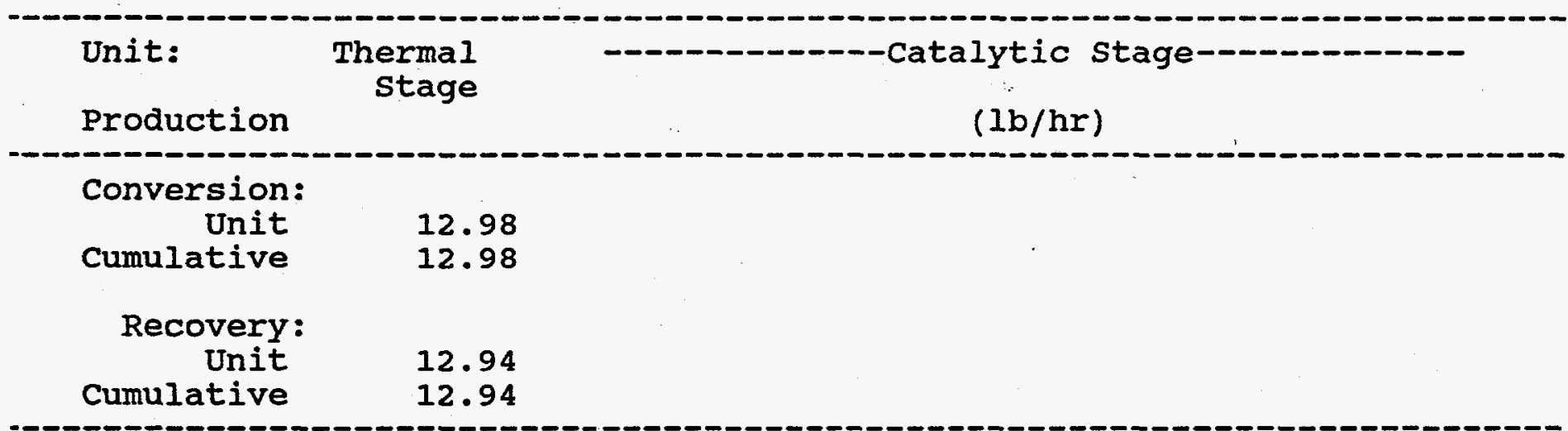

Cotal Inlet Sulphur . . . . . . . . . . . . . . . . . . 19.91 
O/L known Reaction Furnace ( $R$

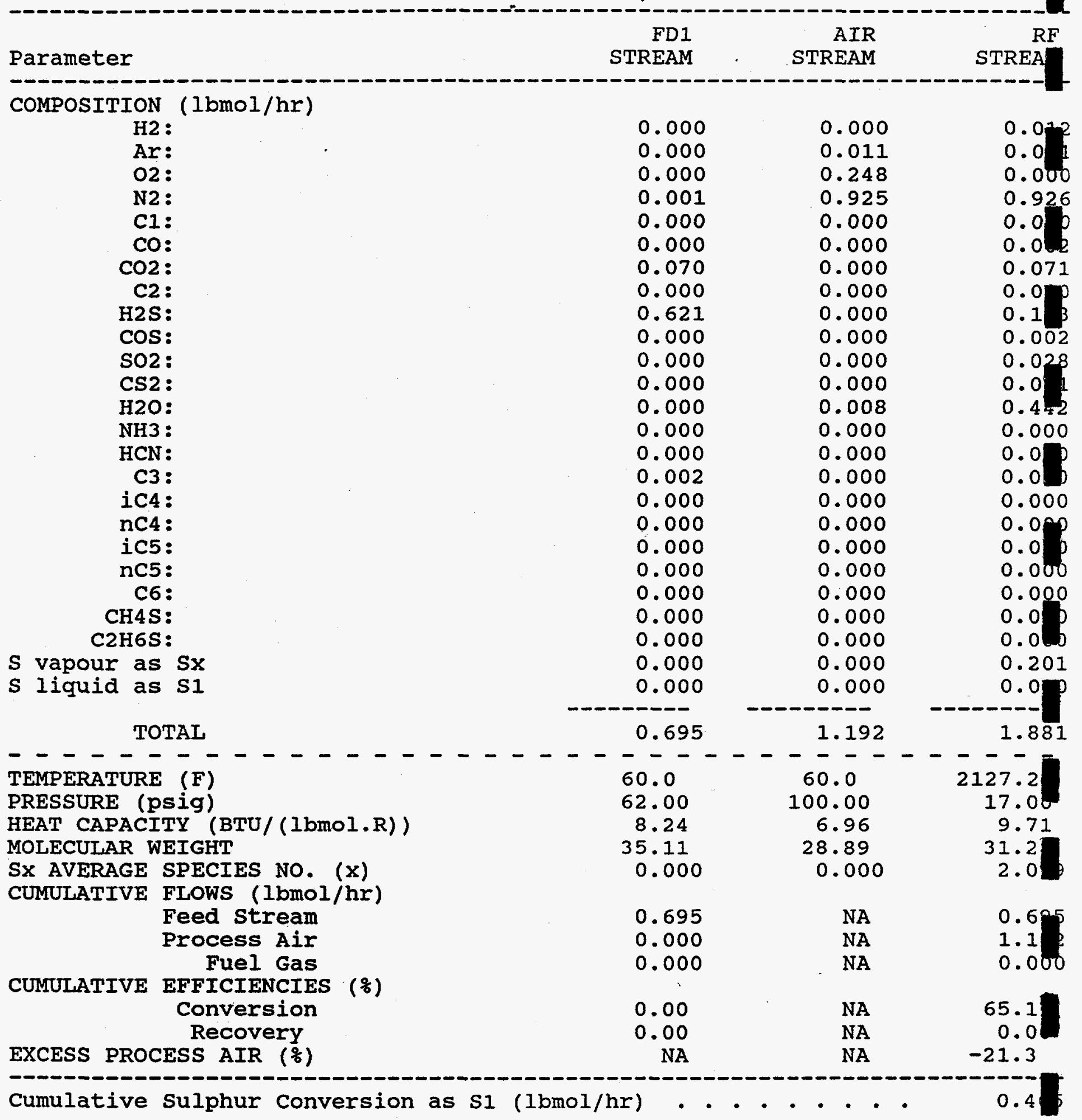


ULSIM CASE: CNG01-11

NG - Test 3; Sample RF11

SULPHUR PLANT PERFORMANCE

EFFICIENCY

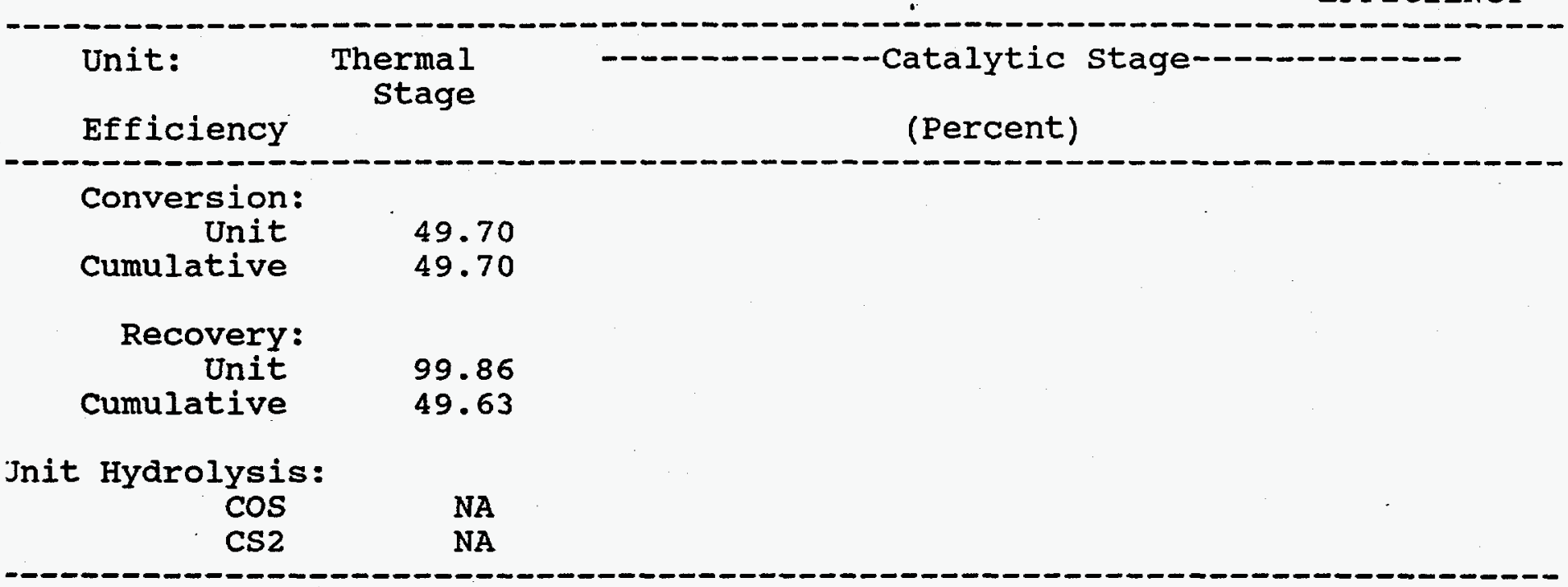

Jverall Recovery Efficiency . . . . . . . . . . . . . . . 49.63

PRODUCTION

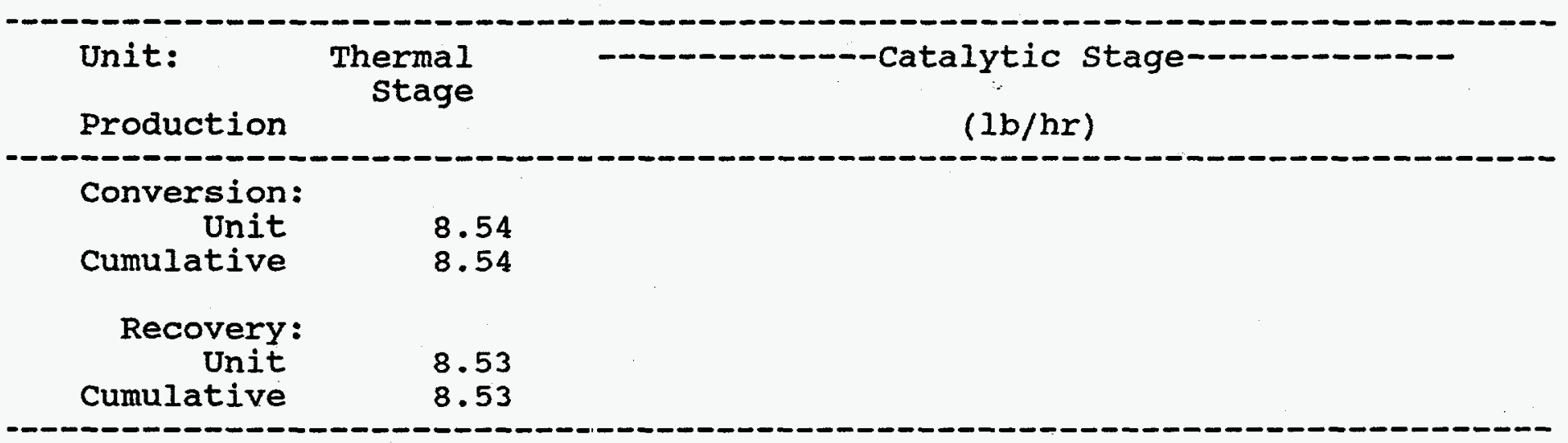

Cotal Inlet Sulphur . . . . . . . . . . . . . . . . . . 17.19 
O/L Known Reaction Furnace (R

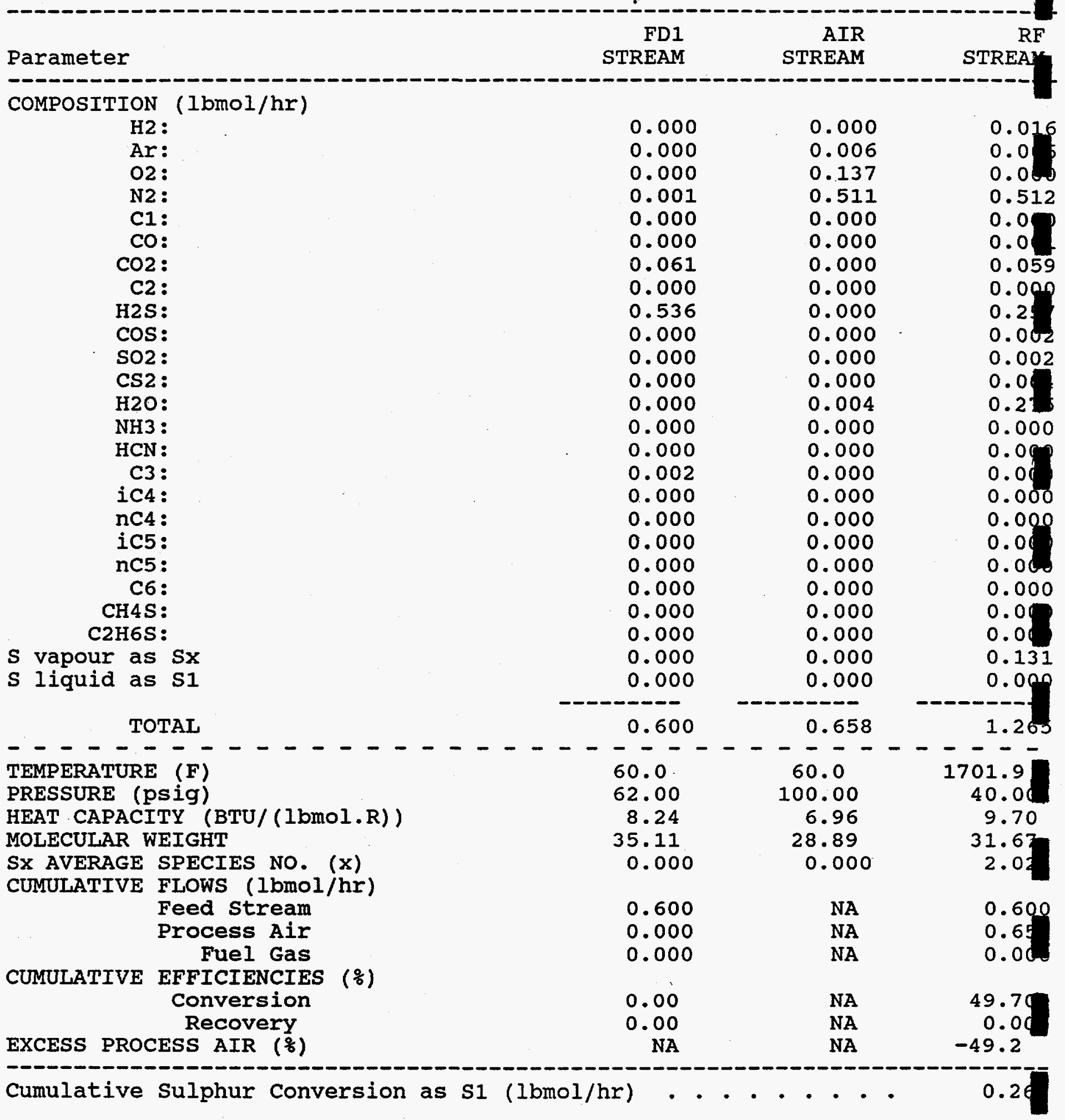


ULSIM CASE: CNG01-12

NG - Test 3; Sample TG12
$98 / 01 / 19$

SUIJPHUR PLANT PERFORMANCE

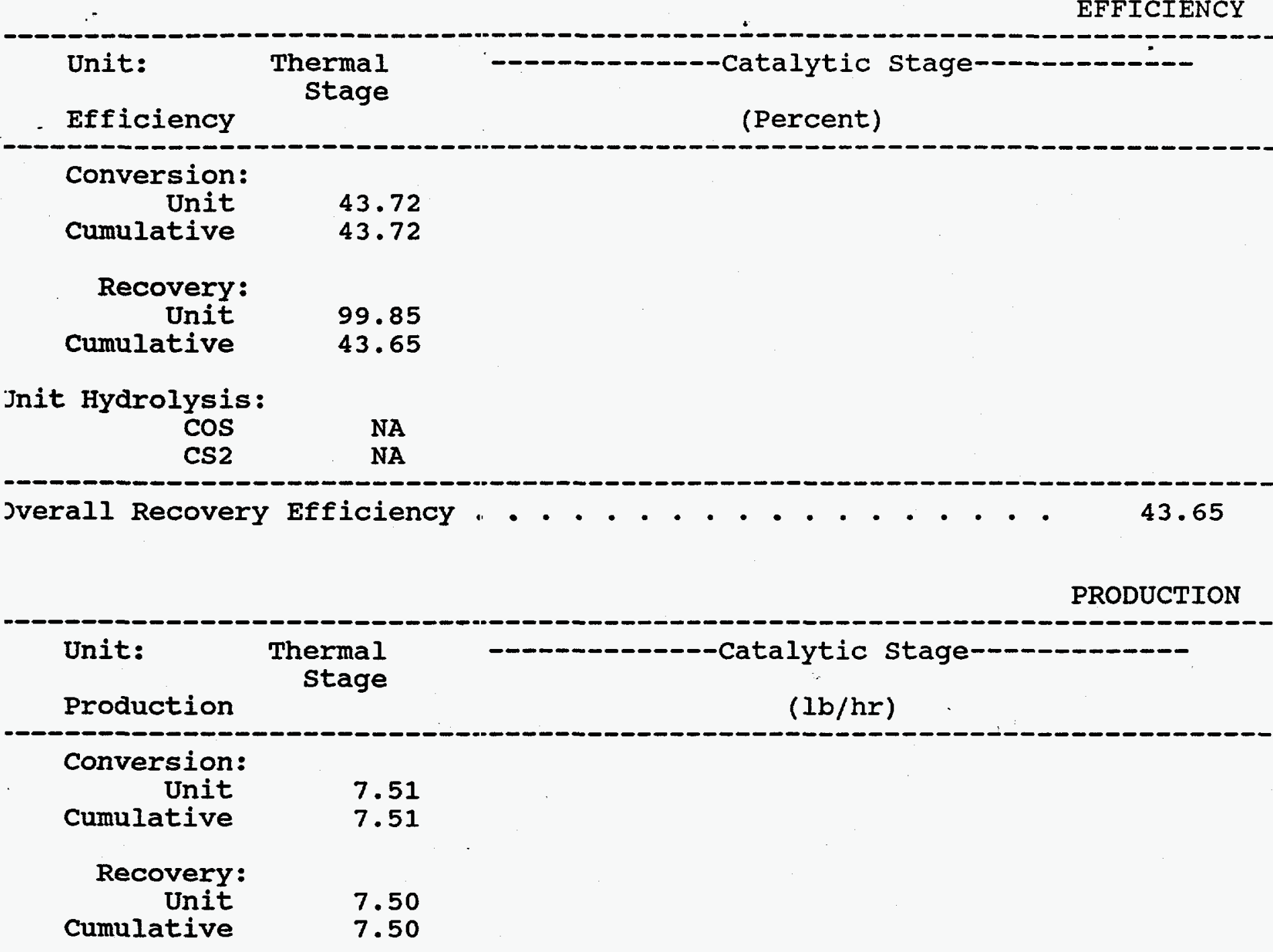

Cotal Inlet sulphur . . . . . . . . . . . . . . . . . . . 17.19 
O/L known Reaction Furnace (

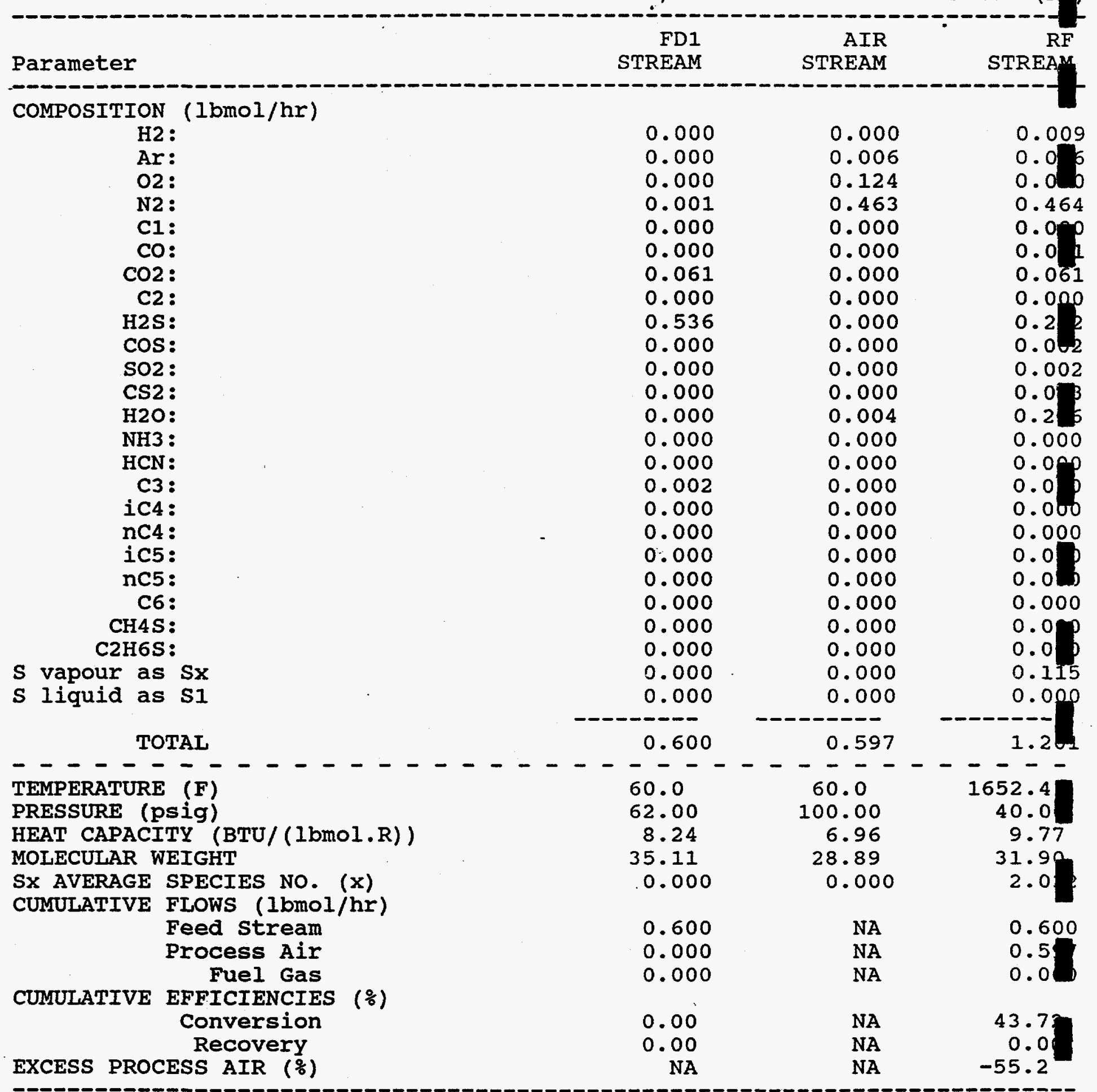


JLSIM CASE: CNG01-13

JG - Test 4; Sample RF13
$98 / 01 / 19$

SUL]?HUR PLANT PERFORMANCE

EFFICIENCY

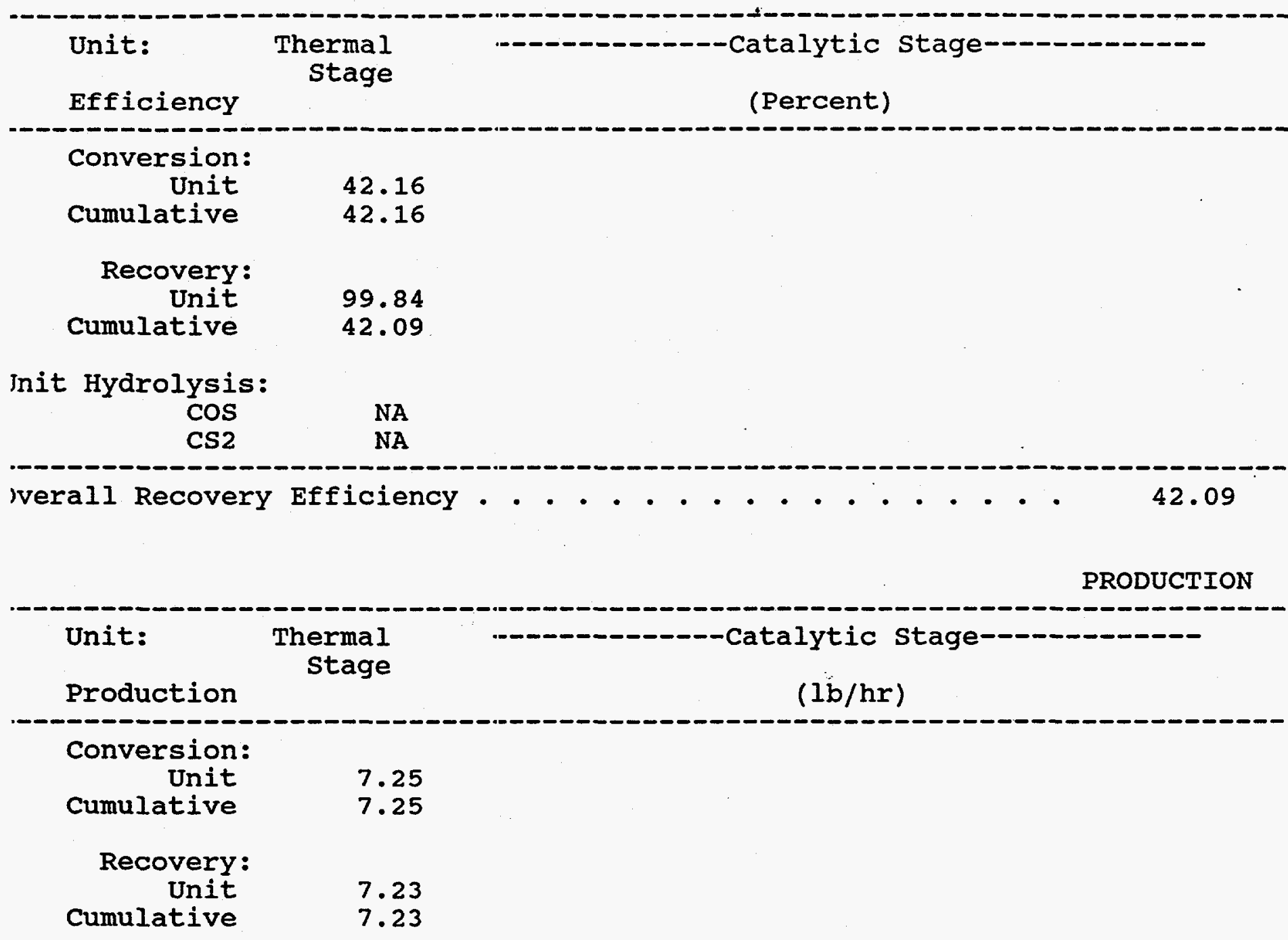

Inlet sulphur

'otal Inlet sulphur 
O/L Known Reaction Furnace

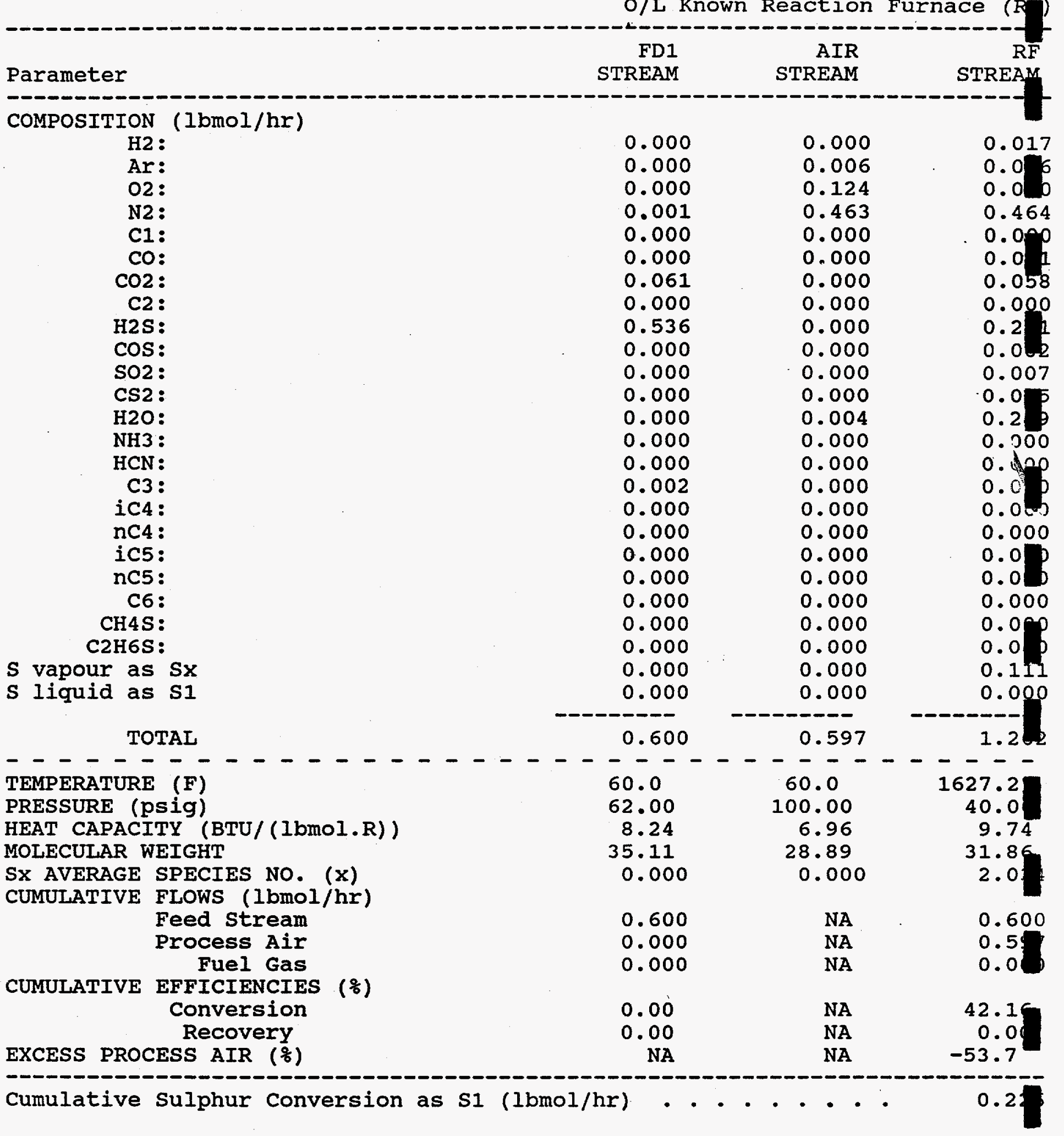


ULSIM CASE: CNG01-14

NG - Test 4; Sample TG14
$98 / 01 / 19$

\section{SULPHUR PLANT PERFORMANCE}

EFFICIENCY

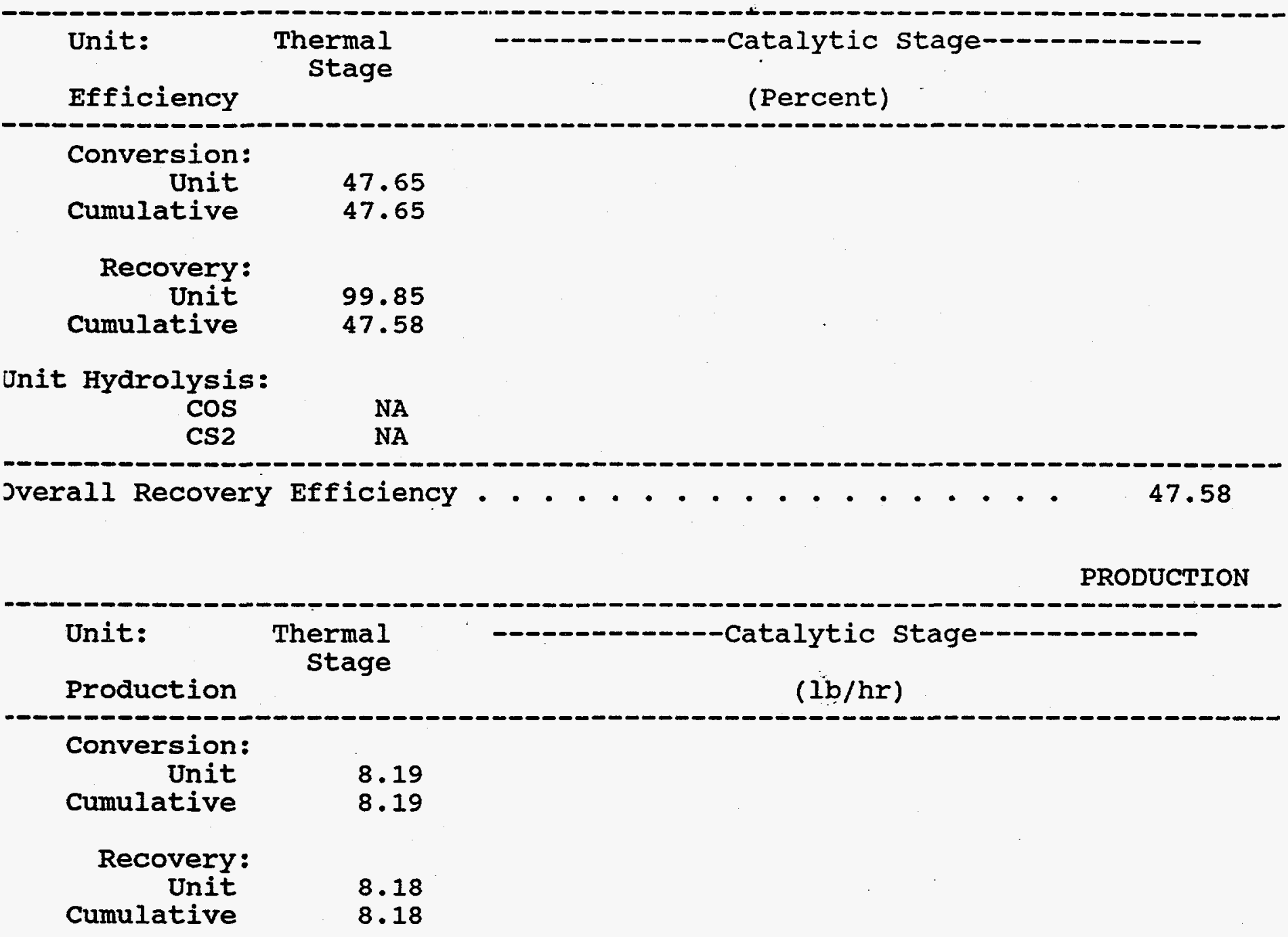

Cotal Inlet sulphur.

17.19 
O/L Known Reaction Furnace ( $R$

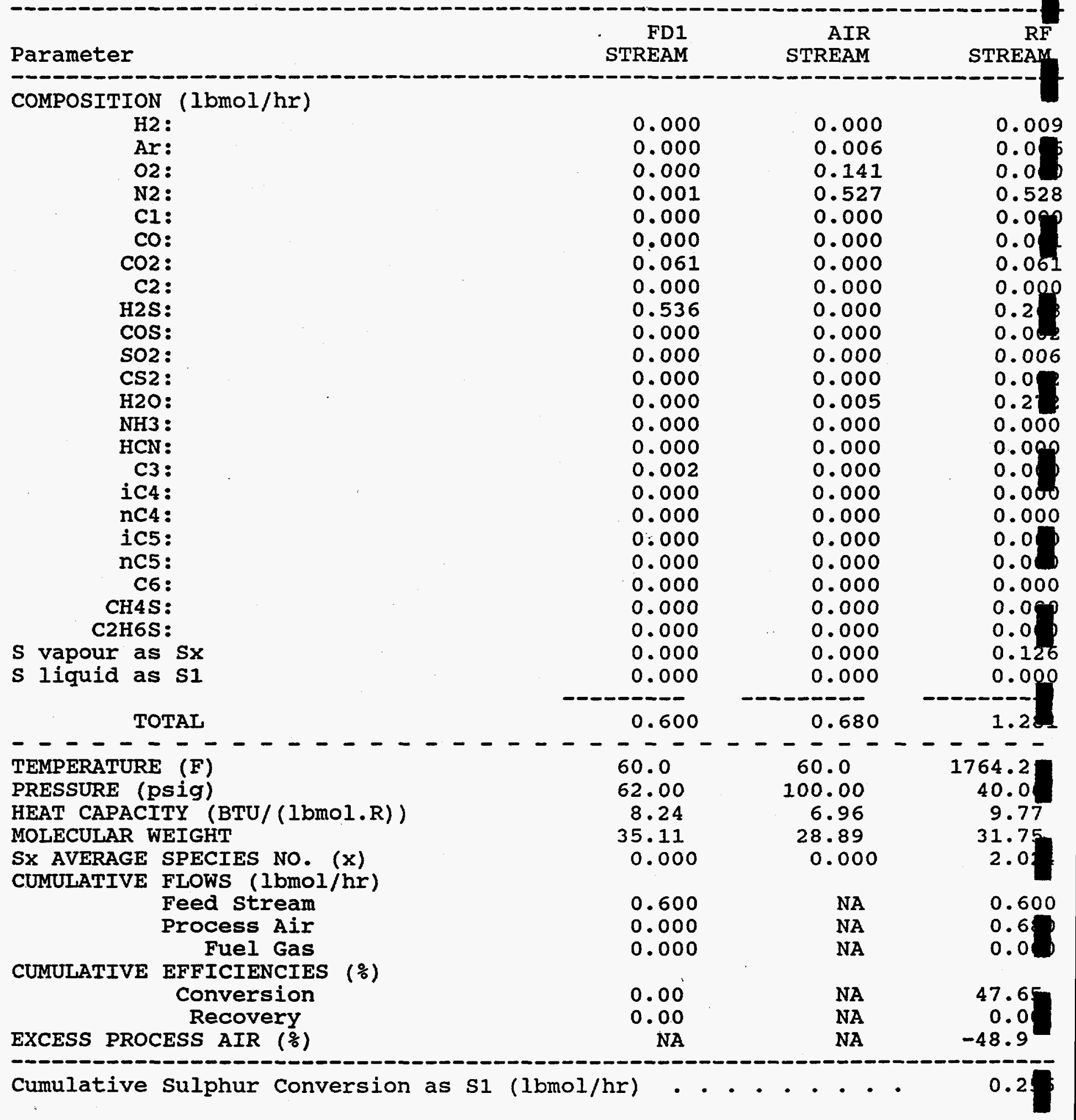


Appendix B-2

Material Balance Calculations

Thermodynamic Equilibrium Results 


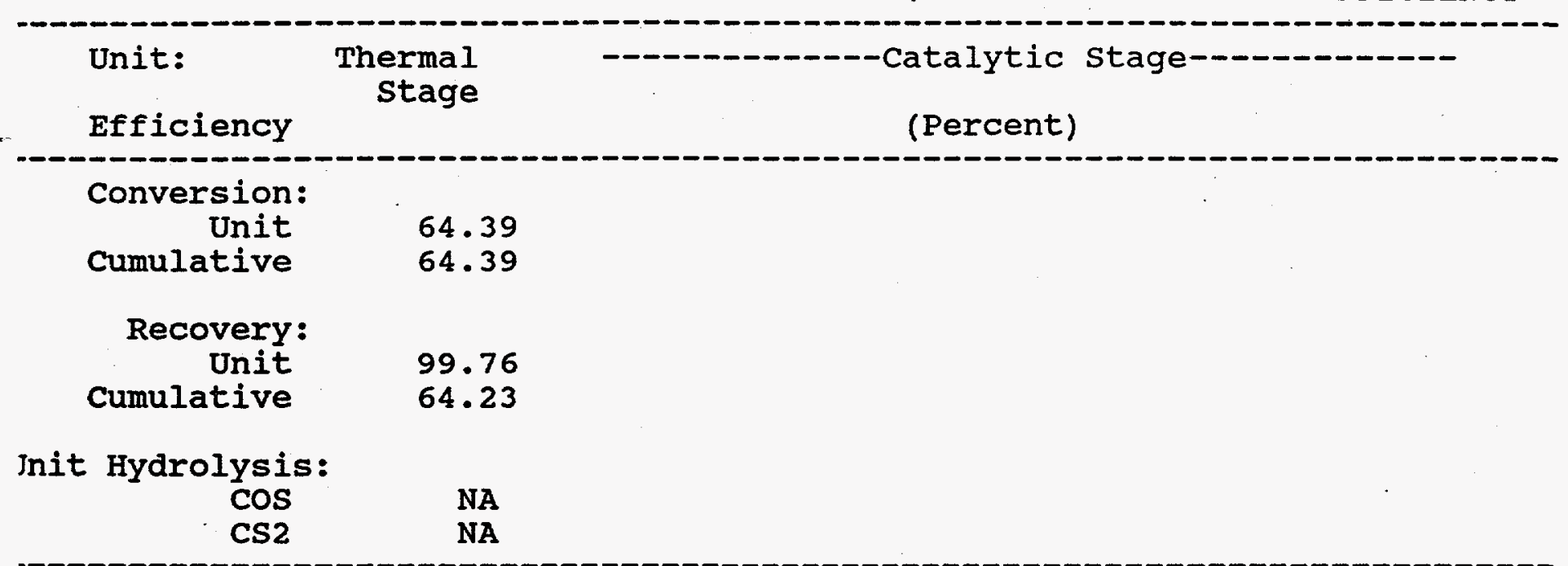

verall Recovery Efficiency.

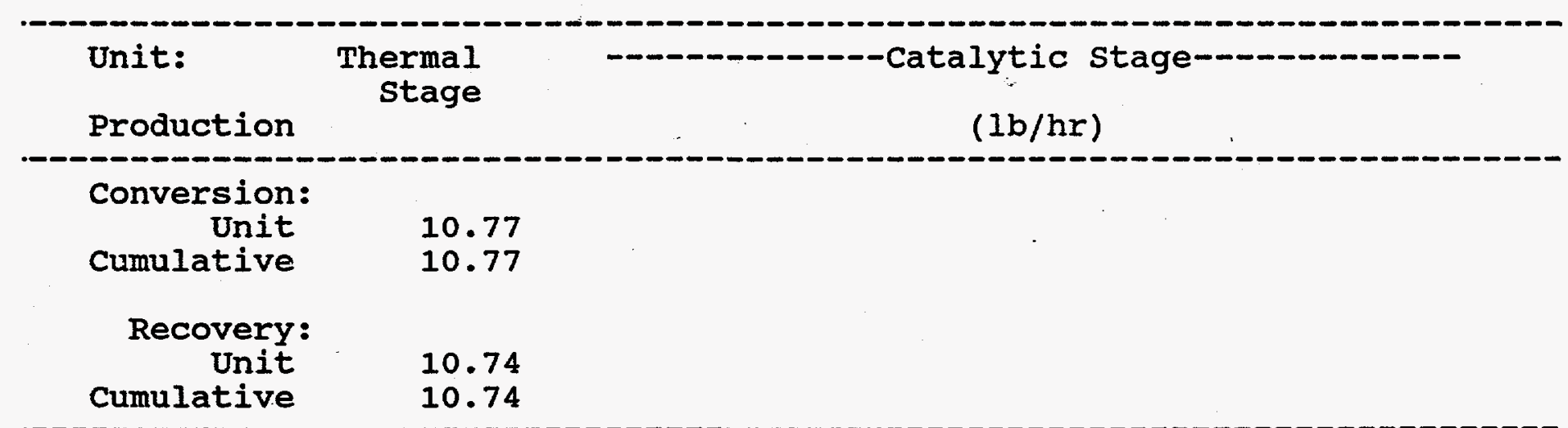

lotal Inlet Sulphur . . . . . . . . . . . . . . . . . . 16.72 
Thermodynamic Reaction Furnace (R

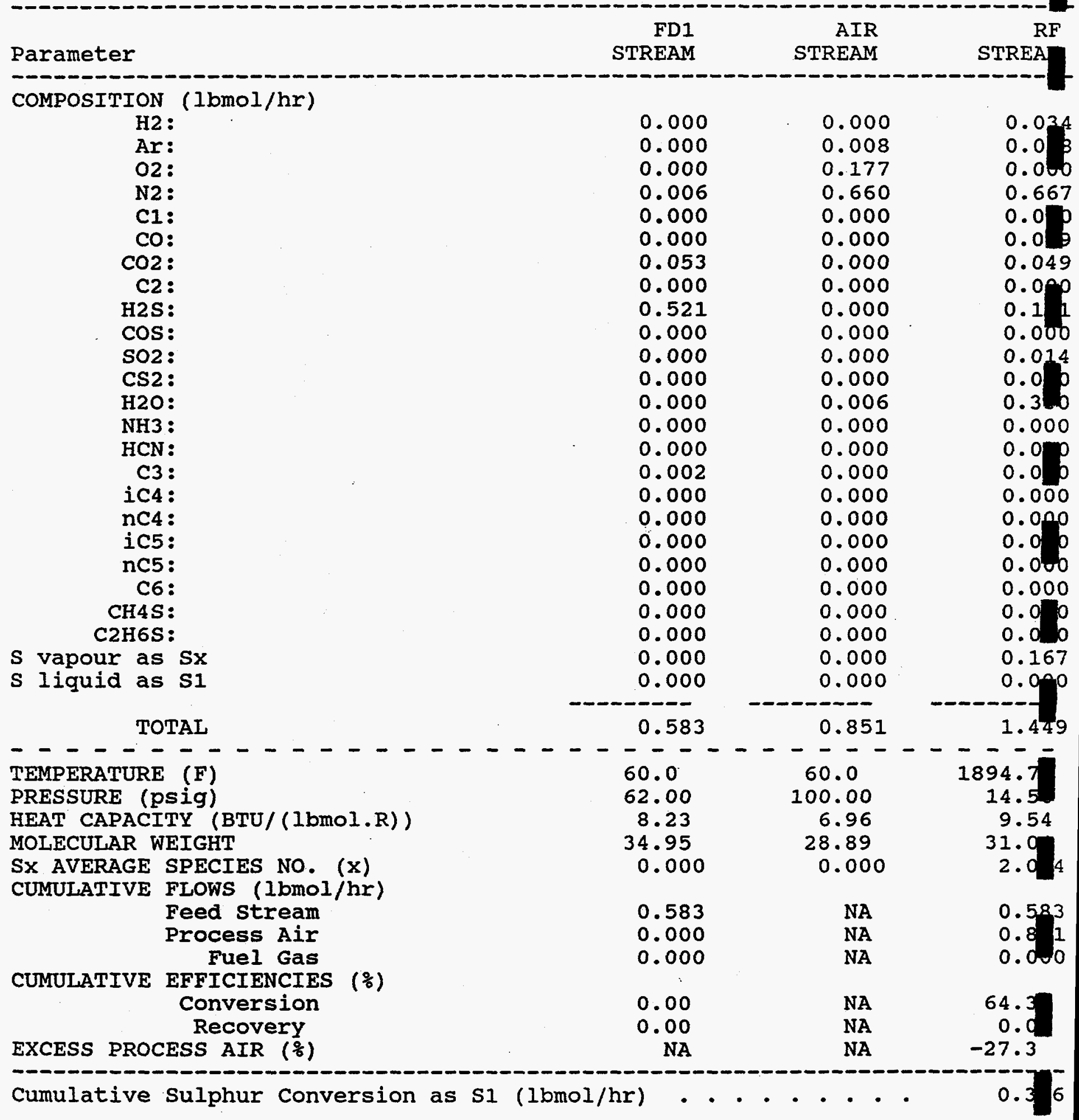


JLSIM CASE: CNG0109S

JG - Test 2; Thermodynamic Model

SULPHUR PLANT PERFORMANCE

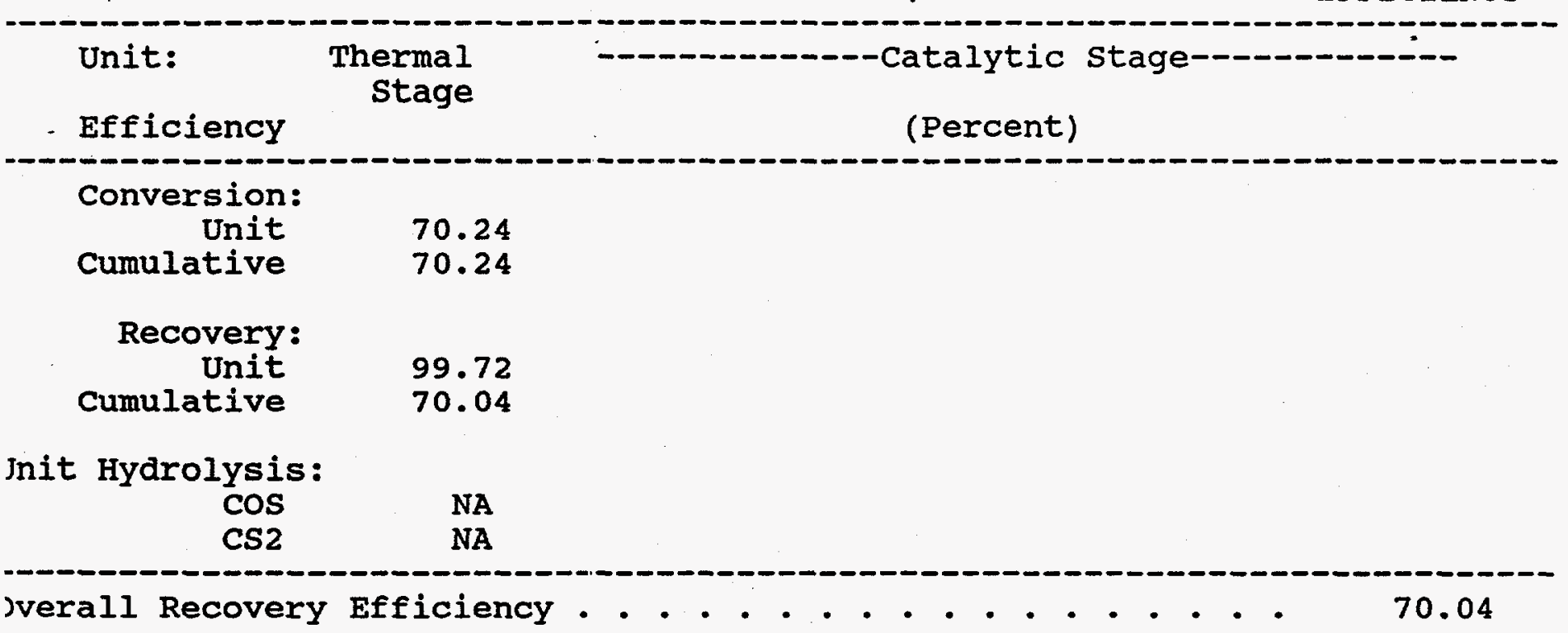

PRODUCTION

Thit:
Stage
Production
$\begin{gathered}\text { Conversion: } \\ \text { Unit }\end{gathered}$
$\begin{gathered}\text { Cumulative } \\ \text { Recovery: } \\ \text { Unit }\end{gathered}$
$\begin{gathered}13.99 \\ \text { Cumulative }\end{gathered}$
13.95

Cotal Inlet Sulphur . . . . . . . . . . . . . . . . . . 19.91 
Thermodynamic Reaction Furnace (R

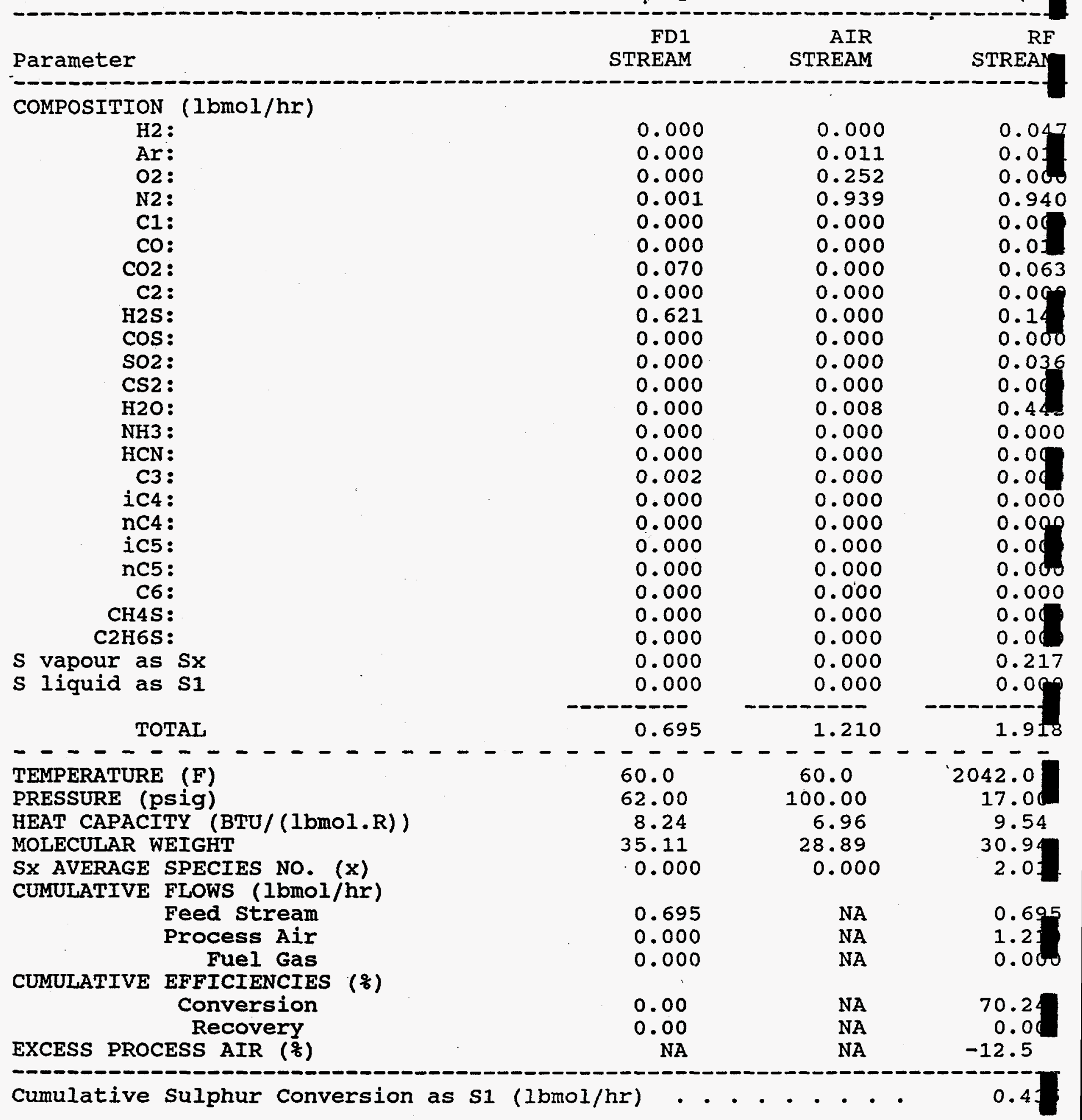




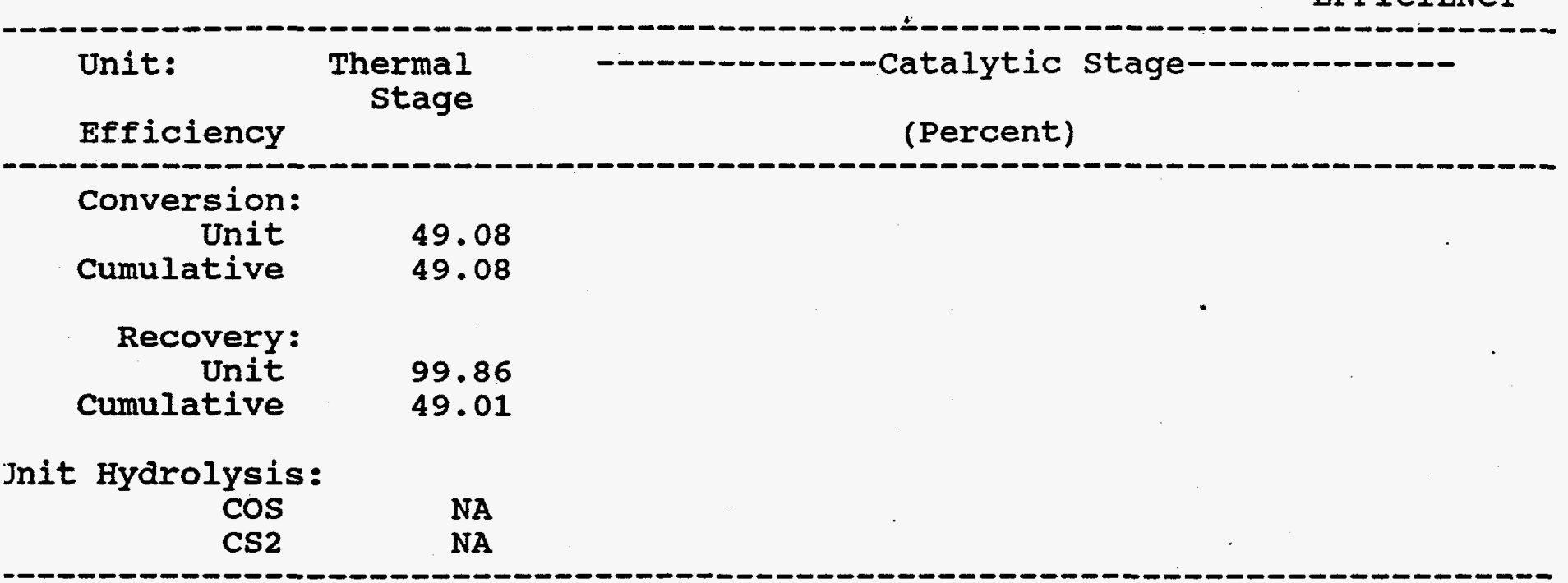

Jverall Recovery Efficiency

49.01

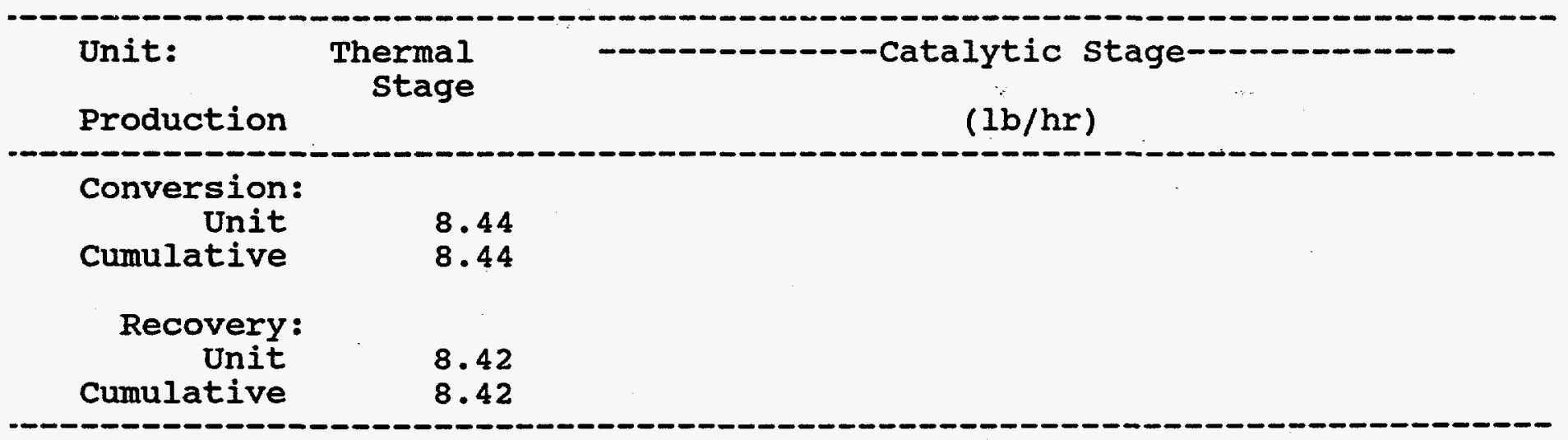

Sotal Inlet sulphur . . . . . . . . . . . . . . . . . 17.19 
Thermodynamic Reaction Furnace ( $R$

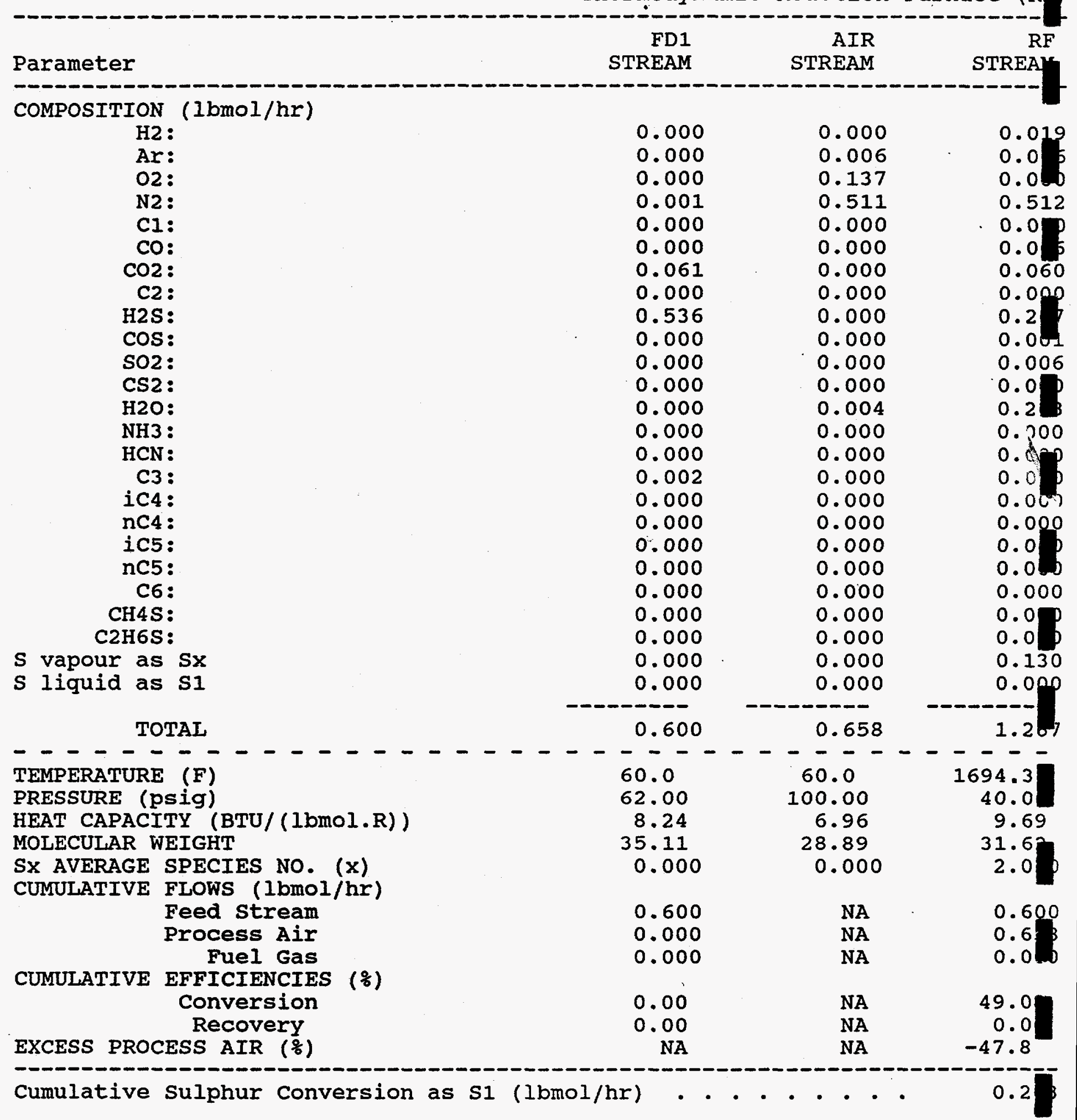




\section{Performance Summary}

CNGi-13S: Train1

CNG - Test 4; Thermodynamic Model

Thermal catalytic stage

EFFICIENCY (\%)

Conversion: Unit

Cumulative

44.41

44.41

Recovery:

Unit

Cumulative

Unit Hydrolysis:

$\cos \quad \mathrm{NA}$

CS2

NA

Overall Recovery Efficiency . . . . . . . . . . . . .

\section{PRODUCTION (LTD)}

Conversion:

Unit $\quad 0.08$

Cumulative

0.08

Recovery:

Unit

Cumulative

Total Inlet sulphur . . . . . . . . . . . 0.18 


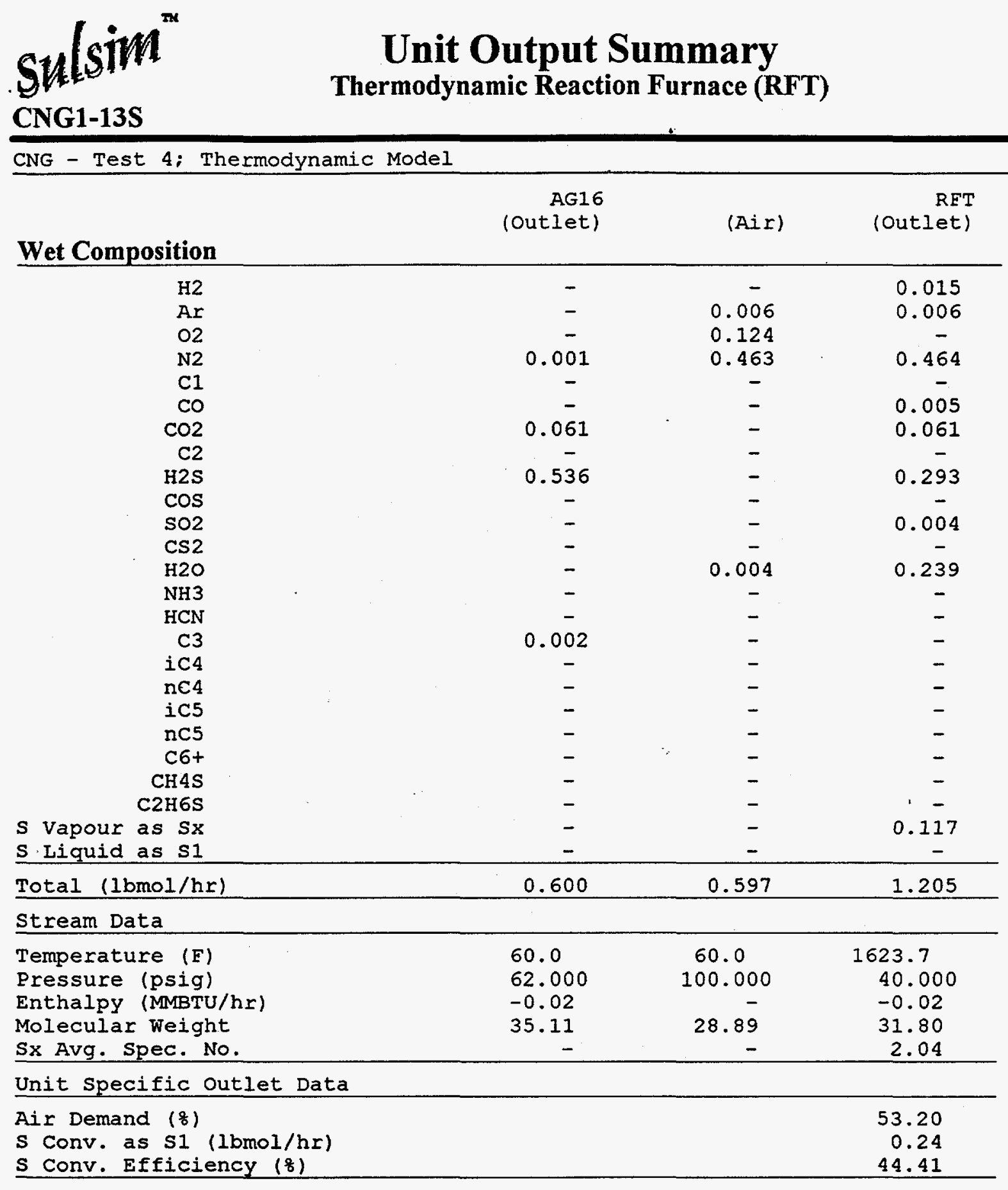


I

I

I

I

I

I

I

I

I

I

I

I

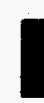

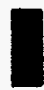

I

I

I

I 


\section{Appendix C}

Site Maps and Equipment Photographs

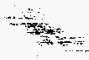




\section{South Central Oklahoma Test Site}

Southwest Davis Gas Treatment Plant

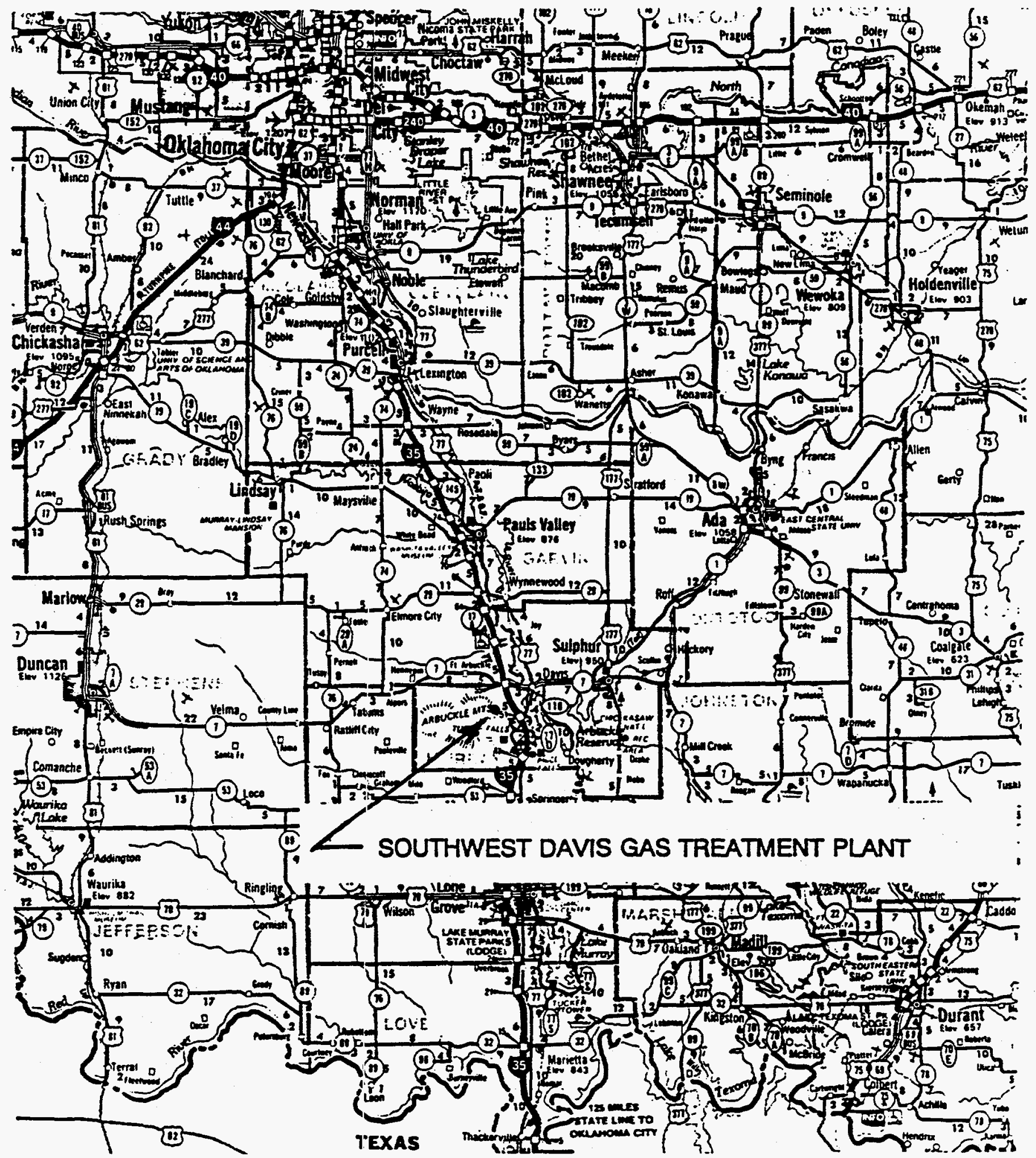


Turner Falls Quadrangle (Oklahoma)

Detail of Southwest Davis Gas Treatment Plant Location

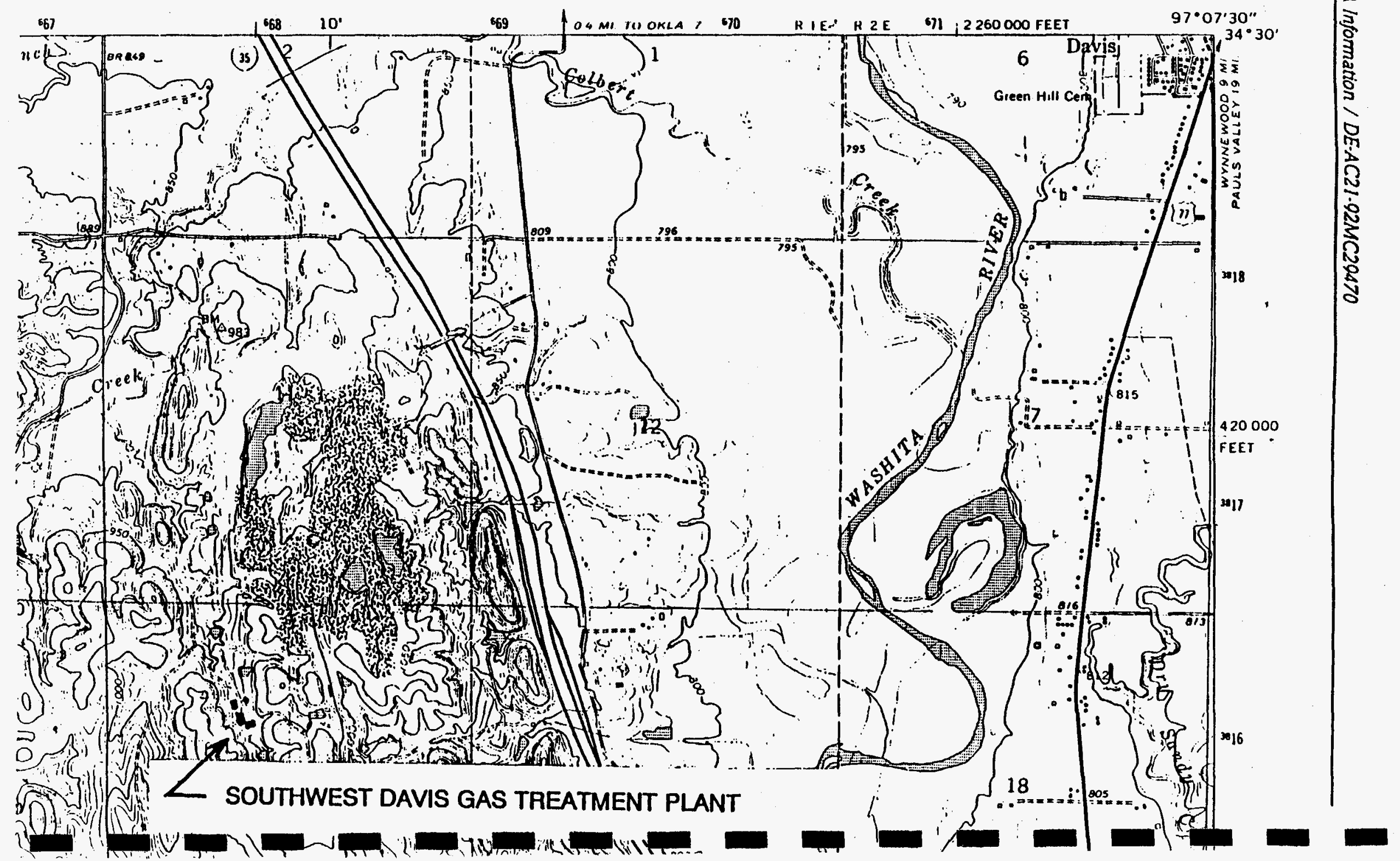




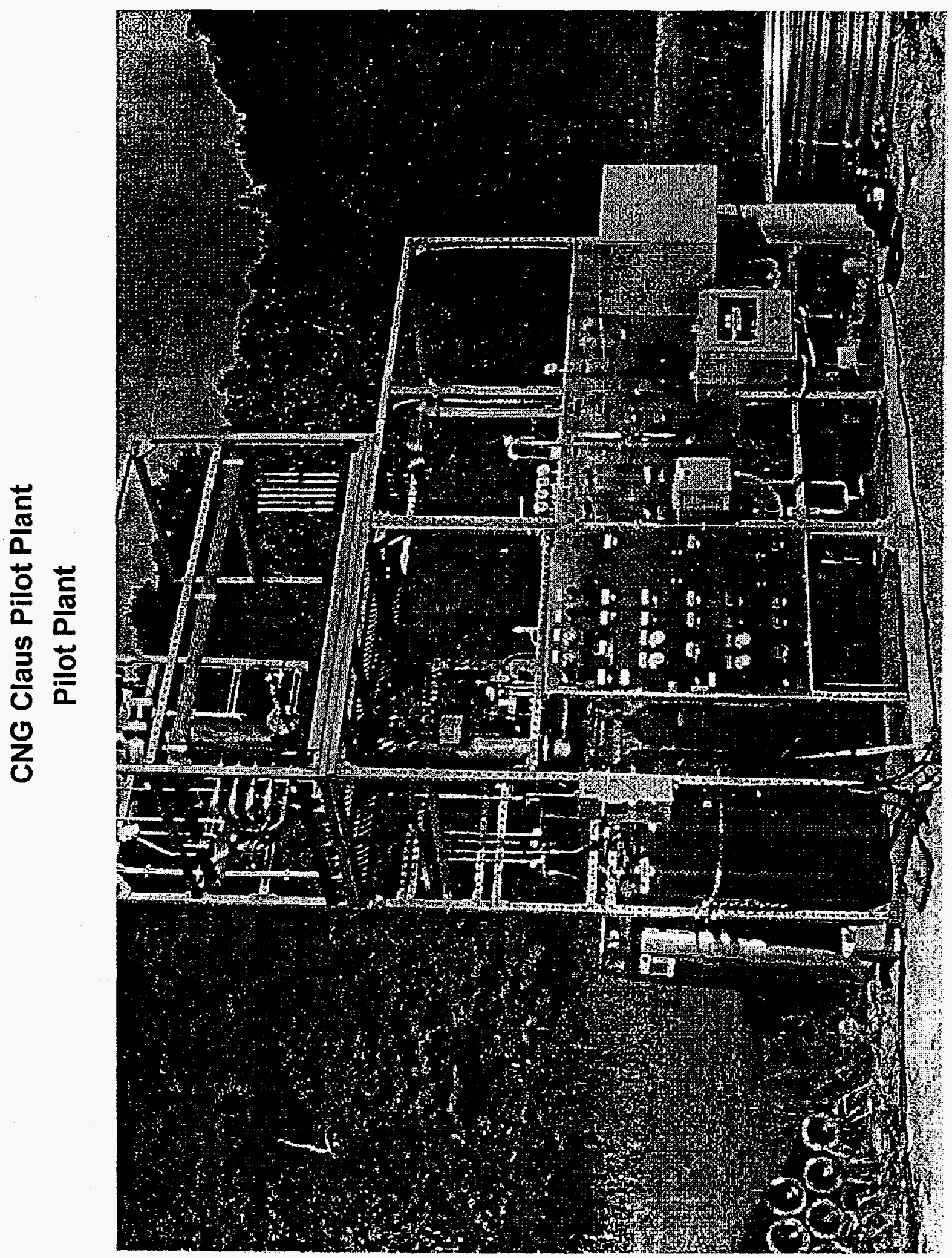




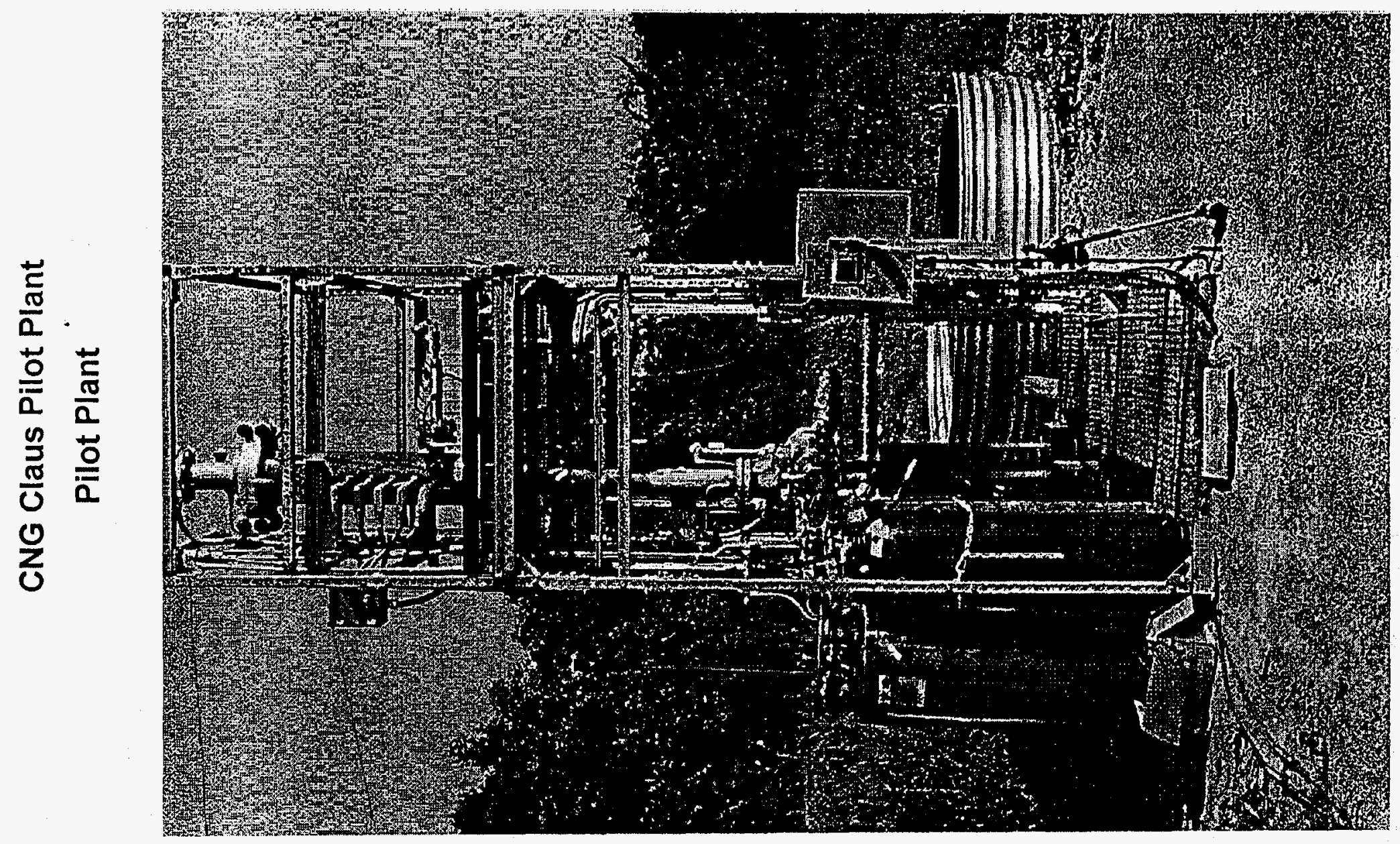


CNG Claus Pilot Plant

Reaction"Furnace

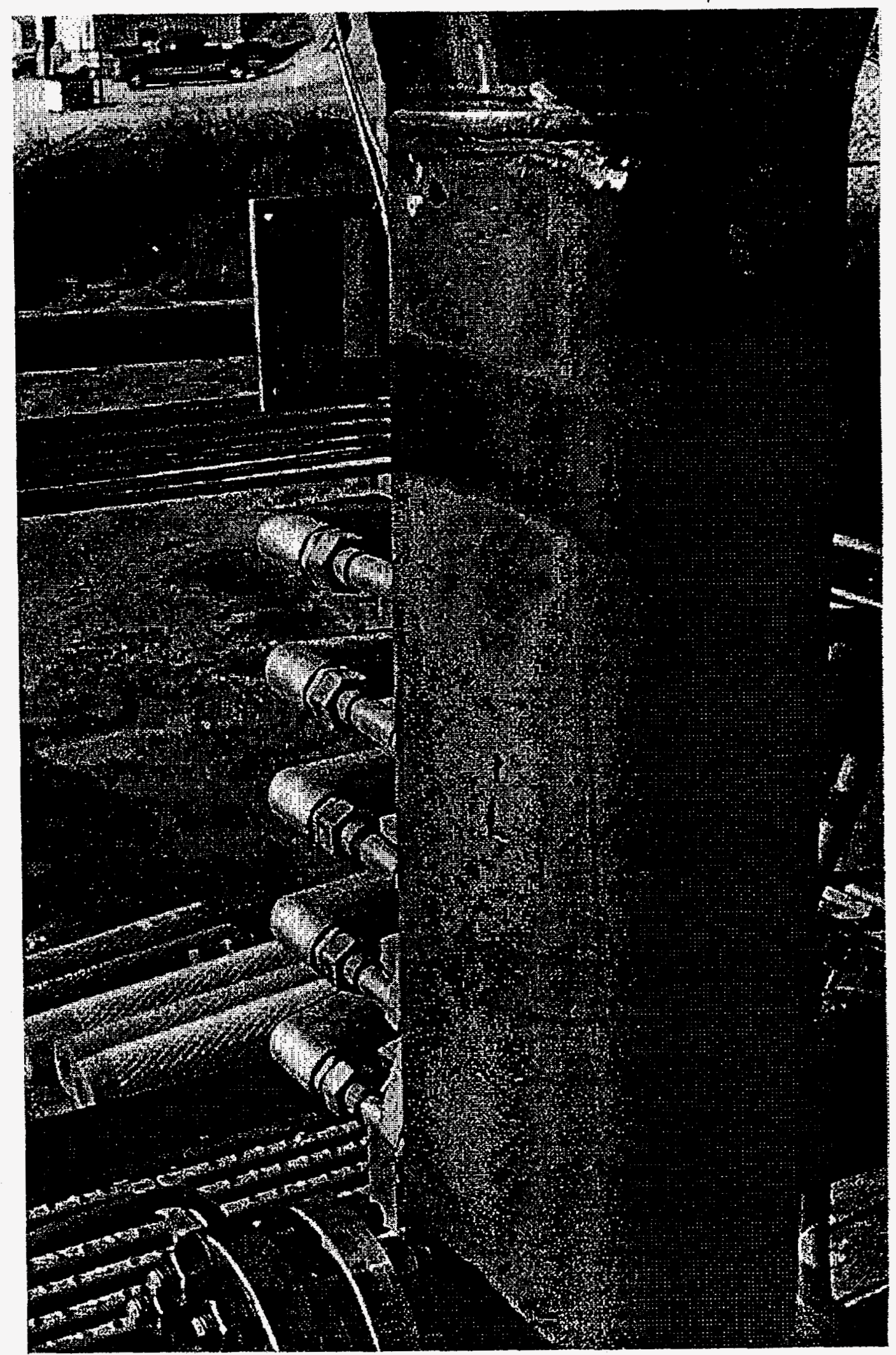




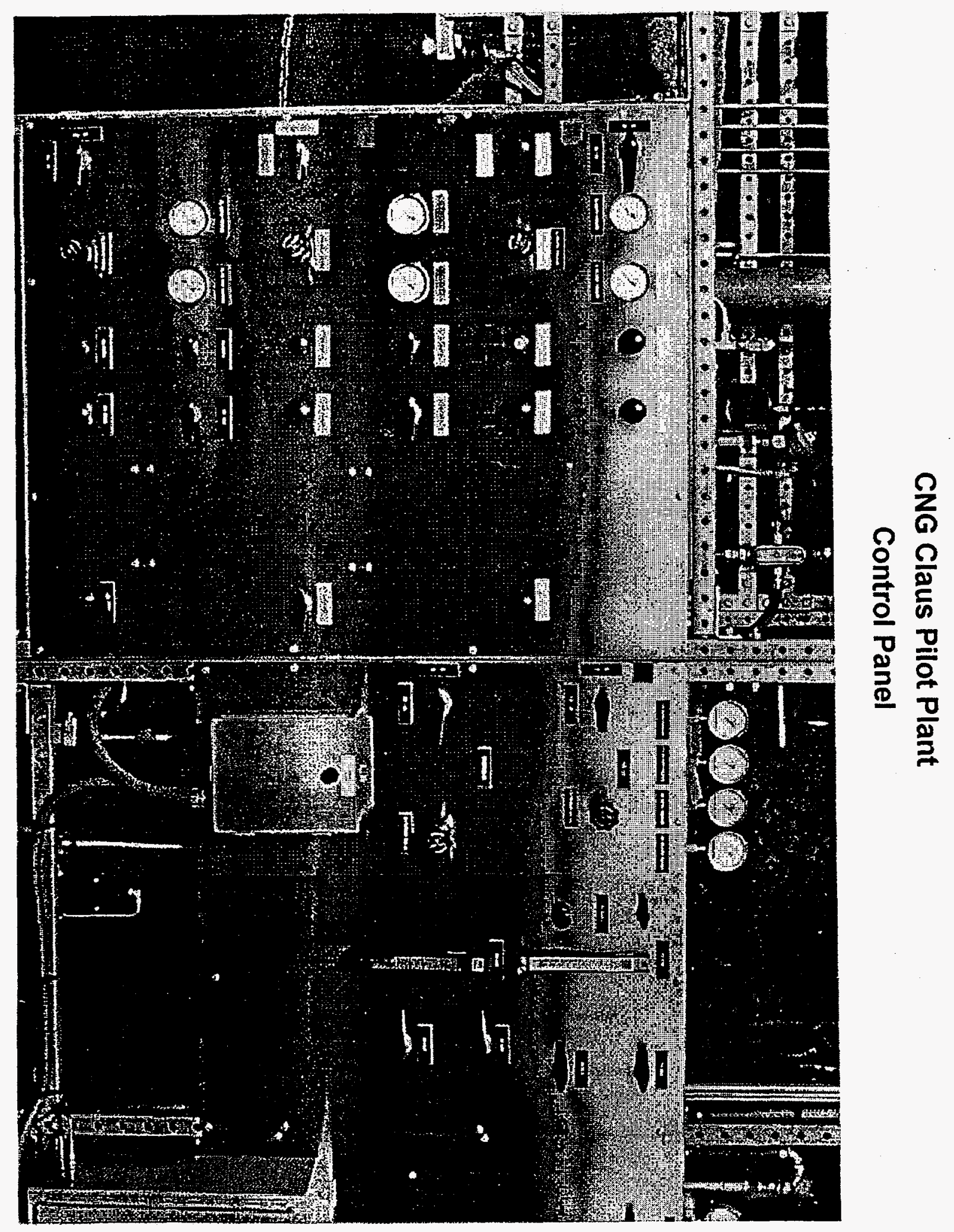




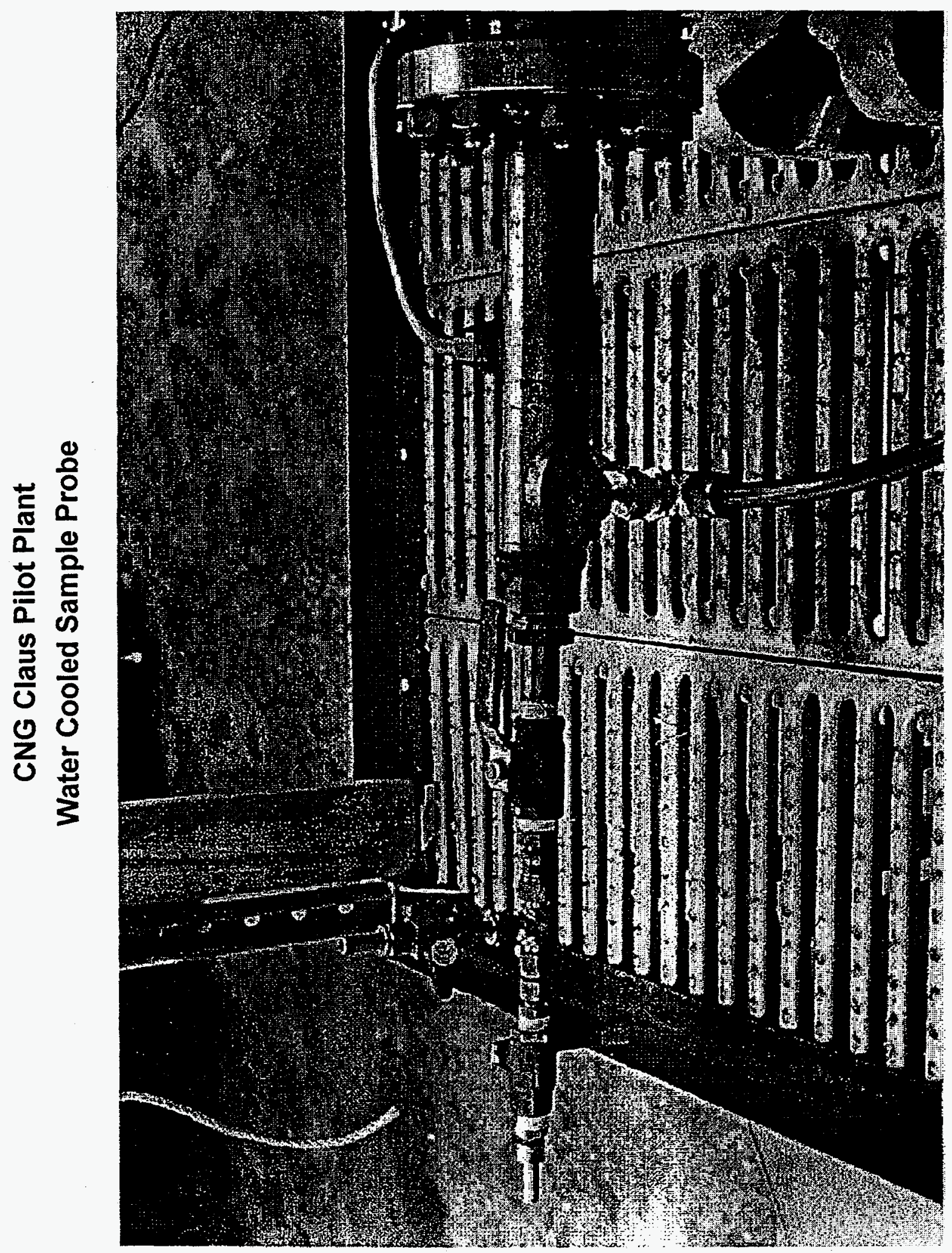


CNG Claus Pilot Plant

Sulfur Condenser

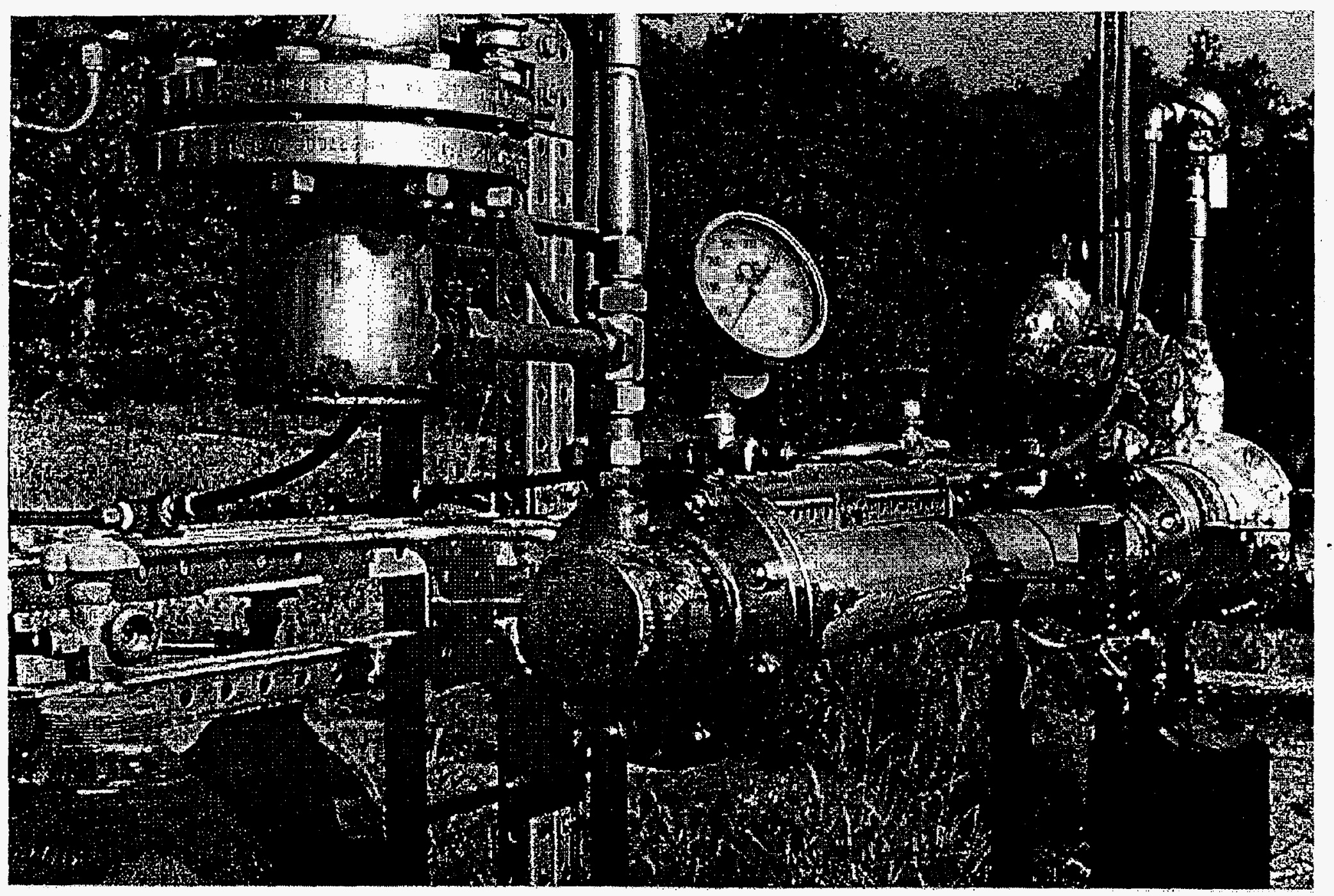


CNG Claus Pilot Plant

\section{Sulfur Collector}

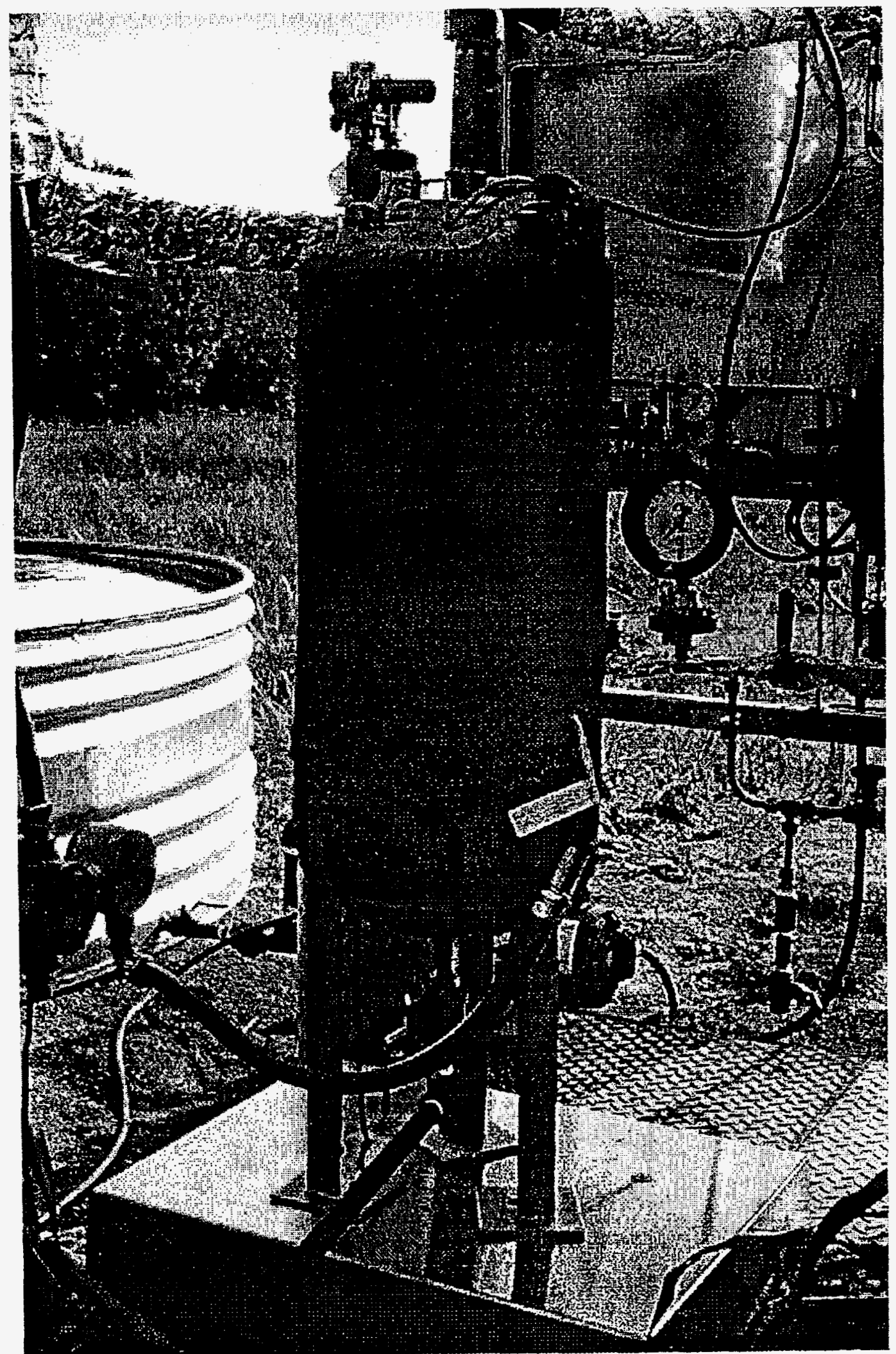

